University of South Florida

DIGITAL COMMONS

Digital Commons @ University of

@ UNIVERSITY OF SOUTH FLORIDA

South Florida

8-1-2005

\title{
Traveling Smart: Increasing Transit Ridership by Automatic Collection (TRAC) of Individual Travel Behavior Data and Personalized Feedback
}

CUTR

Follow this and additional works at: https://digitalcommons.usf.edu/cutr_nctr

\begin{abstract}
Recommended Citation
"Traveling Smart: Increasing Transit Ridership by Automatic Collection (TRAC) of Individual Travel Behavior Data and Personalized Feedback," National Center for Transit Research (NCTR) Report No. CUTR-NCTR-RR-2004-16, Center for Urban Transportation Research, University of South Florida, 2005. DOI: https://doi.org/10.5038/CUTR-NCTR-RR-2004-16

Available at: https://scholarcommons.usf.edu/cutr_nctr/186
\end{abstract}

This Technical Report is brought to you for free and open access by the National Center for Transit Research (NCTR) Archive (2000-2020) at Digital Commons @ University of South Florida. It has been accepted for inclusion in Research Reports by an authorized administrator of Digital Commons @ University of South Florida. For more information, please contact digitalcommons@usf.edu. 
TRAVELING SMART: INCREASING TRANSIT RIDERSHIP THROUGH AUTOMATED COLLECTION (TRAC) OF INDIVIDUAL TRAVEL BEHAVIOR DATA AND PERSONALIZED FEEDBACK

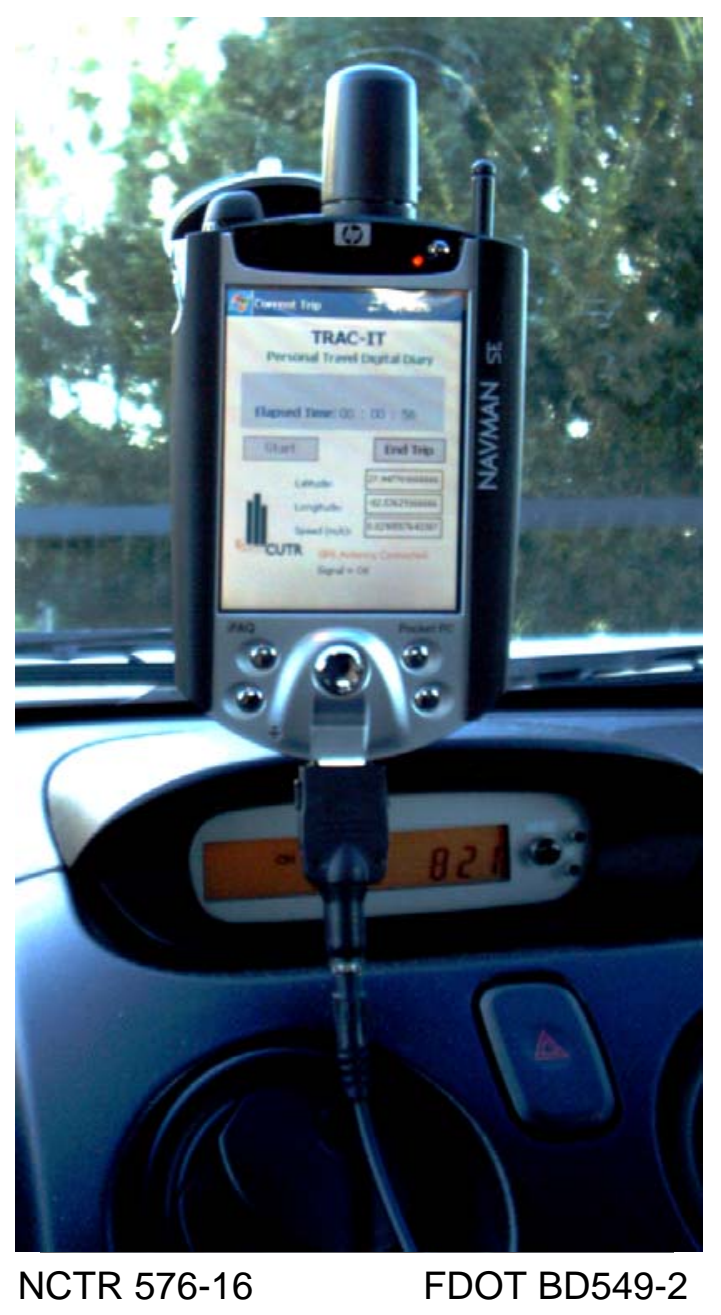

Final Report

August 2005 



\title{
TRAVELING SMART: INCREASING TRANSIT RIDERSHIP THROUGH AUTOMATED COLLECTION (TRAC) OF INDIVIDUAL TRAVEL BEHAVIOR DATA ANd PERsonalized FEEdBACK
}

\author{
Final Report
}

\author{
Prepared by
}

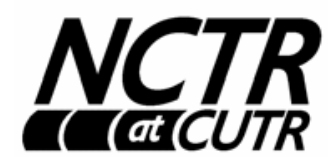

National Center for Transit Research

at the

Center for Urban Transportation Research, University of South Florida

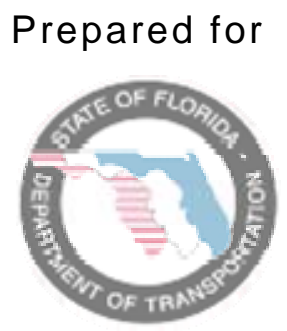

Florida Department of Transportation 


\section{Disclaimer}

The opinions, findings, and conclusions expressed in this publication are those of the author(s) who are responsible for the facts and accuracy of the data presented herein. The contents do not necessarily reflect the views or policies of the Florida Department of Transportation or the Research and Special Programs Administration. This report does not constitute a standard, specification, or regulation.

The report is prepared in cooperation with the State of Florida Department of Transportation and the U.S. Department of Transportation. 
TECHNICAL REPORT STANDARD TITLE PAGE

\begin{tabular}{|c|c|}
\hline $\begin{array}{l}\text { Report No. } \\
\text { NCTR } 576-16 \\
\text { FDOT BD549-2 }\end{array}$ & 3. Recipient's Catalog No. \\
\hline \multirow{2}{*}{$\begin{array}{l}\text { 4. Title and Subtitle } \\
\text { TRAVELING SMART: INCREASING TRANSIT RIDERSHIP } \\
\text { THROUGH AUTOMATED COLLECTION (TRAC) OF } \\
\text { INDIVIDUAL TRAVEL BEHAVIOR DATA AND PERSONALIZED } \\
\text { FEEDBACK }\end{array}$} & $\begin{array}{l}\text { 5. Report Date } \\
\text { September } 2005\end{array}$ \\
\hline & 6. Performing Organization Code \\
\hline $\begin{array}{l}\text { 7. Author(s) } \\
\text { Winters, Philip L.; Perez, Rafael A.; Labrador, Miguel A., } \\
\text { Georggi, Nevine L., and Barbeau, Sean J. }\end{array}$ & 8. Performing Organization Report No. \\
\hline \multirow{2}{*}{$\begin{array}{l}\text { 9. Performing Organization Name and Address } \\
\text { National Center for Transit Research, Center for Urban } \\
\text { Transportation Research, University of South Florida } \\
4202 \text { E. Fowler Avenue, CUT100 } \\
\text { Tampa, FL 33620-5375 }\end{array}$} & 10. Work Unit No. \\
\hline & $\begin{array}{l}\text { 11. Contract or Grant No. } \\
\text { DTRS98-G-00329 }\end{array}$ \\
\hline \multirow{2}{*}{$\begin{array}{l}\text { 12. Sponsoring Agency Name and Address } \\
\text { Office of Research and Special Programs } \\
\text { U.S. Department of Transportation, Washington, D.C. } 20690 \\
\text { Florida Department of Transportation } \\
605 \text { Suwannee Street, MS 26, Tallahassee, FL } 32399\end{array}$} & 13. Type of Report and Period Covered \\
\hline & 14. Sponsoring Agency Code \\
\hline \multicolumn{2}{|l|}{$\begin{array}{l}\text { 15. Supplementary Notes } \\
\text { Florida Department of Transportation Project Manager: } \\
\text { Ike Ubaka, AICP } \\
605 \text {, Suwannee Street, MS 26, Tallahassee, FL } 32399\end{array}$} \\
\hline
\end{tabular}

16. Abstract

This final report is the first in a series to describe a new joint collaboration research effort between the Transportation Demand Management Program at CUTR, and the Computer Science Engineering Department, at the College of Engineering at USF. The research focuses on using innovative technology to better understand and pattern household travel behavior for the purposes of educating, promoting and encouraging households to utilize other alternatives to driving in general and to driving alone in particular. This study documents Phase 1 of the research effort; the development and preliminary testing of a prototype unit and a travel feedback advisory system.

The scope of Phase 1 called for preliminary development and testing of a portable unit consisting of a personal digital assistant (PDA), a global positioning system (GPS) device, and a wireless card, all-in-one unit nicknamed "TRAC-IT." With innovations emerging daily in this field of technology, a GPS-enabled cellular phone was briefly investigated as a possible alterative for the PDA TRAC-IT unit and showed promise. Phase 2 will investigate and analyze the impact of the travel feedback advisory system on household travel behavior. Phase 3 in this research effort will be dedicated to the design, development, and testing of the GPS-enabled cellular phone as a TRAC-IT unit.

The TRAC-IT unit was designed to collect comprehensive individual trip data including; start time, end time, origin, destination, travel speed, trip route, and trip distance with minimal input from participants. Limited field- testing was conducted to validate that the technology works. The project also developed a preliminary personalized feedback system that provides suggestions and encourages participants to utilize other modes than the drive-alone option. These suggestions were sent to participants after the trip data has been transferred from the TRAC-IT unit into a database developed to pattern travel behavior and generate appropriate feedback to participants.

17. Key Words

Transit ridership, travel behavior, and travel survey, global positioning systems, and travel blending
18. Distribution Statement

Available to the public through the National Technical Information Service

(NTIS), 5285 Port Royal Road, Springfield, VA 22161, (703) 487-4650,

http://www.ntis.gov/, and through the NCTR web site at http://www.nctr.usf.edu/.

20. Security Classif. (of this page)

21. No. of pages

22. Price 



\section{Acknowledgments}

This report is prepared by the National Center for Transit Research through the sponsorship of the Florida Department of Transportation and the U.S. Department of Transportation.

FDOT Project Manager:

Ike Ubaka, AICP, FDOT Public Transit Office

Project Team:

Principal Investigator: Philip L. Winters, TDM Program Director, CUTR Co-Principal Investigators:

Rafael Perez, PhD, College of Engineering, USF

Miguel Labrador, PhD, College of Engineering, USF

Research Team:

Nevine L. Georggi, Research Associate, CUTR

Sean J. Barbeau, Research Associate, CUTR

Computer Science and Engineering Student Team:

Edgar Banguero

Mehdi Chemsi

Himanshu Gilani

Kevin Kerrigan

Todd Winchell 



\section{Table of Contents}

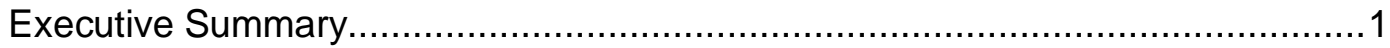

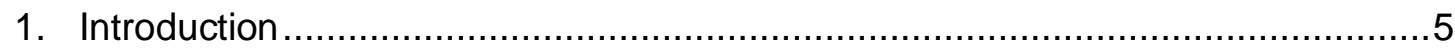

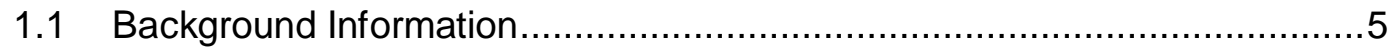

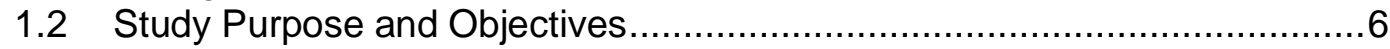

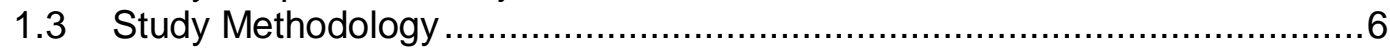

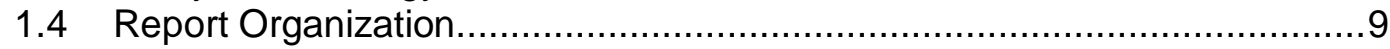

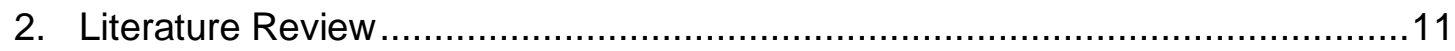

2.1 Critical Issues in Data Collection..................................................... 11

2.2 Market Segment of Technology Users ............................................. 12

2.3 Electronic Data Collection Technologies......................................... 13

2.4 Impacts of Providing Customized Travel Options...............................16

3. Selection Criteria of TRAC-IT Components...................................................21

3.1 Selection Criteria of TRAC-IT Hardware Components ..........................21

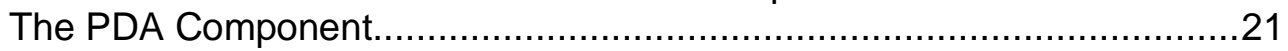

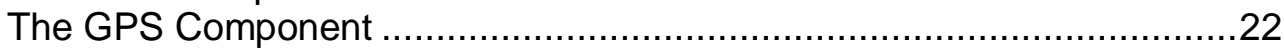

The Wireless Communication Component..........................................22

3.2 Selection Criteria of System Software Components .............................22

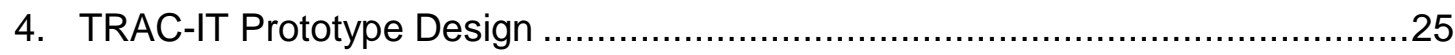

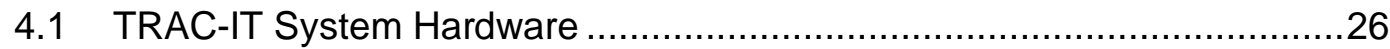

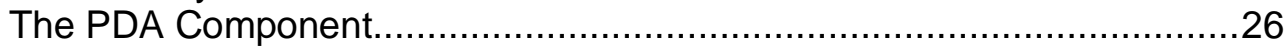

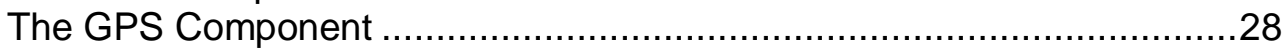

The Wireless Connection Component....................................29

TRAC-IT Limitations ................................................................. 30

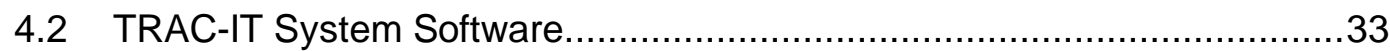

Data Collection Application - TRAC-IT: a Smart Diary ..........................33

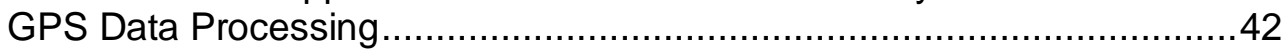

Data Storage and Transfer ................................................... 47

4.3 New Application: TRAC-IT Cell Phone Prototype ................................50

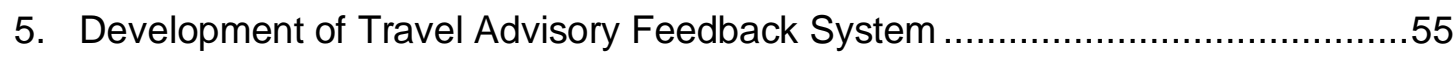

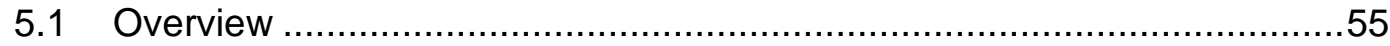

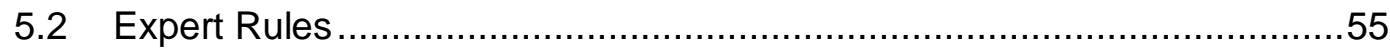

5.3 How the TRAC-IT Expert System Works ......................................... 58

6. Prototype Field Test Application and Assessment......................................63

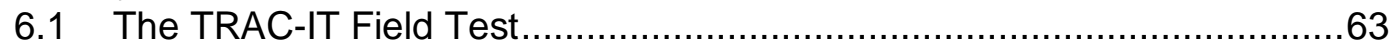

6.2 Prototype Field Test Data Collection................................................64

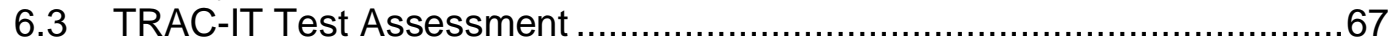

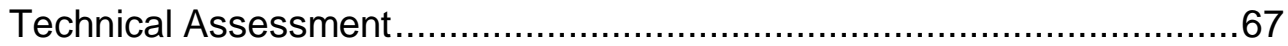

Participants Assessment .......................................................... 69

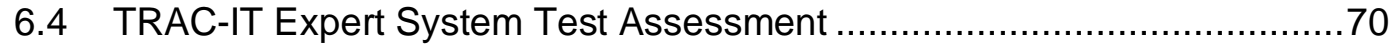

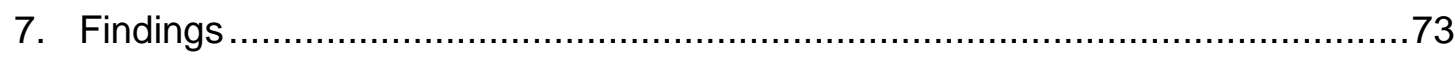

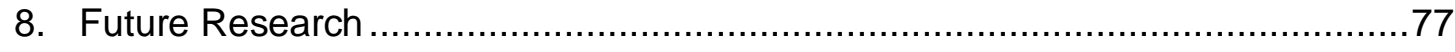

References

Appendices 


\section{List of Tables}

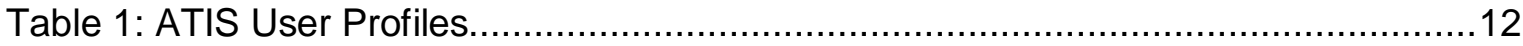

Table 2: Personalized Journey Planning Techniques..............................................17

Table 3: GPS Co-ordinates Recorded While Standing Still .........................................29

Table 4: GPS Points Recorded Using Two Different Algorithms Continuous Update vs. Selective Update....................................................

Table 5: Sample of Trip Characteristics Collected By One User for One Day .................65

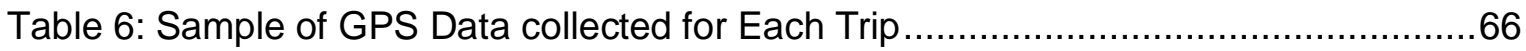

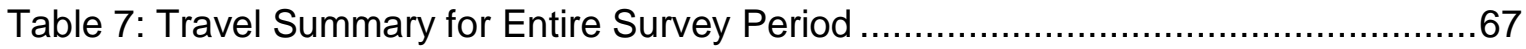

Table 8: Number of transistors on Intel processors .....................................................78

\section{List of Figures}

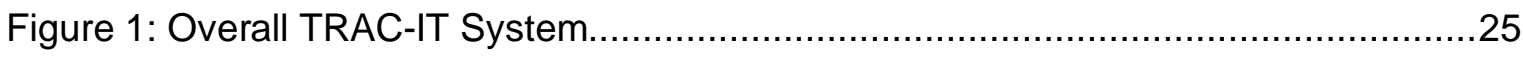

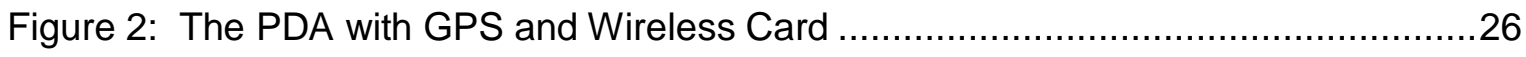

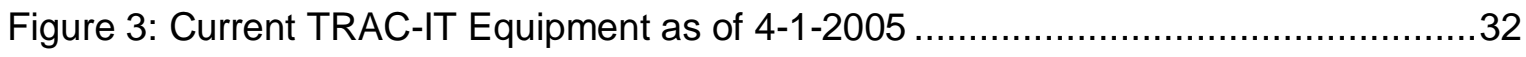

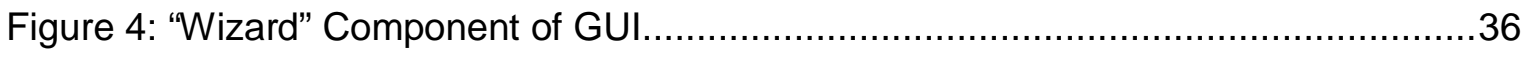

Figure 5: Trips 1 and 2 - GPS Points Recorded Using Two Different

Algorithms - Continuous Update vs. Selective Update ....................................44

Figure 6: GPS Points Recorded Using Two Different Algorithms -

Continuous Update vs. Selective Update for Multimodal Trips.........................45

Figure 7: GPS Points Recorded Using Two Different Algorithms -

Continuous Update vs. Selective Update by Walking ..................................46

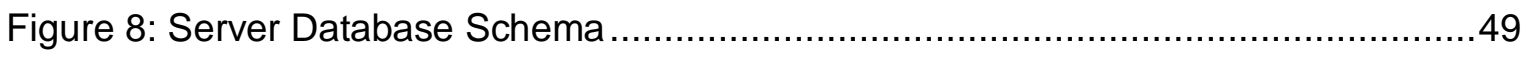

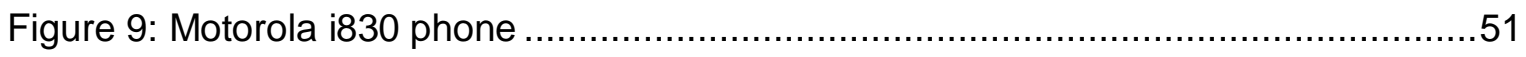

Figure 10: User Interface of the GPS-enabled cell phone ..........................................53

Figure 11: The Travel Advisory Feedback System Framework …….............................56

Figure 12: Travel Advisory Feedback System Scheme ...............................................59

Figure 13: TRAC-IT Advisory Feedback System Main Feedback Procedure ..................60 


\section{Executive Summary}

The research focuses on using innovative technology to better understand and pattern household travel behavior for the purposes of educating, promoting, and encouraging households to utilize other alternatives to driving in general and to driving alone in particular. This study documents Phase 1 of the research effort; the development and preliminary testing of a prototype unit and a travel feedback advisory system. This final report is the first in a series to describe a new joint collaboration research effort between the Transportation Demand Management (TDM) Program, at Center for Urban Transportation Research (CUTR), University of South Florida (USF), and the Computer Science Engineering (CSE) Department, at the College of Engineering at USF.

The scope of Phase 1 called for preliminary development and testing of a portable unit consisting of a personal digital assistant (PDA), a global positioning system (GPS) device, and a wireless card, all-in-one unit nicknamed "TRAC-IT." With innovations emerging daily in this field of technology, a GPS-enabled cellular phone was briefly investigated as a possible alterative for the PDA TRAC-IT unit and showed promise. Phase 2 will investigate and analyze the impact of the travel feedback advisory system on household travel behavior. Phase 3 in this research effort will be dedicated to the design, development, and testing of the GPS-enabled cellular phone as a TRAC-IT unit.

This project builds on previous research conducted by CUTR for the Florida Department of Transportation (FDOT) Research Center Office, "Reducing Vehicle Trips and Vehicle Miles of Travel through Customized Travel Options" (1). The study demonstrated that the travel habits of households provided with personalized advice did reduce vehicles miles of travel relative to the control group. The project offered a practical exercise that led households to re-appraise their needs and rationale for travel. Specific suggestions aimed at use of public transit service, bike paths, trip chaining, ridesharing, and e-commerce options were provided based on specific travel patterns observed in the activity diaries. A weeklong travel diary formed the basis of the personalized advice provided.

Since that CUTR/FDOT project, technology has evolved rapidly to provide a promising method to decrease the costs of collecting and analyzing travel data. In particular, the potential now exists to use PDAs and GPS add-on modules rather than paper diaries for easier and more accurate tracking of person movements, not simply vehicle movements. The GPS unit provides a means of tracking time, route, and speed, while the PDA 
provides a means of recording items such as mode, occupancy, and trip purpose.

The TRAC-IT unit was designed to collect comprehensive individual trip data including; start time, end time, origin, destination, travel speed, trip route, and trip distance with minimal input from participants. Limited fieldtesting was conducted to validate that the technology works. The project also developed a preliminary personalized feedback system that provides suggestions and encourages participants to utilize other modes than the drive-alone option. These suggestions were sent to participants after the trip data has been transferred from the TRAC-IT unit into a database developed for Phase 1 to pattern travel behavior and generate appropriate feedback to participants.

In effect, TRAC-IT's first phase was a proof-of-concept project. The research team sought to develop a system that automatically collected travel behavior data at the person-level (rather than vehicle-level) and provided personalized feedback based on the trip data collected by TRACIT units from participants and their households.

For the purposes of Phase 1, the participants were identified as case studies since the goal of the field test was to make sure the prototype worked under various scenarios representing different modes of travel and varied household dynamics. These scenarios included:

- A two-income household, two adults, two-car ownership, and one child under driving age

- A single-income household, one female adult, zero-car ownership

- A single-income household, two adults, one car and one bicycle, and 3 children under driving age

- A single-income household, two adults, two-car ownership and one child under driving age (trips collected from one household member only)

Before participants were given their TRAC-IT units, each participating household was identified with a unique number, and each adult in the household was issued a user identification number. Also, to reduce data input burden, a user profile was created in the PDA with the person's home and work addresses pre-entered.

The three primary requirements set forth to demonstrate the feasibility of the TRAC-IT prototype were: 
1. Improve the quantity of data collected

Through the GPS component, TRAC-IT was able to collect and record the location of the traveler, travel path, and speed. The PDA component was able to record GPS information as well as collect data on travel purpose and occupancy information. Algorithms developed specifically for this project to reduce non-essential data were developed to simplify the analysis. These algorithms were applied to the PDA component of the TRAC-IT unit. Finally, the system demonstrated the ability to record travel for all major modes (auto, transit, bike and walk) to provide a richer and deeper view of travel behavior.

2. Improve the data quality

The team found that TRAC-IT's design minimized the need for user inputs through the adoption of GUI wizards (e.g., change of mode, frequently visited locations and "QuickStops"). The development of "Smart Diary" components reduced respondent fatigue (allowing for longer periods of data collection) and improved data quality by populating the fields based on previous patterns by performing complicated real-time data processing and analysis. The automated aspects of TRAC-IT gathered completed data because of the development of wizards to capture quick stops, changes of mode, etc. The richness of the data collected via TRAC-IT includes the ability to collect and analyze multimodal travel behavior and patterns at the household level. Since data could be synched directly into a database TRAC-IT eliminated the errors associated with manual data entry.

3. Analyze travel behavior at the individual and household levels

TRAC-IT system was able to successfully upload the data to the server and provide suggestions for more efficient transportation options based on the household travel behavior. The basic feedback advisory system (also referred to as the expert system) was designed to test the ability of collecting and using the data. The system will be further developed and tested in Phase 2 of this research effort. Phase 2 will measure impacts on travel behavior after feedback suggestions are provided.

The costs of deploying TRAC-IT on a wide scale are changing rapidly with changes in the communication field. The preliminary testing of a cell phone application suggested that such a final system, potentially deployable as a client-side or server-side application on a cell phone rather than PDA, could drastically reduce the costs of deployment. In fact, TRAC-IT could be combined with other location-based services to become a desirable feature of cell phone users. Certainly, the e-911 compliance requirements on cell phone providers and expanding market for location- 
based services will increase the attractiveness of cell phones on which TRAC-IT can function.

It is believed that a natural extension to the TRAC-IT project is the development of the TRAC-IT application in a cellular telephone. Cellular telephones already address such issues as size, integration of communication capabilities, availability of GPS coordinates, and battery issues. However, some new challenges will be introduced such as the design of the application user interface, more stringent memory capabilities, and CPU power. Nonetheless, given the experience obtained in TRAC-IT with PDAs and the expected trends, the development of TRACIT on a cellular telephone will enhance transportation professionals' abilities to use the new end-system device technologies as they become commercially available.

Cellular telephones are already in the hands of millions of people. Devices that are more powerful will make possible new applications, such as TRAC-IT, that will make daily lives easier, better, and more secure. These devices will not only be able to collect user travel data but also send and receive customized traffic reports according to the position of the user, receive amber alerts, know location of children, report incidents on real-time including voice, video and images of incidents, query the network for directions and receive maps with precise routes, query the network for services, restaurants, phones, browse the Internet, send and receive emails, transfer files, and more. 


\section{Introduction}

\subsection{Background Information}

The American public values the use of personal automobiles. In fact, according to the Environmental Protection Agency (EPA), the number of vehicles in the United States is increasing twice as fast as the population growth, with three-quarters of all trips made to and from work in singleoccupancy vehicles ${ }^{1}$. Recent numbers from the 2005 Urban Mobility Study stated that in 2003, congestion (based on wasted time and fuel) cost about $\$ 63.1$ billion in major urban areas, compared to $\$ 61.5$ billion in 2002 (2). The amount of wasted fuel per traveler ranged from 36 gallons per year in large urban areas to 8 gallons per year in smaller urbanized areas.

Transportation demand management (TDM) strategies are designed to motivate people to modify their travel choices, particularly the drive-alone preference. TDM strategies and policies seek to increase the transportation system efficiency and achieve specific objectives such as reduced traffic congestion, road and parking cost savings, increased safety, improved mobility for non-drivers, energy conservation and pollution emission reductions. Marketing these strategies to the "consumer" in an effective way that results in behavioral changes, such as increase transit use, necessitates a sustained understanding of how, when, where and why people travel. Therefore, accurate, timely, and comprehensive data is vital in understanding/influencing the consumer. The data collection processes have made use of new emerging technologies that help refine the task of monitoring/measuring the behavior to be modified.

This project builds on previous research conducted by CUTR for the Florida Department of Transportation (FDOT) Research Center Office project, "Reducing Vehicle Trips and Vehicle Miles of Travel through Customized Travel Options," 1999 (1). The study demonstrated that the travel habits of households provided with tailored feedback did increase the use of alternatives to driving alone relative to the control group. The project offered a practical exercise that led households to re-appraise their needs and rationale for travel. Specific suggestions aimed at use of public transit service, bike paths, trip chaining, ridesharing, and e-commerce options were provided based on specific travel patterns observed in the activity diaries. A weeklong travel diary formed the basis of the tailored feedback provided by CUTR.

1 Published on the EPA website at http://www.epa.gov/ 
In a few short years since the CUTR/FDOT project demonstrated the effect such personalized advice had on travel behavior, technology has evolved rapidly to provide a promising method to decrease the costs of collecting and analyzing the data as well as tracking person movements, not only vehicle movements. In particular, the potential now exists to use PDAs) and add-on GPS modules rather than paper diaries to track person movements, not simply vehicle movements. The GPS unit provides a means of tracking time, route, speed, while the PDA provides a means of tracking data including mode, occupancy, and trip purpose.

This study takes refining this task a step further by using new technologies to pattern travel behavior and communicate tailored feedback to trip takers. The feedback suggests to individuals more efficient ways they can use in their trip decision-making, thus, saving time and money.

\subsection{Study Purpose and Objectives}

The ability to collect and expeditiously process and personalize travel behavior data, to use in increasing transit ridership, has a major limiting factor; using activity diary approaches are tedious and time-consuming. So far, GPS has been used to track buses and other vehicles but have not been applied to track the behaviors of individual riders or non-motorized users and their perspective households. The purpose of this research study was to investigate the challenges associated with equipping/tracking people (not vehicles) to pattern their travel behavior, and then communicate tailored feedback that would assist them with better tripmaking decisions.

The study objectives were to

1. Determine the capabilities of existing computer and communication technologies in tracking person movements across modes (car, bike, bus, etc.) and over extended time periods (e.g., week versus daily)

2. Design, develop and test a prototype application to automate the collection of travel behavior data and provide personalized advice to increase use of transit and other alternatives to driving alone.

\subsection{Study Methodology}

This study designed a PDA/GPS/wireless card combination unit (TRAC-IT) that provides the ability to track individuals' travel across all modes (walk, bus, bike, etc.) while minimizing some of the data entry efforts required. In addition to the TRAC-IT handheld unit, custom software was developed to obtain information from the individual traveler including modules that 
receive and analyze GPS data, a local PDA database, a server-side database management system, and a program module to transfer the database information to a central database.

An expert system was developed to provide personalized feedback to individuals participating in the field test. The expert system included rules that were applied to the specific travel patterns collected from participating households and were designed to suggest more use of transit and other alternatives to driving alone. As travel behavior data were collected and transmitted to the centralized database, the expert system rules were triggered to reach the appropriate conclusions for each individual participating in the survey.

Using the research team members as survey participants, the following steps were simultaneously being developed, tested, and refined repeatedly to accomplish the final system design. Finally, the system was field tested with diverse household and the results were documented in this final report.

\section{TRAC-IT Design Methodology}

Hardware

- The PDA selection process was based on six criteria: processing power, operating system (OS) and availability of Software Development Kits (SDKs), device memory, battery power, expansion capabilities, and cost.

- The GPS device selection process was based on four criteria: system integration, expansion capabilities, a high degree of accuracy, and cost.

- The wireless card had to have the ability to connect to the other two devices (the PDA and GPS) using a CompactFlash (CF)-type hardware connection and be compatible with the rest of the system software.

Software

All types of available Software Development Kits (SDKs) for the TRACIT unit components and their operating systems were researched.

Custom software was developed for this project consisting of program modules that implemented a graphical user interface (GUI) to obtain information from the individual traveler, modules that received and analyzed GPS data, a local PDA database and server-side database management system, and a program module to transfer the database information to a central database. 
The TRAC-IT prototype automated most of the data needed to monitor participants' travel behaviors. Data not automatically collected, such as trip purpose and occupancy, were gathered with a unique "Smart Diary" user interface that eased participants' burden to enter data. The field device also integrated communication capabilities to handle remote processing of data and providing feedback to participants.

\section{TRAC-IT Field Test Protocol}

For the purposes of this study, Phase 1, the participants were identified as case studies since the goal of the field test was to make sure the prototype works under various scenarios representing different modes of travel and varied household dynamics. These scenarios included:

- A two-income household, two adults, two-car ownership, and one child under driving age

- A single-income household, one female adult, zero-car ownership

- A single-income household, two adults, one car and one bicycle, and 3 children under driving age

- A single-income household, two adults, two-car ownership and one child under driving age (trips collected from one household member only)

Before participants were given their TRAC-IT units, each participating household was identified with a unique number, and each adult in the household was issued a user identification number. Also, to reduce data input burden, a user profile was created in the PDA with the person's home and work addresses pre-entered.

\section{The Travel Feedback Advisory System}

When the data collected by TRAC-IT were synchronized with the database, they were stored in the appropriate database tables. Triggers in the database set off the expert rules to be applied only to the newly arriving data. The conclusions reached by the expert system were then consolidated into appropriately worded suggestions. These suggestions were stored in the database and sent to the individual as feedback. This mechanism provided a method for feedback analysis and a basis for future improvements to the travel advisory feedback system based on field test evaluations, as proposed for Phase 2 of this research effort, (to be completed fall 2006). 


\subsection{Report Organization}

Following this introductory section, Section 2 reviews previous research in travel survey needs and the dynamics of the population using emerging technologies such as those applied in Advanced Travel Information Systems (ATIS). The same section also sheds light on the concept of Travel Blending ${ }^{\circledR}{ }^{1}$ and electronic data collection technologies. Section 3 describes the overall study methodology with an assessment of existing technology including PDAs, GPS units, and communication options including wireless technology. Section 3 also defines the selection criteria used to develop the hardware and software of the TRAC-IT prototype and finally previews upcoming phases of this research project including the TRAC-IT cellular phone prototype. Section 4 describes the TRAC-IT system design. Section 5 presents the basis for the development of the travel advisory feedback system for this phase of the study. Section 6 details the field test application and assessment of the prototype. Section 7 presents the findings of the study and Section 8 describes the next step in terms of future research and phases of the research project.

\footnotetext{
${ }^{1}$ Travel blending ${ }^{\circledR}$ is an individualised marketing campaign implemented by Steer Davies Gleave Consultancy in Australia. More information can be found at http://www.env.leeds.ac.uk/its/private/level2/instruments/instrument006//2 006c.htm
} 


\section{Literature Review}

The use of automated-data-capture tools in household travel surveys, such as GPS technologies and handheld computers, offers great promise in improving data accuracy and collecting additional relevant data. These data enhancements will improve travel demand models and subsequently air quality analyses by integrating stated and measured travel behavior.

This literature review is presented in four sections. First is a review of critical issues in travel surveying, as identified in the last National Household Travel Survey (NHTS) Conference held in November 2004 in Washington, D.C., (emphasis on market segments). Second is a review of the socio-economic and demographic market segments using technology, particularly in the area of Advanced Travel Information Systems (ATIS). Third is a review of capabilities of existing computer and communication technologies in tracking person movements across modes (car, bike, bus, etc.) and over extended periods (e.g., week versus daily). The final subsection reviews literature on providing personalized advice to households to increase use of transit and other alternatives to driving alone.

\subsection{Critical Issues in Data Collection}

The purpose of the NHTS is to provide information on personal travel within the United States. Detailed data from a sample of U.S. households on daily and longer-distance travel for all purposes and by all modes are expanded to provide national estimates of trip numbers and miles by travel mode, trip purpose, and household attributes. NHTS is the only national source of information on the typical travel of U.S. residents. The survey provides data on the type and amount of travel, the use of various modes, the time and miles spent traveling for various purposes, ownership, and use of the vehicle fleet, and relationships among household composition, life stage, and travel. The latest NHTS conference, Data for Understanding Our Nation's Travel, held November 2004 Washington, D.C., was designed as a forum for users of this national data set to discuss and learn about methodological issues, analysis and estimation applications, and findings related to transportation policy, planning, and modeling (3).

Current and future travel survey issues identified in the conference included non-response, under-reporting, coverage bias, continuous surveys, special populations, and measurement errors. Among suggested strategies to address these critical issues was the use of GPS-based surveys, deemed efficient to collect more detailed and better time, speed, route, and location information, with fewer burdens on respondents. In 
addition, GPS survey components open the possibility of obtaining multiple days of reporting, especially for personal vehicles. More testing would be needed to determine appropriate sample size, length of deployment, and locations of deployment (i.e., across the country or only in select areas).

Sub-section 2.3 will further discuss the use of electronic data collection technologies.

\subsection{Market Segment of Technology Users}

The literature in the area of market segmentation based on socioeconomic and demographic data is abundant in the area of travel information but scarce in comprehensive analysis of factors affecting the use of technology in travel data collection efforts and/or travel blending techniques. A quick review of user profiles based on the results of a 1998 survey carried out among a small sample of those who used Travinfo Travel Advisory Telephone System (TATS) to seek current information about traffic conditions in the San Francisco Bay Area, is summarized in Table 1 (4).

\section{Table 1: ATIS User Profiles}

\begin{tabular}{|c|c|}
\hline Market Segments & Key Characteristics* \\
\hline $\begin{array}{l}\text { Regular, stable } \\
\text { users } \\
\text { ( } 51 \% \text { of the sample) }\end{array}$ & $\begin{array}{l}\text { - } \text { are more educated, } \\
\text { - spend less on cars and are less likely to follow the latest trends, } \\
\text { - } \text { are quite comfortable with using both maps and high-tech } \\
\text { equipment, } \\
\text { - are less satisfied with the quality of current broadcast traffic reports, } \\
\text { and } \\
\text { - Are less likely to own a pager. }\end{array}$ \\
\hline $\begin{array}{l}\text { Occasional users } \\
\text { (16\% of the sample) }\end{array}$ & $\begin{array}{l}\text { - Are more likely to be women (64\%) than the sample as a whole } \\
(35 \%), \\
\text { are likely to be a little less educated than the rest of the sample, find it } \\
\text { hard to use maps, have a low comfort level with high-tech equipment } \\
\text { and are averse to trying new technology, listen less to broadcast } \\
\text { traffic reports, but are generally more satisfied with the quality of the } \\
\text { reports, } \\
\text { - are less interested in predicting travel times accurately, } \\
\text { - } \text { are more likely than the rest of the sample to adjust their routes in } \\
\text { response to traffic reports, and } \\
\text { - Are more likely to accept route guidance than are the other } \\
\text { respondents. }\end{array}$ \\
\hline
\end{tabular}




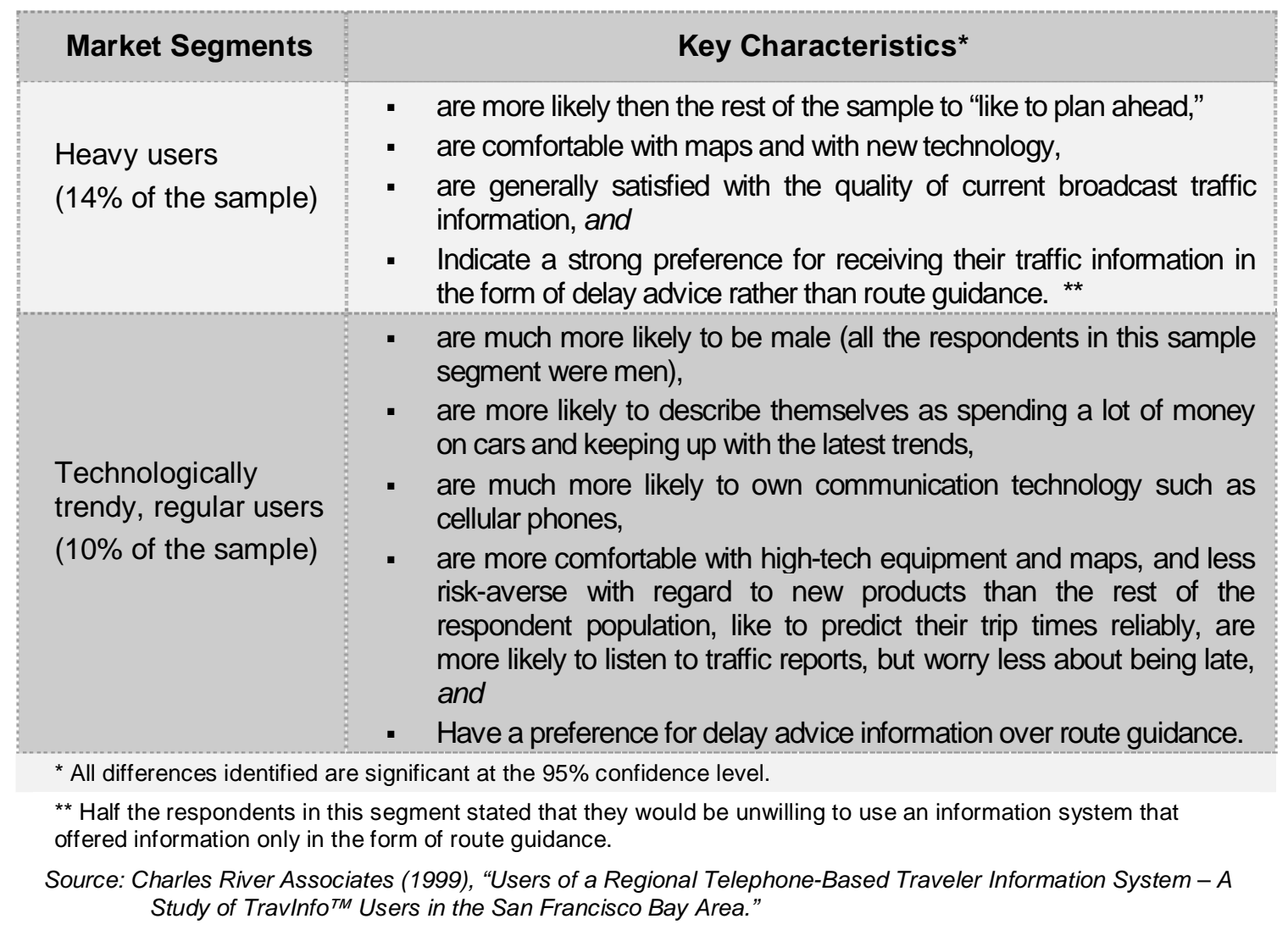

Although the above description of socio-economic, demographics, and attitudinal user categories facilitates understanding potential uses and marketability of ATIS, it remains to be seen whether it is applicable to advanced electronic data collection techniques or feedback systems using wireless technology.

This TRAC-IT research project could also segment by drivers, bicycle riders, public transportation users, car owners with different demographics, zero-car households, households with young children under driving age, and other market segments. This approach may offer a better understanding of different market segments' acceptance of using electronic travel diaries and personalized travel advice.

\subsection{Electronic Data Collection Technologies}

Several research efforts in Japan, Europe and the United States are documented in the field of electronic travel data collection. In a pilot survey in Osaka City, Japan, 10 individuals were given a Personal Handyphone System (PHS) based mobile communication device with a location positioning function (5). Positioning technology as a function of a cellular phone system was applied to determine the longitude and latitude in sequence of time. The PHS system uses smaller signal power than usual 
cellular phone systems and requires densely located base stations. The antennas of a service carrier are equipped about every 100 meters in urban area. A method to transfer the individual's location positioning data to an activity diary was developed. More research was recommended to improve the transfer methodology. The study concluded that the origin, destination and route of a trip can be efficiently determined using the PHS data reducing the coding work and consequently transportation planning surveys costs. However, the PHS is a system specific to Japan, data accuracy depended on the density of base stations, and positioning error was inevitable in suburban areas.

More recently in Japan, the characteristics of positioning data collected with three different mobile communication devices - PHS, Global Positioning System (GPS) and enhanced GPS, were investigated (6). Three measures were used for evaluation: the data collecting ratio, path specification ratio, and positioning error. In automobile testing on urban expressways and arterial streets, enhanced GPS and PHS performed equally well for all indices. The research concluded that the PHS-based location system is suitable for monitoring the behavior of railway passengers, pedestrians, and drivers at relatively slow speeds. As for enhanced GPS, originally designed for manual use, it is envisioned to become a useful device for collecting travel data with additional improvements. Again, PHS technology is specific to Japan.

A new surveillance device for monitoring personal travel behavior called PEAMON (PErsonal Activity MONitor) also was tested in Japan, in an actual travel survey in Osaka City (7). A three-dimensional acceleration sensor is combined with a cellular-phone-based location positioning unit where location and acceleration data were collected every 15 seconds. It was found that travel mode; origin, destination, and route of an individual traveler are precisely traced using the location and acceleration data and may be stored as discrete forms so as not to lose the original geographical information. The study concluded that data management methods specified for travel data should be further investigated, as should analytical tools both for positioning and acceleration data.

In a pilot study in the Netherlands, 12 specific portable devices were developed with emphasis on user friendliness, particularly weight, size, and operation of the device (8). The developed equipment fit in a video camera bag and weighed 2 kilograms, with antennas integrated in the shoulder straps. The GeoMate unit, handheld computer developed for the pilot project, required the operation of only four push buttons. The GeoMate was equipped with a $1 \mathrm{Mb}$ chip able to save its memory even without power supply. The software for the operating menu also was programmed into the chip. Although it was possible to monitor all travel 
modes, the GPS device registered nearly all car driver trips, compared to half of the tram and train trips. Public transport trips were registered at a higher accuracy level than car trips. Some trips were not registered due to the burden placed on respondents to carry equipment or due to lack of time. This was especially true for walking, cycling, public transport, shopping trips and visits. With respect to route choice, the length for trip segments and other valuable information was collected. Some hurdles, mostly technical failures from mistakenly connected cables causing delays and loss of data at the initial field tests, would still have to be overcome for the system to be cost effective.

In the United States, a proof-of-concept study conducted at the Georgia Institute of Technology examined the feasibility of using GPS data loggers to completely replace traditional travel diaries (9). The challenge was that all essential trip data elements, including trip purpose, are derived from the GPS data collected. The three GPS data logging packages deployed contained different GPS and differential GPS (DGPS) receivers to test the ability to accurately derive travel data based on varying accuracy levels available in the GPS data. The GPS data collected in vehicles were processed within a GIS to derive most of the traditional travel diary elements. The study established the capability to accurately identify trip ends within a GPS data stream, to perform land use and address look-ups with a spatially accurate and comprehensive GIS, and to assign individual trip purposes from the derived land use and address data. The study also identified the symptoms of data problems related to equipment malfunction, GPS receiver data acquisition delays, and manual trip reporting errors.

In another Georgia Institute of Technology study, a prototype instrumentation package was assembled and included a handheld electronic travel diary (ETD), a GPS receiver and antenna, an onboard diagnostics (OBD) engine monitoring system, and a rugged industrial computer (9). The study concluded that, by successfully measuring and recording all trip-making characteristics, along with the corresponding origins, destinations, routes, and times, the EDT makes available a host of new research opportunities to better understand human travel behavior and its impact on congestion and emissions.

The previous section provided an overview of available electronic travel data collection technologies that were primarily used for tracking vehicles not individuals. This study will test a PDA/GPS unit that will track individual travel behavior and develop a mechanism of communicating feedback to the individual via the web, or perhaps instantly, that will encourage a change in trip-making decisions. The next section reviews 
previous research on the effectiveness of providing feedback to individuals related to their travel choices.

\subsection{Impacts of Providing Customized Travel Options}

As previously mentioned, this study builds on the 1999 FDOT Research Center Office study prepared by CUTR that demonstrated the travel habits of households provided with personalized advice did increase the use of alternatives to driving alone relative to the control group (1). A total of 75 individuals in 39 households participated in a practical exercise that led households to reappraise their needs and rationale for travel. Specific suggestions aimed at use of public transit service, bike paths, trip chaining, ridesharing, and e-commerce options were provided based on specific travel patterns observed in the activity diaries. A weeklong travel diary formed the basis of the personalized advice provided by CUTR. The study concluded that the provision of travel information would reduce vehicle miles of travel. Furthermore, it demonstrated a statistically significant difference between the travel behavior of people who receive travel reduction suggestions and those who do not receive such suggestions. However, it has yet to be determined if the provision of "generic" suggestions (such as "share a ride," "ride the bus," etc.) has less impact on travel patterns than provision of customized suggestions based on household travel behavior. The study also suggested testing a GPSbased system in conjunction with or in addition to an Internet based system of recording travel modes and providing feedback on a large scale to assess whether such a system would produce enough reduction in travel to merit the cost of implementation.

In Adelaide, Australia, a public awareness campaign, "Travel Blending ${ }^{\circledR} "$ introduced ways for individuals to reduce car use by blending, or mixing, their travel choices over time (11). The program involved the development of a unique travel awareness campaign while working directly with households to:

- measure current travel behavior using a travel diary instrument,

- provide personalized information for making simple, incremental changes to travel behavior using a feedback sheet,

- give people a chance to implement the suggested incremental changes, and

- measure travel behavior changes using a second travel diary.

In all, 84 percent of participating households in the Adelaide trial received some feedback. Nearly three quarters of the participating households $(72 \%)$ received comparative feedback for at least some members of the 
household. This comparative feedback provided information about changes they had made during the program. Although the diaries are primarily a tool for participants to observe their own behavior, one of the benefits of the two-diary format for the Travel Blending ${ }^{\circledR}$ Program is the ability to measure changes in reported travel behavior and car use. Results from Adelaide indicate about a 10 percent reduction in vehicle kilometers traveled and a slightly higher percentage reduction in vehicle trips and total hours spent in the car. These results, while encouraging, must be interpreted cautiously. Further research was recommended to explore the generality and magnitude of travel behavior changes due to travel blending.

In February 2001, a study commissioned by the UK Department of the Environment, Transport and the Regions, analyzed the effectiveness of personalized travel planning techniques in general and the "personalized journey planning" process in particular (12). "Personalized Journey Planning" covers a variety of techniques that provide individualized analysis or advice to trip takers based on their specific travel characteristics, consequently, influencing their modal choice, particularly car use. Table 2 includes the techniques reviewed in the study.

\section{Table 2: Personalized Journey Planning Techniques}

\begin{tabular}{|c|c|c|}
\hline $\begin{array}{l}\text { Overlapping } \\
\text { Groups of } \\
\text { Techniques }\end{array}$ & Approach & Techniques \\
\hline $\begin{array}{l}\text { Techniques aimed at } \\
\text { specific journeys }\end{array}$ & $\begin{array}{l}\text { Covers a range of techniques that have the } \\
\text { provision of journey information for specific } \\
\text { journeys as their common theme. }\end{array}$ & Personalized journey planners \\
\hline \multirow{2}{*}{$\begin{array}{l}\text { Techniques aimed at } \\
\text { affecting overall travel } \\
\text { behavior }\end{array}$} & \multirow{2}{*}{$\begin{array}{l}\text { Which are broadly those asking for most } \\
\text { involvement from participants and aiming to } \\
\text { change the way a person thinks about their } \\
\text { travel. }\end{array}$} & $\begin{array}{l}\text { Direct marketing of transport } \\
\text { modes }\end{array}$ \\
\hline & & $\begin{array}{l}\text { Household and community } \\
\text { behavioral change }\end{array}$ \\
\hline \multirow{4}{*}{$\begin{array}{l}\text { Other individualized } \\
\text { approaches to change } \\
\text { travel behavior }\end{array}$} & \multirow{4}{*}{$\begin{array}{l}\text { This covers a set of approaches arising out of } \\
\text { other concerns. This set is more disparate } \\
\text { than the other groups. }\end{array}$} & Personalized disincentives \\
\hline & & TravelWise teachers pack \\
\hline & & Mobility centers \\
\hline & & Travel awareness campaigns \\
\hline
\end{tabular}

Source: "A review of the effectiveness of personalized journey planning techniques." UK Department of the Environment, Transport and the Regions, February 2001.

It was concluded that these techniques work "on their own" only if there was a large gap in perception between what exists and what is perceived. For public transportation, where services and travel quality were much higher than perceived, personalized approaches had very large effects, but 
where such a gap does not exist, the travel behavior effects could be negligible. For modal shifts to walking and cycling, factors are more complex but the concept of a "perception gap" is still of relevance. The study also concluded that Personalized Journey Planning techniques could bring about the desired changes in travel behavior if they are part of a wider comprehensive travel demand strategy. Since these techniques represent relatively new types of initiatives in the field of transportation and until more trials are conducted, the study concluded that potential impacts of these initiatives should not be generalized.

In Japan, a field experiment was conducted to investigate the effectiveness of a travel feedback program for reducing family car use (13). A total of 292 fifth-grade students (10 and 11 years of age) and members of their families participated in the experiment. Of these, 155 participants received individualized information and advice on reducing family car use (the advice group), and 137 participants were asked to make behavioral plans with respect to methods of reducing car use (the planning group).

Six weeks prior to experimental intervention, the students and their families answered a questionnaire on the frequency of car, public transportation use over three consecutive days (Sunday, Monday, and Tuesday), and the number of days the family car was used each month. Four weeks before the experiment, all students were lectured on impacts of global warming, the role of carbon monoxide $\left(\mathrm{CO}_{2}\right)$ and $\mathrm{CO}_{2}$ emission levels from car use.

The families in the advice group were asked to fill in a three-day activitytravel diary on starting times, ending times, types, and locations for all their activities, and mode of transportation used to travel to and from activities. Upon analyzing the diaries, each family was presented with a diagram with their three-day activity-travel patterns and how the patterns might be modified to reduce $\mathrm{CO}_{2}$ emissions.

Each household in the planning group was asked to develop behavioral plans to modify up to three of their home-based car trip chains with the aim of reducing $\mathrm{CO}_{2}$ emissions. They were asked to log their planned departure time, arrival time and travel mode for each trip and the location of each stop in their modified car trip chains.

One week later, participants in both groups answered a duplicate of the original questionnaire. It was found that families encouraged to make behavioral plans particularly by reducing car use reportedly reduced car usage. The actual reduction was estimated to be 27.7 percent in terms of total trip duration and $\mathbf{1 1 . 6}$ percent in terms of car-use days. By contrast, 
households that merely received advice on how to reduce car use did not make similar changes. Theories of implementation intention state that forming an intention to implement a behavioral plan is necessary in the actual implementation of that behavior. Encouraging individuals to make behavioral changes provides a more powerful incentive by directly urging them to form implementation intentions.

The concept of travel feedback shows promising results in travel behavior modification efforts. This NCTR/FDOT study takes that concept one step further by designing and implementing a system that provides feedback to activity diary users via the web or perhaps instantly. The activity diary will collect information such as travel purpose, origin, destination, travel time, speed, occupancy, etc. Subtasks under this task include designing the service (including user devices and communication options); identifying the data to be captured, transmitted, and processed; designing user interfaces, creating the database design, and preparing system testing procedures (communication system and PDA). Using the data collected from the activity diaries (PDA/GPS units) that are interconnected with readily-available databases will provide feedback to individuals and/or households on realistic and relevant options such as transit.

The previous section provided a review of research conducted in the field of electronic data collection and modifying travel behavior by using personalized advice. The next section will review existing technology and communication options including wireless. The same section will also review interface options available in PDAs, identify existing databases (GIS, transit stops, bike paths, road construction, etc.) that are readily available and easily accessible in the testing area (Tampa) to facilitate feedback on alternatives to driving alone. A technical and economical evaluation of the systems and their options will be conducted and the type and quantity of equipment to buy will be selected. 


\section{Selection Criteria of TRAC-IT Components}

The methodology and criteria for the selection process of the TRAC-IT prototype system components were defined in two areas: hardware and software.

\subsection{Selection Criteria of TRAC-IT Hardware Components}

The hardware selection process began with identifying the functional requirements for the PDA, the GPS and the wireless card.

\section{The PDA Component}

The PDA selection process was based on six criteria: processing power, operating system (OS) and availability of Software Development Kits (SDKs), device memory, battery power, expansion capabilities, and cost.

1. Processing Power - The system must have sufficient computing power to provide the user with an appropriate interface, read data from the GPS unit, perform initial data processing and data storage in real-time, and transfer the necessary data back to a central location. Initial estimates were that at least a $200 \mathrm{MHz}$ CPU would be required in order to execute real-time complex algorithms.

2. PDA Memory - Storage on the PDA must be able to accommodate the operating system, custom-developed software application, collected data, and drivers and software for the GPS device. It was estimated that if Read Only Memory (ROM) of at least $32 \mathrm{MB}$ were utilized to store the operating system, then only an additional $64 \mathrm{MB}$ of Random Access Memory (RAM) would be required for application execution and data storage.

3. Operating System \& Availability of Software Development Kits (SDKs) - Microsoft ${ }^{\circ}$ Visual Studio .NET 2003 (VS .NET 2003) provides an extensive developer support environment for the Microsoft ${ }^{\circledR}$ Pocket PC 2003 (PPC 2003) operating system. Many third-party software development resources were available for consultation. To lessen development time for custom software, PPC 2003 was acquired as an operating system on the PDA. The development environment and the custom software are discussed in detail in the "System Software" and "Data Collection Application: TRAC-IT" sections.

4. Battery Power - To allow the user to carry the device for an entire day, an estimated minimum battery life of 5-8 hours is required.

5. PDA Expansion Capabilities - either the PDA or the GPS must provide adequate expansion slots so that the wireless 
communication card can be added to the system. Additionally, the selected PDA must be compatible with the chosen GPS device. All devices must attach to form a single physical device.

6. Cost - The cost of the PDA unit should be affordable so the benefits of reduced processing, etc. are not exceeded by the capital cost of the equipment.

\section{The GPS Component}

The GPS device selection process was based on four criteria: system integration, expansion capabilities, a high degree of accuracy, and cost.

1. System Integration - To function adequately, the combined device must be able to rely on battery power and not require an external power source such as a car charger. Additionally, the selected devices must attach to each other to form a single physical device.

2. Expansion Capabilities - either the PDA or GPS must provide adequate expansion slots so that the wireless communication card can be added to the system. Additionally, the selected GPS must be compatible with the chosen PDA device.

3. GPS Accuracy - to accurately represent a user's trip, the GPS component of the system must provide adequate positional accuracy (within 10 meters) for trip reconstruction using the collected data.

4. Cost - the cost of the GPS unit should be affordable so the benefits of reduced processing, etc. are not exceeded by the capital cost of the equipment.

\section{The Wireless Communication Component}

The only requirement for the card is the ability to connect to the other two devices using some type of connection, in this case a CompactFlash (CF)type hardware connection, and the compatibility with the rest of the system software.

\subsection{Selection Criteria of System Software Components}

In addition to hardware features, types of available Software Development Kits (SDKs) for these devices and their operating systems were researched as well. Several SDKs were considered, including those available for the Palm ${ }^{\circledR}$ OS and Microsoft ${ }^{\circledR}$ Pocket PC operating systems.

Palm ${ }^{\circledR}$ provides a SDK for its handheld devices that consists of libraries and headers. It does not include a compiler or an automatic distribution environment. An additional component must be downloaded and installed 
in order to run the application on an emulator. The component must be developed inside of a text editor and include the external libraries in their code. Developer support on Palm's ${ }^{\circledR}$ website was sparse, with relatively few links to sample code, knowledge base issues, and overall documentation. For these reasons and the strengths of Microsoft's ${ }^{\circledR}$ Pocket PC OS, the Pocket PC OS was chosen as a development platform. This eliminated all hardware devices running the Palm® OS.

Pocket PC 2003 allows the developer to write software in the Visual Studio .NET 2003 environment in the languages Visual Basic .NET and C\# .NET, which is an advantage over Pocket PC 2002 that only allows development in the embedded Visual Basic and $\mathrm{C}++$ languages. The embedded languages contain a subset of functions of their .NET counterparts, and the additional functionality of the .NET environment related to database access and application deployment greatly aids in the development process.VS.NET 2003, when combined with the Pocket PC 2003 SDK, provides a fully integrated compiler and application distribution environment. The emulator packaged with the Pocket PC SDK allows the developer to instantly test the application with the simple click of a button and requires no additional hardware. Additionally, the .NET Compact Framework, which is the foundation of Pocket PC 2003, also has also proven to be a stable foundation for third-party software solutions (18).

Together VS.NET 2003, the Pocket PC SDK, and the .NET Compact Framework create a powerful environment where the developed application can be tested and deployed to many different physical devices with varying levels of processing power and physical memory. Developers have been frustrated in the past by investing time and resources into creating an application only to be restricted to using the single device that it was designed on because of incompatibilities with other proprietary hardware or software (15) and (16). If that specific device should become unavailable, the software would have to be re-designed and re-written for a different device (14). Any application developed in VS.NET 2003 will execute on any device that runs the Pocket PC 2003 operating system, which allows great flexibility in current and future device selection. Microsoft $₫$ also provides extensive developer support and sample code for many different concepts and systems related to portable devices (18). 


\section{TRAC-IT Prototype Design}

This project uses advanced technology to construct a system that improves both quality and quantity of data gathered on individual travel behavior across multiple modes of transportation, including non-motorized travel, and submits the data from any location. Survey participants carry a system consisting of PDAs and GPS devices and automates the collection of much of the data needed to measure individual travel behavior. Data that are not automatically collected, such as trip purpose and occupancy, are then gathered using a unique "Smart Diary" user interface that attempts to ease the burden of data entry on the individual. The field device also integrates communication capabilities to handle remote processing of data and providing feedback to the individual. Figure 1 illustrates the conceptual relationship between the portable system and other related technologies.

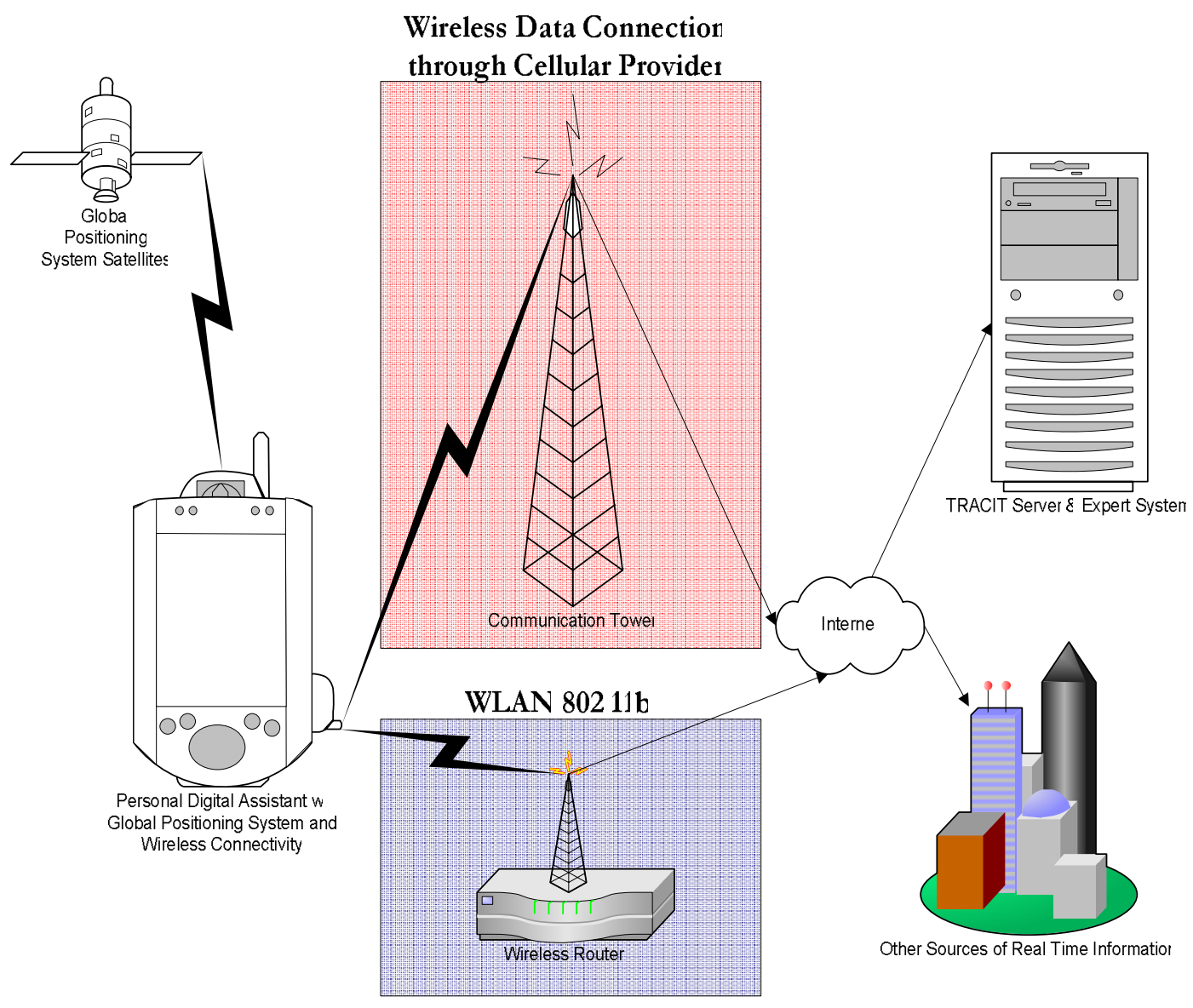

Figure 1: Overall TRAC-IT System 
This data collection system is best described by dividing it into two categories: system hardware and system software. A PDA-based solution is described in Sections 4.1 and 4.2. Finally, in Section 4.3 the GPSenabled cell phone is introduced as a prototype cost-effective replacement for the PDA/GPS/Communication Component tool that can also be used for GPS data collection and communication with a central server database.

\subsection{TRAC-IT System Hardware}

The system hardware consists of three commercially available devices: a PDA, a GPS unit, and a wireless card. The GPS unit and the wireless card mount on the PDA, as shown in Figure 2. All three components combine into one portable handheld device.

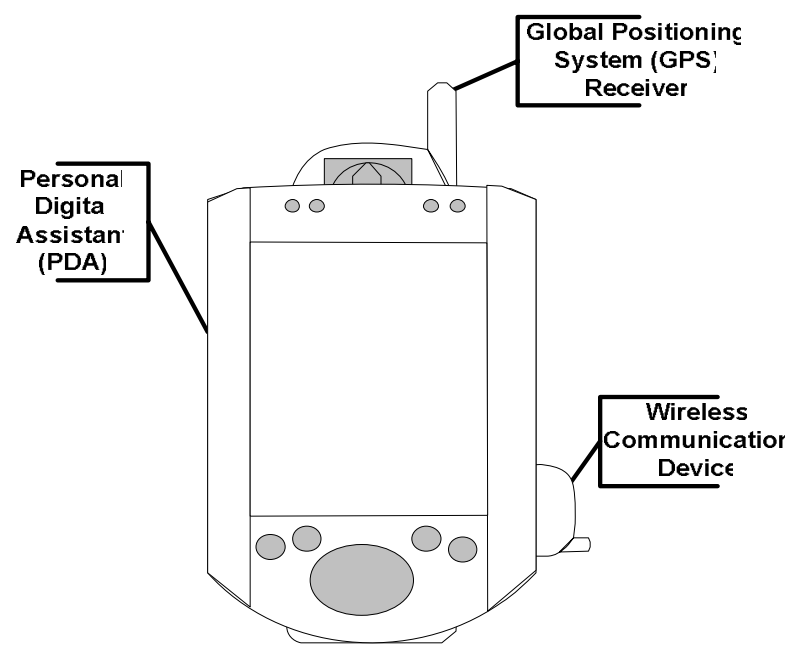

Figure 2: The PDA with GPS and Wireless Card

\section{The PDA Component}

The selection of a Hewlett Packard $(\mathrm{HP} \circledast)$ iPAQ H5555 PDA was made after examining the following characteristics of a large number of PDAs: processing power, operating system (OS) and availability of software development kits (SDKs), device memory, battery power, and expansion capabilities. The $400 \mathrm{MHz}$ processor is capable of data collection, analysis, and storage in real-time as well as communication with external sources. Pocket PC 2003, the OS featured in the IPAQ H5555, supports applications developed in the Visual Studio .NET 2003 (VS .NET 2003) environment using the Visual Basic and $\mathrm{C \#}$ languages. Software development is discussed in detail in Section 3.3, "Selection Criteria for Software System Components." 
Since storage is limited on portable devices, total memory is often shared between file storage space and system memory for executing applications and is a very desirable commodity. At the time of selection, the IPAQ H5555 contained the internal memory of the devices on the market, with $48 \mathrm{MB}$ of flash ROM dedicated to the operating system and vital resources and $128 \mathrm{MB}$ of SDRAM that can be used for file storage or as memory for applications. The SDRAM is volatile and is lost if the battery is removed from the device.

Another important issue for portable devices is the amount of battery power available. It is desirable for the system to be able to track an individual's travel behavior for at least 5-8 hours without recharging. Many processors designed for mobile use perform their own power management, which allows the system to run off the Lithium-Ion 1250 mAh battery for an estimated 3 to 4 hours before it must be recharged. Several options exist that allowed the use of the system for the required 5-8 hours per day. For example, an additional "external" battery can be carried in a small pouch to provide approximately 22 hours of operating time; however, this battery is slightly larger than the combined system of the PDA, GPS, and wireless communication device, and therefore is cumbersome to carry. Another option would depend on the user to recharge the battery during the day, either while driving in a vehicle or while sitting at a desk. The energy issue is considered a very critical component to the system. Field tests will have to address the issue of battery failure to avoid losing collected data and the customized application, which are both stored in the volatile SDRAM of the device. Additionally, data corruption issues may develop if the custom application is interrupted during data collection by battery failure or any other type of device power-down.

Since the system requires not only a GPS but also a wireless communication device, the expansion capabilities of the PDA were closely examined. The iPAQ H5555 provides a Secure Digital (SD) media slot capable of SDIO communication, which can be used for external memory up to $512 \mathrm{MB}$ or for additional hardware devices. The CompactFlash (CF) port can support add-on hardware as well. At the time of hardware selection, most available GPS and wireless communication devices interfaced through the CF slot. This implied that either the GPS or the wireless communication device has to provide additional expansion to accommodate the other unit. The selected Navman ${ }^{\circledR}$ GPS 3450 device supports only $\mathrm{HP}{ }^{\circledR}$ iPAQs, so all other PDA products were eliminated leaving HP®'s products as the remaining choices. This selection was made after examining the following characteristics of GPS devices: system integration, expansion capabilities, and positional accuracy. 


\section{The GPS Component}

The Navman ${ }^{\circledR}$ GPS 3450 connects to the iPAQ H5555 through the CF port and therefore does not require a separate source of power. It also is compatible with the Pocket PC 2003 operating system including device drivers that allow communication between the PDA and the GPS units. This GPS unit also included a built-in CompactFlash expansion slot where a wireless connection card can be added to the system. Finally, the Navman ${ }^{\circledR}$ GPS 3450 provides an adequate accuracy of more than 5 meters for 95 percent of readings ${ }^{1}$.

Previous research confirmed that GPS data alone were sufficient for recording travel along roadways without other secondary independent data sources; therefore, the selected GPS unit would be an accurate indicator of user's positions (8), (14), (15), and (16). An additional test, performed to ensure the accuracy of the Navman ${ }^{\circledR} 3450$, involved recording multiple coordinates from the unit while it remained in the same physical location.

The results, as shown in Table 3, confirmed that accuracy based on the average distance between consecutive readings (within 2.275 meters) is considered adequate within the scope of this project.

One of the few limitations to the system could be the lack of GPS signal reception. The GPS must have a clear line-of-sight to satellites in order to receive location information, which means a user cannot receive his/her position inside most buildings and parking garages or in "urban canyons" and areas between large buildings. While data for some trips may be unavailable due to lack of signal, the majority of trips are expected to be correctly represented.

${ }^{1}$ Detailed unit specifications are on the Navman $®$ website at http://www.navmanusa.com/product.asp?pn=AA005215, accessed April 2005.

${ }^{2}$ Urban canyon is defined as an area located between high-rise buildings, usually in downtown sections of cities, that may be partially or completely denied GPS coverage due to the surrounding buildings. These buildings tend to block GPS signals that are transmitted from satellites orbiting the earth. 
Table 3: GPS Co-ordinates Recorded While Standing Still

\begin{tabular}{|l|l|l|l|}
\hline & $\begin{array}{c}\text { Latitude } \\
\text { (Decimal } \\
\text { Degrees) }\end{array}$ & $\begin{array}{c}\text { Longitude } \\
\text { (Decimal } \\
\text { Degrees) }\end{array}$ & $\begin{array}{c}\text { Distance from } \\
\text { Previous Point } \\
\text { (Meters) }\end{array}$ \\
\hline Point 1 & 28.05829333 & -82.41527667 & \\
\hline Point 2 & 28.05828333 & -82.41527833 & 1.0 \\
\hline Point 3 & 28.05827833 & -82.41527500 & 0.6 \\
\hline Point 4 & 28.05828667 & -82.41528000 & 1.0 \\
\hline Point 5 & 28.05829333 & -82.41528333 & 0.8 \\
\hline Point 6 & 28.05831500 & -82.41528833 & 2.5 \\
\hline Point 7 & 28.0583500 & -82.41529667 & 4.0 \\
\hline Point 8 & 28.05839833 & -82.41531667 & 5.7 \\
\hline Point 9 & 28.05844333 & -82.41534667 & 5.7 \\
\hline Point 10 & 28.05844667 & -82.41535333 & 0.8 \\
\hline Point 11 & 28.05843833 & -82.41537000 & 1.9 \\
\hline Point 12 & 28.05843000 & -82.41539167 & 2.3 \\
\hline Point 13 & 28.05842667 & -82.41540167 & 1.0 \\
\hline
\end{tabular}

Notes

+ Average distance between sequential points (in Meters): 2.275

++ Distances were calculated using http://jan.ucc.nau.edu/ cvm/latlongdist.html\#formats

\section{The Wireless Connection Component}

The third and final hardware component of the device is the wireless connection card. While Wireless Local Area Network (WLAN) capabilities of a PDA can be used to transmit or receive data, real-time communication while driving or traveling through areas not covered by WLAN would have to be covered by a cellular-based communication device. This type of connection card and the required subscription service can be purchased from most cellular carriers. The only requirement for the card is the ability to connect to the other two devices some type of mechanism such as the CompactFlash (CF)-type hardware connection and the compatibility with the rest of the system software. The wireless connection card can transfer data via various cellular protocols such as the Global System for Mobile Communications (GSM), Code Division Multiple Access (CDMA), General Packet Radio Service (GPRS), or Time Division Multiple Access (TDMA). The selected protocol depends on the cellular provider's network 
technology. The only device that met the requirement of the CF interface was the CF 2031 by Sprint ${ }^{\circledR}{ }^{1}$.

While expansion sleeves that allow other connection cards of a PCMCIAtype interface to communicate with the iPAQ H5555 are available, these sleeves would conflict with the addition of the GPS component to the system. If WLAN coverage is available, it can serve as a suitable replacement of the cellular service during system development and testing. The WLAN available on the USF campus served as a testing ground for the custom software before the system was released for field use.

\section{TRAC-IT Limitations}

To date, limitations of the system hardware are listed below:

- Since the current system requires three hardware components, one individual unit costs approximately $\$ 1,200$.

- While smaller than most previous devices, the system becomes bulky when all three hardware components are connected. The size of the device could deter participants from using the device on every trip taken and, therefore, the collected data may not be a complete record of their travel. A possible solution may be to carry only the PDA and GPS combination without the wireless card. This would eliminate the real-time communication and feedback component of the system but would still allow for multi-modal collection of travel behavior data. The wireless card could be added to the system only when desired, such as in a vehicle where the system would be mounted instead of carried.

- Battery life of the system is very short. When PDA and GPS components are used together, battery life is under 3 hours. When the communication component is constantly used, it is estimated that battery life will drop significantly under 2 hours.

- It was found that very few available hardware devices were all intercompatible. The different limitations of each device quickly reduced the selection pool to very few hardware components. Hopefully, as the portable computing market continues to advance, integrated devices will become available that will combine the features of two or perhaps even all three components.

\footnotetext{
${ }^{1}$ Specifications are available online at http://www1.sprintpcs.com/explore/ExploreHome.jsp, accessed April 2005.
} 


\section{System Hardware Update - October 2004}

Due to limitations identified above for the original hardware configuration, equipment that had been released to the commercial market after the initial selection process was evaluated. It was found that two products both met the initial system selection criteria and improved upon limitations found in the initial equipment selected. A PDA manufactured by HP, the $\mathrm{H} 6315$, combined two of the system components, the PDA and wireless connectivity, into one device. A similar 2-in-1 device is the Audiovox XV6600. However, the XV6600 did not include WLAN connectivity that was very important for prototype testing and other high-speed data communication, so it was eliminated from consideration in current system (XV6600 uses the Verizon Wireless EV-DO broadband wireless subscription service. At the time of the second equipment selection process, the monthly subscription fee along with the cost to break any contracts pushed the cost for this unit out of the scope of the project budget. However, the XV6600 should be interchangeable with the H6315 in this system if further benefits for using the XV6600 are determined in the future and the cost is within the operating budget). The H6315 includes both WLAN connectivity as well as GPRS service through a subscription to the cellular carrier T-Mobile. Therefore, the H6315 was chosen as the new PDA/Wireless Communication device. Figure 3 shows the specifications for the $\mathrm{H} 6315$.

At this point, the issue of the GPS device was revisited using the same initial selection criteria. The possibility of using the cell carrier's GPS positioning mechanism (required under government mandate for e-911 Phase 2 implementation ${ }^{1}$ ) was investigated. However, it was determined that the only cellular carrier that has fully implemented such a system or makes this information available to third party developers is Nextel, which is not a carrier supported by the H6315 or XV6600. Additionally, Nextel currently does not offer any Pocket PC PDA devices for use with their system. Therefore, the GPS device that would be used with this system would again have to be hardware-based. A new GPS device to be paired with the H6315 was identified as the Navman 4410, as shown in Figure 3. This GPS device communicates with the PDA through the Bluetooth

\footnotetext{
${ }^{1}$ From the Federal Communication Commission at http://www.fcc.gov/911/enhanced/ : "Under the FCC's rules, wireless carriers must transmit the location of a wireless 911 caller within certain accuracies. The wireless E911 program is divided into two parts Phase I and Phase II. Phase I requires carriers, upon appropriate request by a local Public Safety Answering Point (PSAP), to report the telephone number of a wireless 911 caller and the location of the antenna that received the call. Phase II requires wireless carriers to provide far more precise location information, within 50 to 300 meters in most cases."
} 
wireless protocol. Therefore, the PDA and GPS can be carried separately and do not have to be physically attached to each other.

\section{$\underline{\text { HP IPAQ h6315 }}$}

Operating System:

CPU:

Connectivity:

Memory:

Display:

Expansion:

Digital camera:

Input type:

Dimensions:

Weight:

Cost:

Data transfer rate:

Price per month:

GPS capability:

Web address:

314903-f60-430120.html)
Windows Mobile ${ }^{\mathrm{TM}} 2003$ software - Premium with Phone Edition

Texas Instruments OMAPTM 1510 (Approx. 200MHz)

Quad-band GSM/GPRS, WLAN 802.11b, Bluetooth, and IrDA

$75 \mathrm{MB}$ user available (includes up to 20MB iPAQ File Store)

3.5" Transflective TFT; 64K colors Touch Screen

MMC/SD expansion slot - supports SDIO

Yes

Removable snap-on thumb keyboard

$5.42 \times 2.94 \times .82$ inches

6.7 ounces

$\$ 534$

20-35 kbps avg. download \& upload

$\$ 29.99$ (Unlimited)

T-Mobile does not currently offer GPS service

(http://h10010.www1.hp.com/wwpc/us/en/sm/WF05a/215348-64929-215381-

\section{Navman GPS 4410}

Blue tooth device

http://www.navmanusa.com/product.asp?pn=AA005411

Figure 3: Current TRAC-IT Equipment as of 4-1-2005

The H6315 improves upon power management issues found in the H5555. The H6315 is able to hold a battery charge in standby mode for more than a week and therefore can retain the data and programs installed on the PDA, which were usually lost on the $\mathrm{H} 5555$ after an extended duration in the "sleep" mode. While carrying two separate hardware components was initially viewed as a disadvantage, prototype system tests found that with current technology mounting all three components together created a bulky unit that was not easily carried. Having the PDA and GPS as two separate units allows the GPS to be placed in a location with good signals (i.e., on the car dashboard, carried using an armband, or placed in the top of a bag). At the same time, the PDA can be tucked somewhere less conspicuous (i.e., on a belt clip, at the bottom of a bag, in the center console of a car). Separating the system into two units also lengthens battery life significantly. Using the first set of selected equipment, all three units drew power from the battery of the PDA, which drained very quickly (less than 2 hours). With this updated hardware configuration, the 
PDA and integrated communication component rely on the rechargeable PDA battery while the GPS functions on its own internal battery. This should substantially contribute to the battery life and easily capture a full day of travel behavior. While the user now has to remember to carry two separate devices, it is believed the benefits outlined above that contribute to vital features of the system outweigh this negative aspect.

The expense of the system could be an issue when mass deployment is considered, and the combination of the PDA and Wireless Connection Component into one device significantly lowers the price. Estimated system cost using the $\mathrm{H} 6315$ and Navman 4410 as calculated from vendor quotes is $\$ 854$. Another issue related to cost is the product lifecycle of the PDA/Wireless Communication components. The original GPS device, the Navman 3450, was compatible only with the specific PDA model H5555 from HP. Since technology is advancing rapidly in both the handheld PDA and wireless communication markets, the H5555 was being phased out of the market by the time of our second equipment selection analysis. Therefore, the Navman 3450 is rendered useless when the only compatible PDA is discontinued. GPS manufacturers have identified this problem and are moving production from physically attached GPS devices to wireless Bluetooth connection GPS devices. Since the Bluetooth protocol is an industry standard, the Navman 4410 should be forward-compatible with any future PDA/Wireless Communication units that support the Bluetooth protocol.

\subsection{TRAC-IT System Software}

The custom software developed for this project consists of program modules that implement a graphical user interface (GUI) to obtain information from the individual traveler, modules that receive and analyze GPS data, a local PDA database and server-side database management system, and a program module to transfer the database information to a central database. A detailed description of each software module follows.

\section{Data Collection Application - TRAC-IT: a Smart Diary}

A basic flowchart of the Graphical User Interface (GUI) is shown in Figure 4. The custom software, "TRAC-IT," was designed to guide the user through the data entry process via "wizards" or interactive screens providing step-by-step instructions. These wizards collect trip information from the user that cannot be automatically determined with 100 percent accuracy, including a description of the location visited, mode of transportation taken, purpose for the trip, and the occupancy of the mode of transportation. The following list of trip purposes, used for TRAC-IT 
system design, is based on the National Travel Household Survey (NTHS) Glossary's definition of trip purposes ${ }^{1}$ :

- Work / Work-Related

- School / religious activity

- Go to school as student

- Go to religious activity

- Go to library: school related

- Medical / dental services

- Shopping / errands

- Buy goods: groceries / clothing / hardware store

- Buy services: video rentals / dry Cleaner / post office / car service / bank

- Buy gas

- Personal or family business

- Social / recreational

- Go to gym / exercise / play sports

- Rest or relaxation / vacation

- Visit friends / relatives

- Go out / hang out: entertainment / theater / sports event / go to bar

- Visit public place: historical site / museum / park / library

- Transport someone or myself

- Pickup someone

- Take and wait

- Drop someone off

- Change mode of transportation

- Meals - go out to eat / get take out

- Return home

- Other: miscellaneous reasons

Properties for each trip that are automatically recorded and are not entered by the user are trip start and end times, travel path, speed, and

\footnotetext{
${ }^{1}$ NTHS Glossary link http://www.bts.gov/publications/highlights of the 2001 national household travel surve y/html/appendix b.html, accessed April 2005.
} 
heading. These automatically collected properties are discussed in depth in the below section "GPS Data Processing."

During the GUI design process, it was determined that the final design should contain as few screens as possible to avoid extensive user input. Initial prototype evaluation showed that user fatigue quickly becomes an important issue and could deter the use of this system for data collection in a similar way that it affects the paper diary format. Therefore, the main flow of application execution was designed to consist of three main screens: Pre-Trip, During Trip, and Post-Trip. These GUI sections can be seen in Figure 4, along with a few other screens to provide advanced functions to the user.

In addition to providing a guide to the user for data entry, TRAC-IT also acts as a "Smart Diary," which can perform complicated real-time data processing and analysis in order to reduce the burden of data entry on the user. Each trip that the user records, along with associated locations and modes of transportation, is stored in a database on the PDA. These data are then referenced during future trips, preventing the user from manually entering the similar information about his/her travel behavior. For example, when he/she travels to the grocery store for the first time while carrying the device, the user can enter a short description of the location (i.e. "Publix $56^{\text {th }}$ street" or "Bob's house") as well as classify the type of the location (i.e., food-related, work-related, gas station, bus stops, etc.). On future visits to this same location, the user can select this location from a drop-down box instead of repeating the entry of the same information.

The classification of the location type expedites the manual selection of locations since they are logically grouped according to the activities that the user performs at the location. Also, identifying the specific location by name and type, not just by GPS coordinates, and referring to the same location in future trips will allow for further detailed analysis of repeated trip patterns to the same location. At a location like a mall, it is important for the user to define his/her actual destination by name, since the physical location and address could be tied to several surrounding businesses. The classification of location type also aids in automatic processing of the data as it defines specific types of locations that are clearly categorized, as opposed to the many possible user descriptions of the same location (i.e. "Publix" vs. "grocery store" vs. "my work" vs. "store"). If he/she does not enter a classification, the system will attempt to assign a classification based on the purpose that the user chooses for visiting that location (i.e., a location will be marked as "work-related" if the purpose for visiting the location is "work / work-related"). 

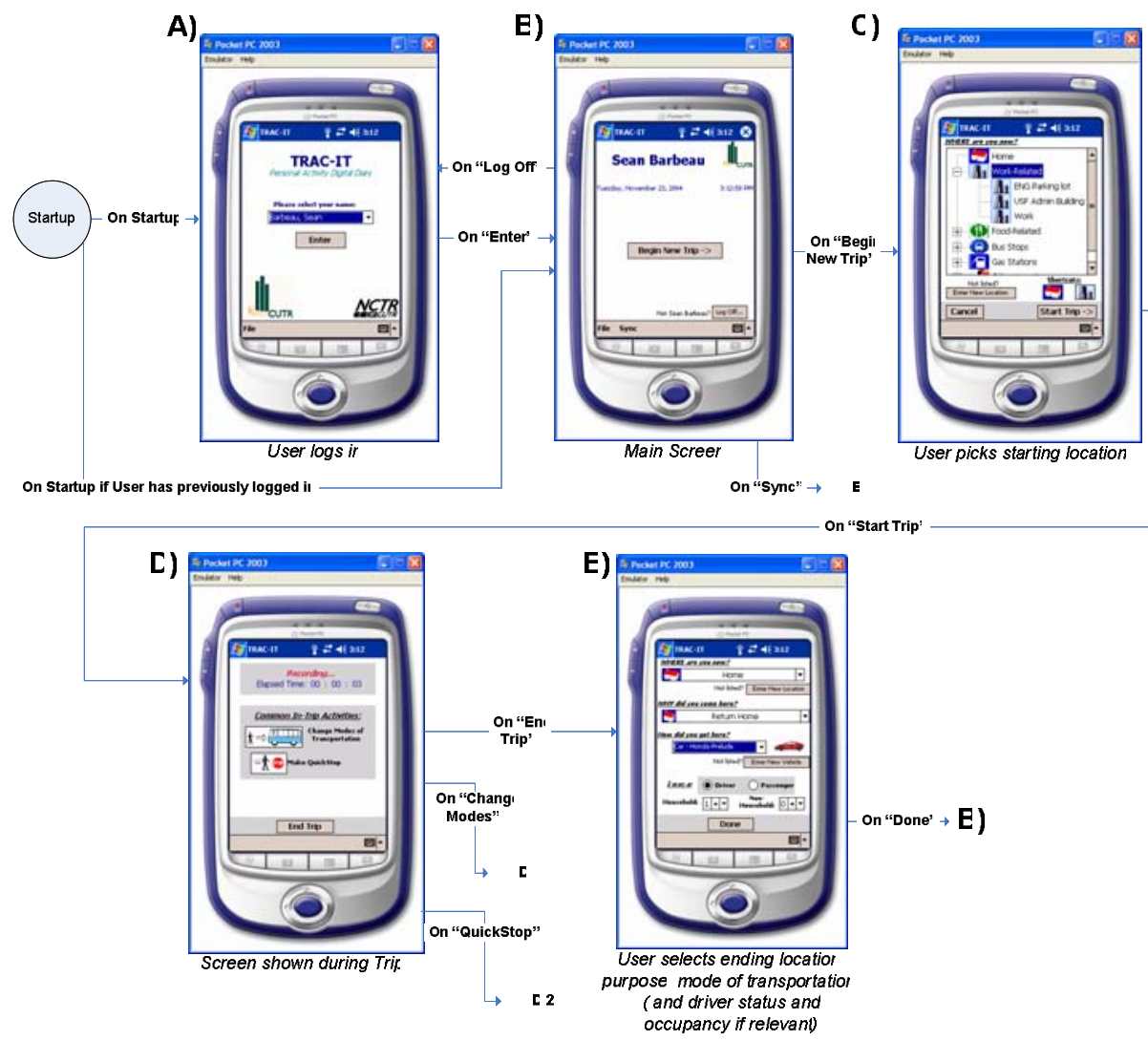

on "Done' $\rightarrow E$ )

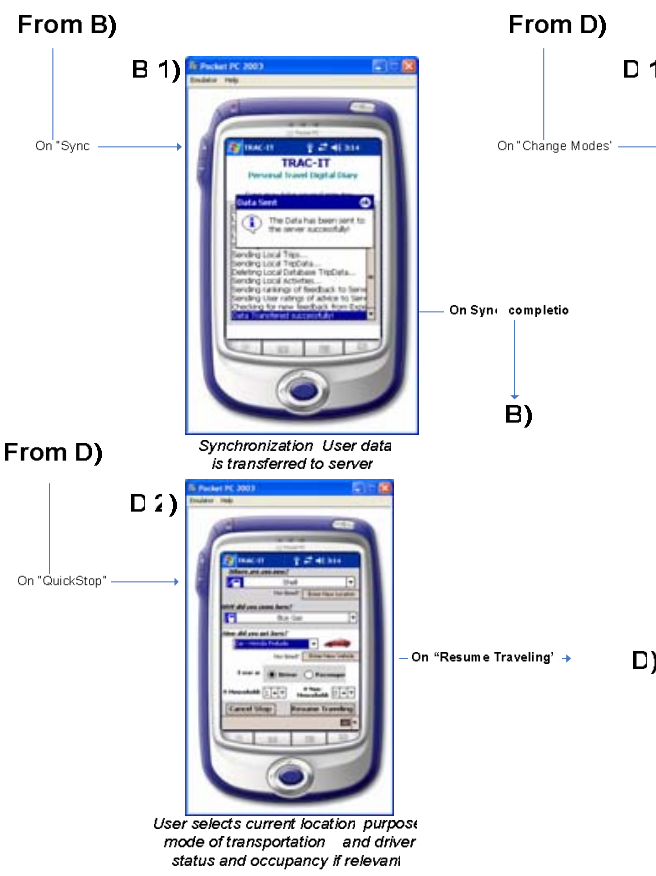

Figure 4: "Wizard" Component of GUI 
For the Expert System discussed in Section 5, "Travel Advisor Feedback System," it is also vital to be able to deliver trip feedback to the user that describes the visited locations in his/her own words, since user will not be aware of GPS data or even physical addresses linked to many of the locations that he/she visit. For this same function, the classification feature allows the Expert System to unequivocally identify location types of users and apply rules based on the location category.

Similar concepts of user-defined descriptions apply to the modes of transportation that the individual uses. When first traveling by a new mode, the user can enter a short description of the mode such as "Bob's Toyota," "Bus Route A," or "Red Bike" and classify the type of mode (i.e., "Walk," "Bus," "Bike," "Truck," or "Car,"). Like the locations, the mode can then be referenced during future trips to precisely define how the person traveled to their current location and establish patterns of travel by specific modes, even down to a specific household vehicle or bus route. These mode classifications again aid the Expert System in applying modespecific rules.

Perhaps the greatest feature of the "Smart Diary" is that the survey software itself is location-, user-, and time aware. These features can be leveraged to further reduce the burden placed on the user by implementing a significant amount of survey automation tailored specifically to the current user of the device. Sample automation includes a "locationstamping" mechanism that tags the user's locations with GPS coordinates the first time a location is visited. At the beginning and end of subsequent trips, TRAC-IT performs real-time calculations that compare a list of the geographic position of the user's stored locations to the user's current GPS position. TRAC-IT automatically fills in the "Current Location" field with the closest location that is within a certain threshold distance (i.e., 20 meters) of the current position. If the location was correctly identified, the user can proceed to the next survey field without inputting any information. If TRAC-IT selected a wrong location, the user can enter the correct information. This "pre-fill" feature enables the user to verify that the information is correct before continuing and does not force manual selection of the same information repeatedly. The threshold can be lowered or raised based on the accuracy of the GPS coverage in the survey area to an acceptable value that does not trigger too many falsepositive location identifications but still provides a significant reduction of user effort.

The user's mode of transportation can be estimated as well, based primarily on the speed detected during the last trip. Once the user reaches his/her destination, TRAC-IT examines the travel data and eliminates certain modes that are not probable given the detected 
maximum speed during the trip. For example, if the user's top speed was 60 miles per hour, any modes of type "Walk" and "Bike" could be eliminated from consideration. Current research continues to evaluate a system implemented on the cell phone version of TRAC-IT (see Section 4.5, "New Application: TRAC-IT Cell Phone Prototype") that focuses on mode-identification algorithms that have an extremely high success rate at 94 percent.

The "Purpose" field is pre-filled based mostly on the classification of the location selected as the "Current Location" pre-fill. For example, if the location is of the type "Work-Related," then the "Work / Work-Related" purpose is selected. If the location is of the type "Home," then the "Return Home" purpose is selected.

In the case of an unavailable GPS signal (which is sometimes the case at the beginning of a trip, due to the time the GPS takes to get a first fix, or in parking garages or other closed structures) or the detection of an unclassified location, other methods of pre-filling can be triggered. Pattern recognition techniques can be used to identify the most likely type of travel behavior based on the travel behavior history stored in the PDA for that particular user. A simple method is to recall the last recorded visited location when the user begins a new trip and fill the "Current Location" field with this last location. This way, if the user is carrying the PDA at all times, the "Current Location" field always will be filled with the correct information (i.e., the person arrives at work in the morning and finishes his/her trip; when they begin their trip in the afternoon to return home the current location will be selected as "Work").

Other more sophisticated methods perform data analysis based on the time and day of the week that the trip is taking place. This system "learns" as the person makes trips and gives pre-fills that are more accurate over time. For example, the first time the user records a trip; it may begin at $5 \mathrm{pm}$ and end at 5:30pm from "Work" to "Home" with the purpose of "Return Home." If the next day, the person takes a trip around $5 \mathrm{pm}$ and arrives at his/her destination at 5:28pm, TRAC-IT will automatically select the "Return Home" purpose. After the user records more than a week of trips, TRAC-IT will take into consideration the day of the week when pre-filling the purpose. For example, if the user tends to go to the gym directly after work on Mondays, Wednesdays, and Fridays but goes directly home on Tuesday and Thursdays, when trip is completed after leaving work on a Thursday, the purpose of "Return Home" will be selected. However, if he/she leave work and arrive at the destination on a Wednesday, the purpose "go to gym / exercise / play sports" will be selected. 
If desired, this pattern detection could be extended to include specific months as well to create seasonal predictions of travel purposes. Since each time the purpose pre-fill algorithm is executed it takes into account all the data collected for that particular user up to the current date, TRACIT should be able to predict trip purposes more accurately as it is carried longer in the field by the participant. However, in these situations, the pattern recognition pre-fill will be overridden if possible by the GPS data pre-fill because the GPS data pre-fill is based on real-time information rather than predictions using patterns and should be more accurate.

An evaluation of the pre-fill feature's positive and negative impact on data collection is ongoing. From a participant's perspective, the effort that the individual has to put forth to correct an erroneous pre-fill is the exact same as the effort that the user expends when the pre-fill feature is not enabled. When the pre-fill of a field is correct, the user does not have to expend any effort at all, other than visually verifying the selection. Therefore, the user stands only to benefit from this feature.

From a survey analyst's perspective, the two main areas of the survey that the pre-fill feature may impact are data accuracy and data completeness. Regarding accuracy, a concern is that some users may not verify that the information is correct before proceeding to the next question if the field is pre-filled for them. However, if a user is likely to skip through this process for the sake of time he/she may be equally likely to "Christmas tree" the survey by selecting random responses to each question. In this case, it is preferred to record an answer to the survey question that has been identified as credible by the "Smart Diary" instead of a response that is selected purely by random. If TRAC-IT can eliminate even one choice from its selection pool, it will yield a higher probability of identifying the correct response than a random selection. When adding quantitative properties like GPS position or speed to the selection process, the probability of a correct pre-fill response in a field is significantly higher than a random selection performed by the user.

Regarding data completeness, the survey analyst presumably wants to take any reasonable measure to encourage the participant to carry the survey tool at all times so that normal travel behavior is accurately reflected in the collected data. The implementation of the pre-fill feature aims to reduce user fatigue and could potentially result in extended participation in the study yielding a more complete and representative data set of travel behavior. Therefore, it appears that a certain amount of survey automation is beneficial to the data collection process.

Aside from the significant advantages associated with the electronic "Smart Diary," an important issue that differentiates the paper diary format 
from this system is the way the user is prompted to create diary entries. In the paper format, the user is asked what activity he/she just performed, which addresses his/her actions in a retrospective format. This form of diary is often filled in by participants hours or even days after the trip is made. Often trips are forgotten, and many trips are reported inaccurately. Research has shown that participants in travel surveys tend to round times and distances when recalling a daily trip schedule from memory (15) and (16). However, GPS data recorded on the same day show that arrival and departure times and traveled distances are much more evenly distributed than the subject remembered (15) and (16). These data suggest that GPS-based diaries recorded in real-time are significantly more accurate than paper or phone-based surveys that rely on the subject's memory. Additionally, if location information is reported incorrectly due to lack of memory, it may be assumed that other information regarding mode, occupancy, and trip purpose that is also user reported may suffer from these same inaccuracies. If this is indeed the case, then prompting the user for the trip information in real-time is very important in creating an effective survey tool.

The resulting challenge encountered in the design of the GUI is when to prompt the user for trip information such as trip purpose and the trip destination. An initial GUI prototype was formatted to ask the user to provide a planned destination and a trip purpose in addition to his/her current location when the user began a trip. However, this format proved to be functionally inadequate as it was found that many users did not follow their planned itinerary. When traveling from "Work" to "Home" with the Purpose of "Return Home," many users would actually stop at an intermediate location such as the grocery store or gas station before reaching the "Home" location. Even though a user may view this as one trip with the purpose of "Return Home," it should actually be recorded as two separate trips, with the second trip having the "Return Home" purpose. This concept of trip segmentation with unique destinations within a longer "trip" with separate purposes is referred to as "trip chaining." Trip chains are usually anchored by home or work locations (19). The original GUI prototype format either failed to record the intermediate locations or required the user to review and correct the original purpose and planned destination. This problem has been experienced in other GPS-based surveys and is a disadvantage to using a "prospective" diary format (15) and (16). Since some research suggests that up to 30 percent of trips are complex chains that contain more than one intermediate stop, insisting that the user review and correct almost one third of his/her trips either in real-time or at a later date seemed extreme (19) and (20). This situation would essentially double the effort required by the user for reporting any trips in a chain. Therefore, the GUI was modified as follows: 
- Upon beginning a trip, the user is asked to select only his/her current location. After selecting the current location, the user clicks on "Begin New Trip." The timer then begins to count the time elapsed during the current trip. The user is then given three options that can be chosen at when the user reaches, his/her next stop "End Trip," "Make Quick Stop," and "Change Modes of Transportation."

- If the user selects "End Trip," he/she is asked to select his/her current location, purpose for coming to this location, and his/her mode of transportation. When the user selects the "Done" button, the trip is then saved with the original source location and this recently entered data.

- If the user selects "Make Quick Stop," the user is again asked to identify his/her current location, his/her purpose for stopping there and his/her mode of transportation. However, instead of the "Done" button a button, "Resume Traveling" is placed on the form. When this button is pressed, not only is the data recorded in the same manner as "End Trip," but also this trip is identified as a link in a new trip chain. While transparent to the user, this function actually creates a second trip, with the source being the current location and with the destination location, mode, and purpose being defined once the user chooses to end the trip or make another quick stop. Using this method, multiple trip links can be recorded sequentially without the user entering duplicate information for the destination of one link and the source of the next. All subsequent trips up to and including the trip during which the user finally chooses "End Trip" are identified as links in the trip chain.

- If the user selects "Change Modes of Transportation," the "Make Quick Stop" protocol is followed. The sole difference is that the user is not prompted for the trip purpose because it is already known that the trip purpose is to "Change Modes of Transportation."

This format allows the user to automatically redefine trip parameters in real-time without burdening him/her with the task of low-level information manipulation. Additionally, when crossing between two modes of transportation, a user can quickly identify his/her new mode without having to go through the process of ending one trip and beginning another. This diary format can be considered to be real-time, immediate "retrospective" implementation. This format should avoid the memory failure issues involved with the long-term "retrospective" diaries while preventing duplicate user effort associated with "prospective" formats. 
The topic of diary format also is important when considering automation pre-fill factors, discussed above in this section. The device can provide only an estimate of the user's mode of transportation and pre-fill this field intelligently if it can examine the GPS data from the trip. Therefore, the question related to mode of transportation must be asked after the user chooses to end the trip as opposed to asking his/her mode before the user starts the trip. Similarly, purpose can only be estimated using a post-trip prompt since knowledge of the trip and current ending location must be available. These automations provide an educated guess as to what the user might have done, but his/her behavior must already have been completed for the analysis to take place. Therefore, an additional advantage to the real-time retrospective implementation is that it also alleviates some of the data entry burden on the participant by allowing such automations.

\section{GPS Data Processing}

The GPS data processing component of the system allows the user's position, speed, and heading to be automatically recorded. This feature provides not only the starting and ending points of a user's trip but also records the exact route taken to the destination and therefore the precise distance traveled (21) and (22). GPS devices use signals from multiple satellites in orbit above the earth to triangulate the user's position and calculate other information such as speed and heading. This technology must have a direct line-of-sight path to at least four satellites to fix the user's location in three dimensions, and to fix at least three satellites to identify the user's location in two dimensions (21) and (22). The information from these signals are then processed by the GPS hardware and delivered to the PDA through a virtual serial connection by either the CompactFlash port in the case of the H5555 and Navman 3450 combination or the Bluetooth protocol in the case of the H6315 and Navman 4410 pairing (21) and (22). This information is a string formatted in the National Marine Electronic Association's (NMEA) 0183 Version 2.20 standard, and is updated once every two seconds. This string is then parsed to yield location information including latitude, longitude, speed, and heading (21).

The software module that analyzes the GPS data contains an algorithm that determines the critical GPS coordinates that must be recorded to be able to accurately reconstruct each trip taken. Instead of recording GPS coordinates on a continuous basis and sending these to the central database, the software examines every new GPS reading and decides whether it is needed to reconstruct a trip. Examples of GPS data that are not needed to reconstruct a trip include GPS data when there is no significant travel movement or when the travel is in a straight line. Since 
the system is designed to operate over a longer period than a standard activity diary, a significant amount of data will be produced.

The software was tested by comparing identical trips recorded using all available GPS coordinates (Continuous Update method) and GPS coordinates selected by this algorithm (Selective Update method). The results for two different trips are shown in Figure 5. It can be seen in this figure that the Selective Update method was just as accurate as the Continuous Update method but with fewer GPS coordinates recorded. Trip 1 in Figure 5 represents a car trip in an urban setting that lasts approximately 10 minutes at an average speed of $25 \mathrm{mph}$ and consists mainly of straight travel segments. The data generated by the Selective Update method were only 13 percent of the amount of data generated by the Continuous Update method. Trip 2 in Figure 5 shows a car trip with fewer straight travel segments that lasts approximately five minutes at an average speed of approximately $25 \mathrm{mph}$. In this situation, the data generated by the Selective Update method were approximately 37 percent of the amount of data generated by the Continuous Update method. 


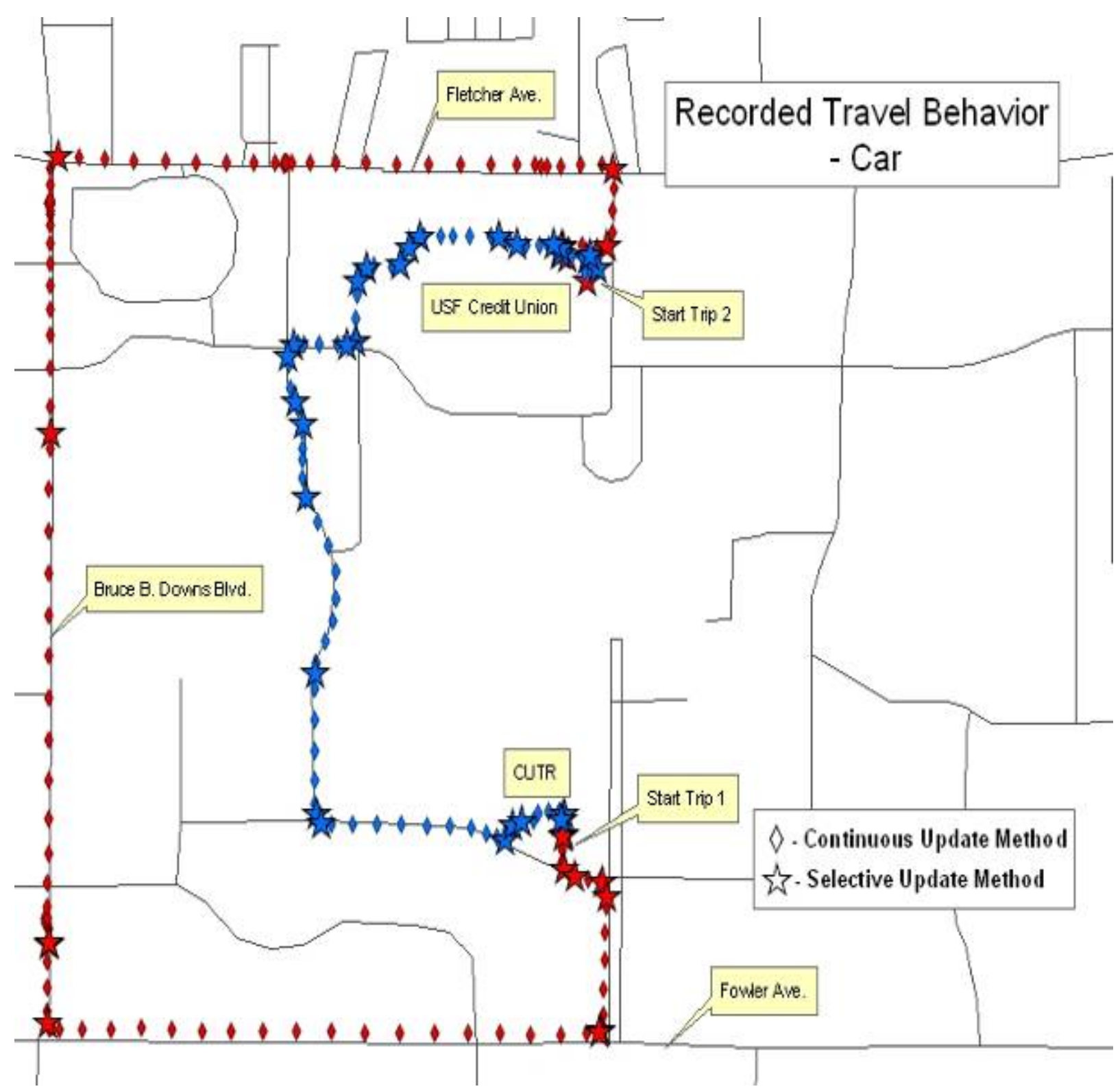

Figure 5: Trips 1 and 2 - GPS Points Recorded Using Two Different Algorithms - Continuous Update vs. Selective Update

Figure 6 represents a multimodal trip using walk, shuttle bus, and driving a private vehicle. Again, the Selective Update method was nearly as accurate as the Continuous Update method even with several mode changes for the same trip. The recorded distance using the Continuous Update method is more precise than the Selective Method due to slight fluctuations in heading not recorded in the Selective Method, so the distance measurements can be made by measuring the length between two critical points by way of all non-critical points. This measurement can 
be tallied during data collection and saved as a measurement with each critical point record. This method provides a more accurate distance measurement while still reducing the amount of redundant data collected.

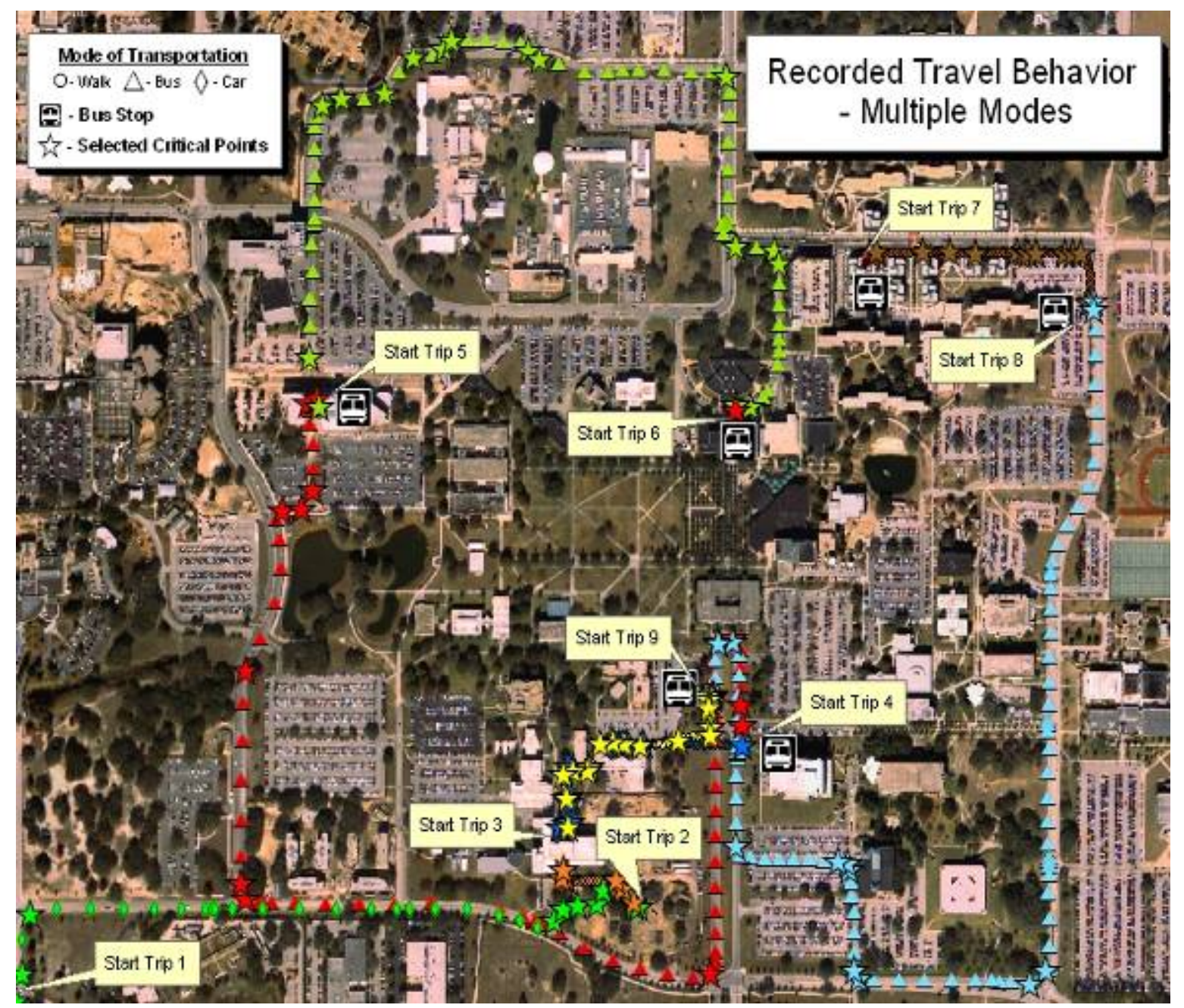

Figure 6: GPS Points Recorded Using Two Different Algorithms Continuous Update vs. Selective Update for Multimodal Trips

Figure 7 represents five different walking trips around the USF campus. On average, the Selective Update method recorded about 29 percent of the amount of total data collected by the Continuous Update method. 


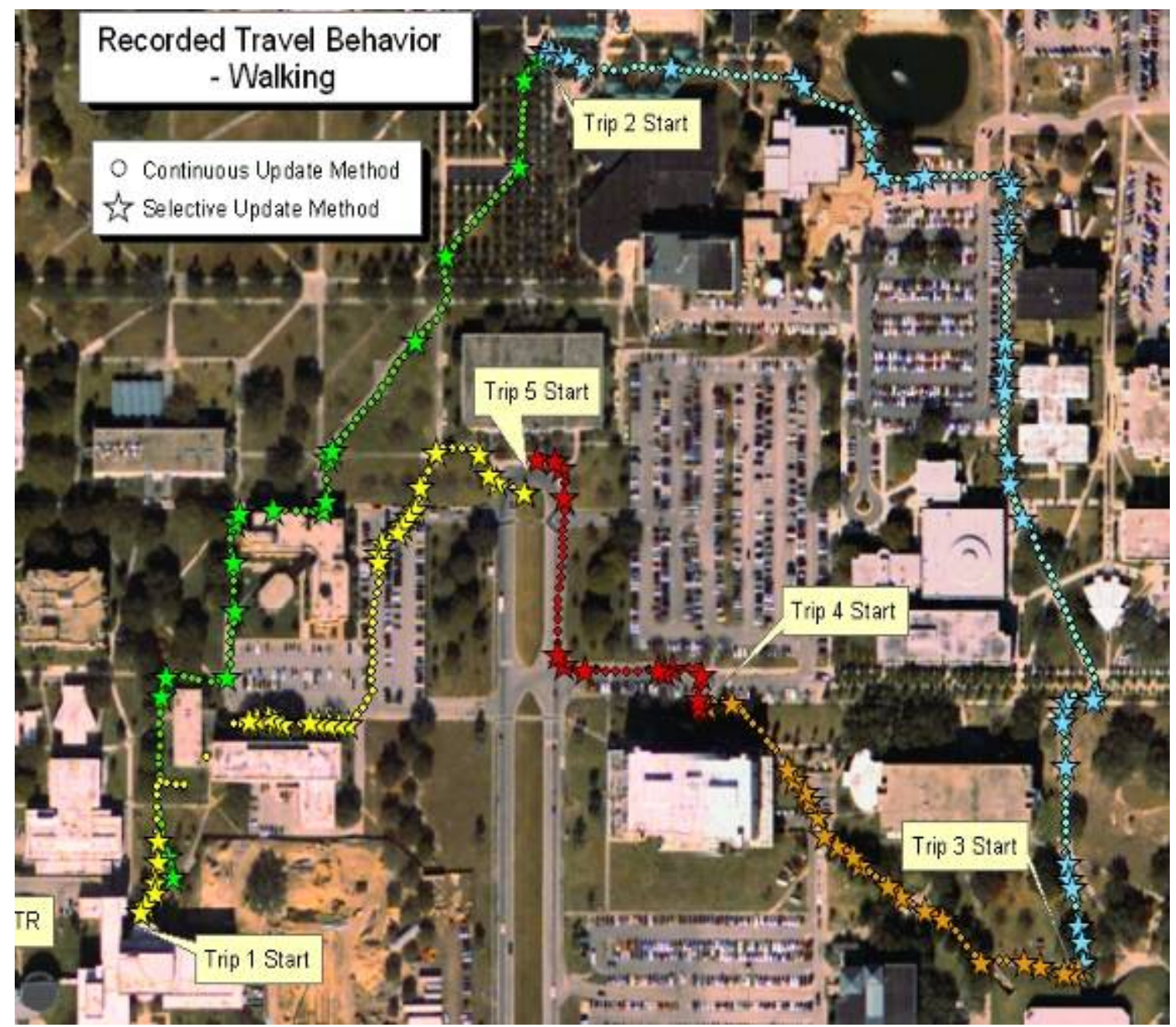

Figure 7: GPS Points Recorded Using Two Different Algorithms Continuous Update vs. Selective Update by Walking

Table 4 summarizes the savings for all the trips represented in Figures 5, 6 and 7. Overall, there was a 72 percent reduction in the data storage and data transfer bandwidth requirements without significant loss of travel patterns. The reduction in the amount of data collected is beneficial in several ways. First, the overall size of both the local (PDA) database and server database is significantly reduced, which allows faster querying and record retrieval for real-time operations and requires a fraction of the total storage space. Second, the communication time between the PDA and the Server when uploading trips is reduced. Last, no further processing is required at the central server to eliminate redundant or useless data. 
Table 4: GPS Points Recorded Using Two Different Algorithms -
Continuous Update vs. Selective Update

\begin{tabular}{|c|c|c|c|c|c|c|}
\hline Trip Type & Trip & Mode & $\begin{array}{c}\text { No. of } \\
\text { Records - } \\
\text { Continuous }\end{array}$ & $\begin{array}{c}\text { No. of } \\
\text { Records } \\
- \\
\text { Selective }\end{array}$ & $\begin{array}{c}\text { Percent } \\
\text { Selective } \\
\text { out of } \\
\text { Continuous }\end{array}$ & $\begin{array}{l}\text { Total } \\
\text { Savings } \\
\text { in Data } \\
\text { Storage } \\
\text { (bytes) }\end{array}$ \\
\hline \multirow[t]{5}{*}{$\begin{array}{l}\text { Walk Trips } \\
\text { Only }\end{array}$} & 1 & walk & 104 & 20 & $19 \%$ & 4956 \\
\hline & 2 & walk & 146 & 40 & $27 \%$ & 6254 \\
\hline & 3 & walk & 56 & 21 & $38 \%$ & 2065 \\
\hline & 4 & walk & 44 & 14 & $32 \%$ & 1770 \\
\hline & 5 & walk & 75 & 30 & $40 \%$ & 2655 \\
\hline \multirow[t]{4}{*}{$\begin{array}{l}\text { Car Trips } \\
\text { Only }\end{array}$} & 1 & car & 167 & 21 & $13 \%$ & 8614 \\
\hline & 2 & car & 79 & 29 & $37 \%$ & 2950 \\
\hline & 3 & car & 89 & 17 & $19 \%$ & 4248 \\
\hline & 4 & car & 111 & 17 & $15 \%$ & 5546 \\
\hline \multirow[t]{4}{*}{$\begin{array}{l}\text { Shuttle } \\
\text { Trips Only }\end{array}$} & 5 & bus & 72 & 20 & $28 \%$ & 3068 \\
\hline & 6 & bus & 33 & 7 & $21 \%$ & 1534 \\
\hline & 7 & bus & 12 & 4 & $33 \%$ & 472 \\
\hline & 8 & bus & 80 & 13 & $16 \%$ & 3953 \\
\hline \multirow[t]{9}{*}{$\begin{array}{l}\text { Multimodal } \\
\text { Trips }\end{array}$} & 1 & car & 85 & 19 & $22 \%$ & 3894 \\
\hline & 2 & walk & 56 & 13 & $23 \%$ & 2537 \\
\hline & 3 & walk & 29 & 8 & $28 \%$ & 1239 \\
\hline & 4 & bus & 99 & 14 & $14 \%$ & 2655 \\
\hline & 5 & bus & 70 & 16 & $23 \%$ & 3186 \\
\hline & 6 & bus & 3 & 3 & $100 \%$ & 0 \\
\hline & 7 & walk & 65 & 13 & $20 \%$ & 3068 \\
\hline & 8 & bus & 93 & 14 & $15 \%$ & 4661 \\
\hline & 9 & walk & 57 & 17 & $30 \%$ & 2360 \\
\hline
\end{tabular}

\section{Data Storage and Transfer}

To store data locally on the PDA, a Microsoft ${ }^{\circledR}$ SQL CE database is utilized. Visual Basic .NET provides a SQLCE Database Connection as well as data manipulation objects to access the SQL CE database, allowing normal SQL "SELECT," "INSERT," and "UPDATE" queries as well as many other SQL commands. Since the .NET Compact Framework and its components are designed for the reduced capacity of handheld devices, 
SQLCE does not provide the complete functionality of a SQL Server 2000 database. However, the available functions are adequate for the scope of this system. Data storage is implemented at the TRAC-IT server through a Microsoft ${ }^{\circledR}$ SQL Server 2000 database. This enterprise-level database allows the organized storage of data as well as mechanisms to analyze and generate reports about these data.

The database consists of multiple tables that are interrelated to give each user his/her own unique profile. A diagram of the database schema, implemented on both the PDA and the TRAC-IT Server, is shown in Figure 8. Every user has his/her own set of frequently visited locations and frequently used vehicles. The schema of the database allows multiple users to be assigned to the same PDA but allows each user to view only his/her own travel information. Additionally, to be able to compare users that live in the same house, information regarding the user's household and status in the household (driver, dependent, etc.) is stored and can be retrieved at any time. This design allows sophisticated cross-references to be performed so that researchers can analyze travel data in relation to other individuals in the same household. Each user's travel behavior is recorded and stored in the database as a series of trips. Each trip contains information includes origin, destination, time of arrival and departure, travel path as GPS data, purpose of trip, mode of transportation, occupancy of the vehicle, driver status (yes/no), distance traveled, and the status of this trip in a trip chain (used when identifying trip chains discussed in the subsection titled "Data Collection Application: TRAC-IT, a Smart Diary"). This relational database also provides the mechanisms that TRAC-IT can use in order to retrieve and analyze travel pattern data in real-time, which can then be used for survey automation or other tasks.

The expert system, discussed in detail in Section 5, "Travel Advisor Feedback System," resides in the SQL Server 2000 database. This mechanism analyzes the user's travel behavior and provides "suggestions" that may help improve his/her behavior by reducing time and/or money spent on travel and may recommend the alternatives to using only single occupancy vehicles. Suggestions may recommend the use transit if the individual's commonly visited origin and destination locations are near transit stops, or that the individual and others in his/her household combine multiple trips to similar locations (i.e., grocery store). The database contains several tables to hold both the recommendations generated by the expert system and user ratings of these suggestions. 
This structure provides an evaluation mechanism so that the survey analyst can track and record the usefulness of the automated suggestions, as reported by the individual to whom they were given so that the Expert System can be refined in the future.

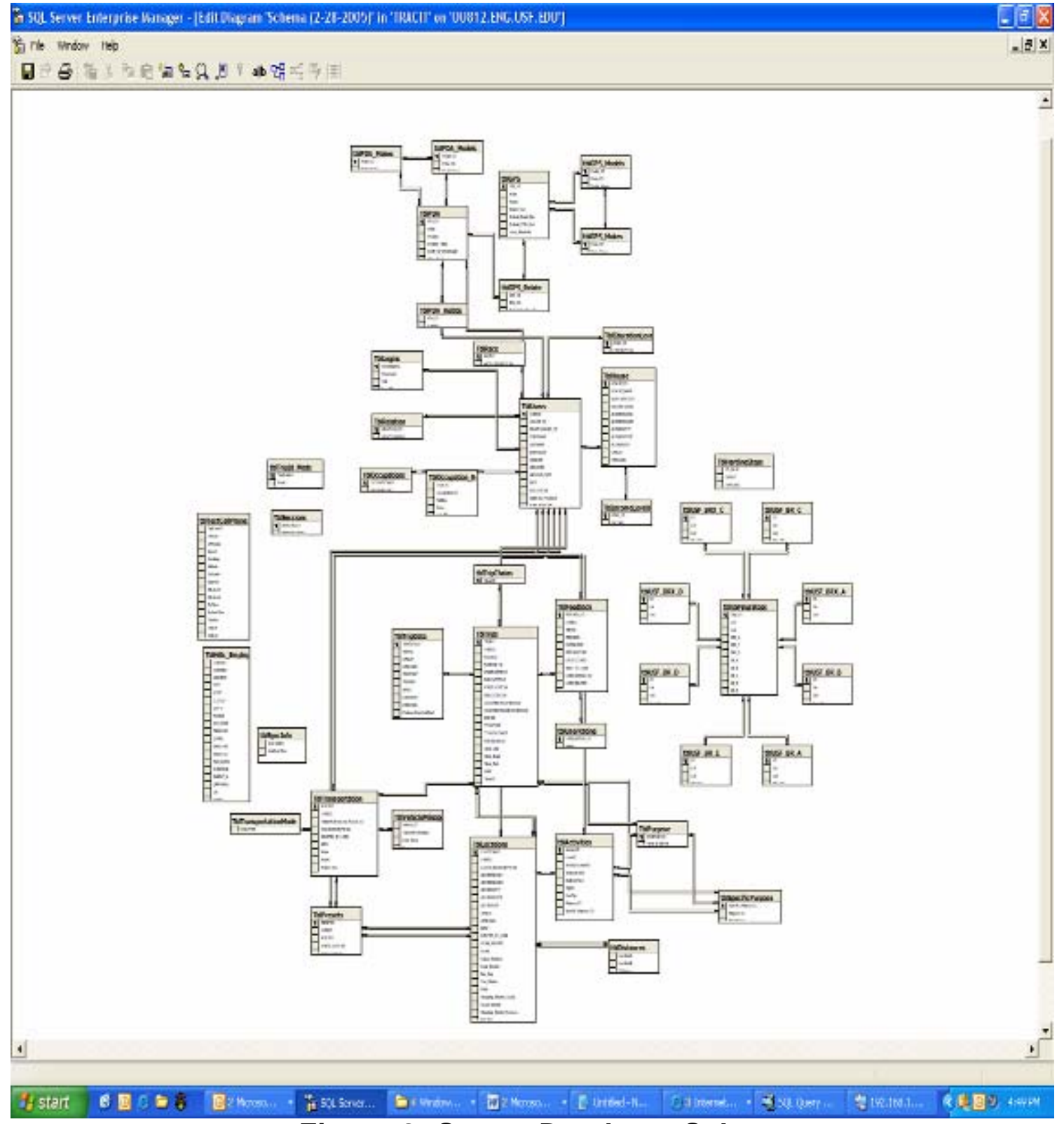

Figure 8: Server Database Schema 
Once the PDA \& GPS record the coordinates associated with travel path and other information related to trip purposes and modes of transportation for a trip, they could be uploaded to the central database. The diagram in Figure 8 shows the logical structure of the PDA and TRAC-IT server communication. Located within the TRAC-IT software on the main menu is a "Sync" option. This process synchronizes all data on the PDA with the data that is stored on the central SQL 2000 Server. In the first phase of the synchronization, any fields that have been created or updated locally on the PDA are updated at the server upon "Sync" through a process called Remove Data Access, or RDA. Because limited data storage is an issue on handheld devices, after all travel path GPS data relating to individual trips transferred to the central server, the data are deleted on the local PDA. However, a record of each trip containing information such as travel time, visited locations, and mode of transportation is still maintained on the PDA. If the user has rated any feedback from the Expert System, these data will be transferred as well.

The second phase of the synchronization involves pulling any new information that is stored on the server but not on the PDA (excluding travel path GPS data) to the local database on the PDA. This data could be information entered by the administrative staff of TRACIT or information that has been entered by the user via a webpage. Since the Expert System is triggered during the submission of new trips in the first phase, any suggestions that the system generates will be immediately available in the "feedback" table (see Section 5, "Travel Advisor Feedback System"). These suggestions are then pulled to the local database on the PDA for the user's review and rating.

Users have the freedom to "sync" with the server whenever an Internet connection is available to them. Possible internet connection methods are a Wi-Fi connection, a cellular subscription service such as GPRS, or using a "cradle" that physically attaches to a desktop computer and PDA and utilizes their home internet connection. Researchers can examine submitted data at any time by viewing the contents of the Server database through an Active Server Pages (ASP) web site. The data can then be exported to a local Microsoft ${ }^{\circledR}$ Excel file where they can be analyzed or imported into another program.

\subsection{New Application: TRAC-IT Cell Phone Prototype}

GPS-enabled phones were investigated in this project as a possible costeffective alternative to the PDA. Since initial investigations during the equipment selection stage yielded conflicting information about the possibility of using GPS-enabled cell phones as survey tools, the focus of the project remained on the PDA/GPS/Communication Component 
combination while investigating the potential for using a GPS-enabled cell phone as a secondary prototype. However, as time progressed extensive testing and analysis showed that using a specific carrier, Nextel, and specific phones, i.e. Motorola iDEN phones, it was indeed possible to retrieve an individual's GPS position and store than information on a central database server.

Among the many phones considered, the Motorola i830 phone (Figure 9) was selected as the best choice for building a prototype alternative to the PDA. This phone works on Nextel's iDEN network, which has AssistedGPS (a-GPS) capability. Other networks either do not have a-GPS capabilities or do not allow access to their a-GPS capabilities. The Nextel network supports Motorola phones using iDEN technology for developing location-based applications. This technology should allow the GPS portion of the TRAC-IT software to be forwards compatibility for all iDEN phones developed in the near future. The most relevant specifications of this phone, including cost, are given in Figure 9.

\section{Motorola i830 phone}

Screen Color:

Cost:

Screen Size:

J2ME Support:

Max Sockets:

Heap Size:

Networking Support:

Midlet File Storage:
$64 \mathrm{~K}$ colors, 16- bit

$\$ 150$

$130 \times 130$

MIDP 2.0 (JSR-118) and CLDC 1.1 (JSR-139)

TCP: 24, HTTP: 8, UDP: 24

1.1 MB

UDP, TCP, SSL, HTTP, HTTPS, Serial, SMS, and AGPS greater than $2 \mathrm{MB}$

Figure 9: Motorola i830 phone

Software was developed for this phone using Java 2 Micro Edition (J2ME) platform. J2ME is currently the most versatile programming language for mobile devices and is compatible across most phones used by all cellular carriers. Therefore, most of the modules of the TRAC-IT software developed for the cell phone should be compatible across many other phones. The TRAC-IT cell phone software implemented a user interface, a method to obtain locations, a location data filter, and a method to transmit the filtered location data to a central server.

The graphical user interface (GUI) shown in Figure 10, was designed as a simple prototype interface allowing a user to start and stop a trip activity. Further development will elaborate on this GUI to create a survey tool that can report other trip information similar to the PDA GUI (i.e., trip purpose, 
occupancy). During a trip, the phone records speed, location data in latitude and longitude, and direction of travel approximately every 3 seconds. Since the amount of storage for every GPS fix requires approximately 200 bytes and the phone has limited storage capability, only the GPS data necessary for recreating a trip are selected for transmittal to a central database. The algorithm utilized for this filtering of GPS data uses the speed of travel as well as the change in travel direction. This algorithm was tested in 20 field test trips taken ( 5 walking, 5 bicycles, 5 cars, 5 bus trips) and was found to be accurate in all trips. Anywhere from 40 percent to 80 percent of all locations obtained during these trips were filtered out by this algorithm, and, still, the route of the trip was accurately recorded at the central database. The filtered location data is transmitted to a central server using an HTTP protocol and deleted from the phone after it has been successfully transferred. An Apache Tomcat 5.0.27, deployed at the server, receives the transmitted data. After the data are received, a JDBC connection is established with an MS-SQL 2000 database and the data stored in appropriate tables created for this purpose.

Cell phones could potentially report a more accurate picture of an individual's travel behavior and be more realistically distributed on a wide scale than the PDA-based system for several reasons. First, the cell phone is a technology that many individuals are used to carrying and utilizing on a daily basis. Therefore, they may be more comfortable with the device and less likely to forget it when traveling. Second, the cell phone is a much smaller and more compact device than the PDA/GPS/Communication Device combination. Third, if individual's current cell phone could be used, there would be no equipment overhead cost for the survey analyst. The TRAC-IT software could be distributed over the cell phone network and automatically installed on any participant's phone that is compatible with the software. Alternately, even if the survey analyst must pay for the equipment, the average cost of a GPS-enabled cell phone is approximately $\$ 150-300$, which is significantly less than the cost of the PDA-based system. Finally, various locationpositioning methods (i.e., assisted GPS [a-GPS], Time Difference of Arrival [TDOA], and Enhanced Observed Time Difference [E-OTD]) can be implemented on cell phone networks that can potentially surpass the accuracy and area of coverage of a standard satellite-based GPS system. These technologies may be able to detect the location of an individual indoors, a function that virtually impossible using standard GPS methods.

While the GPS-enabled cell phone promises to be a powerful tool to conduct travel surveys, there are some features that the cell phone may lack when compared to the PDA, including screen size, processing power, and storage space. For surveys that require a large amount of manual 
entry in the field, the small size of the cell phone screen and limited methods of data entry (12 digit keys plus "soft keys") may be insufficient.

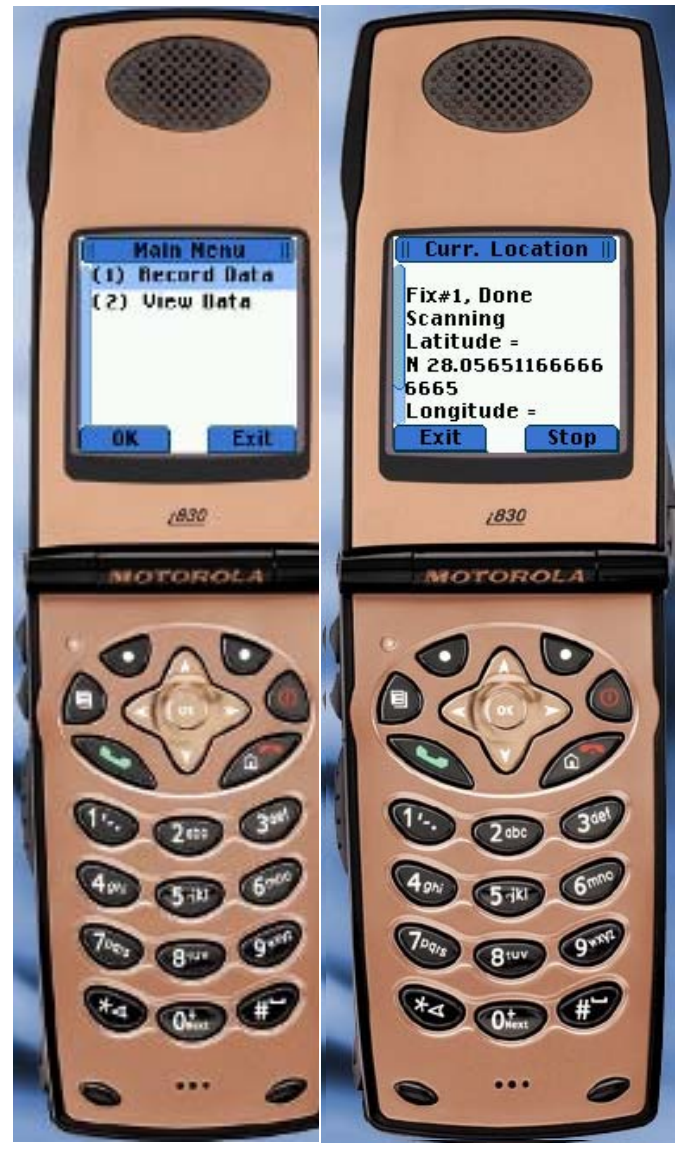

(a)

(b)

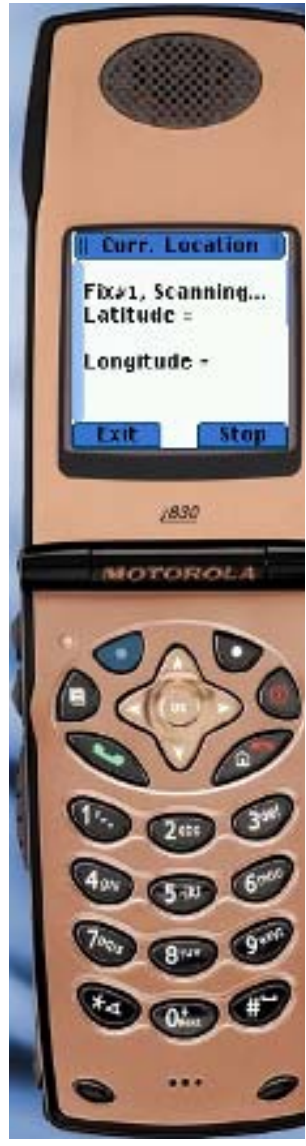

(c)

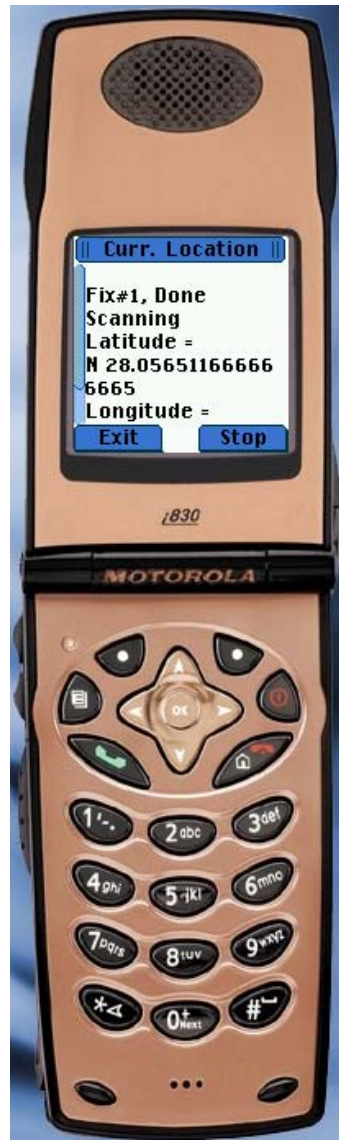

(d)

a) Select Record Data from Main Menu.

b) Enter Trip Name

c) Scanning current Location

d) Displaying coordinate of current Location

Figure 10: User Interface of the GPS-enabled cell phone

Additionally, some of the survey automation features may not be possible to implement on a cell phone due to limited processing power. Application design must address these limited resources and properly handle other events such as incoming phone calls. Finally, data storage must be implemented mainly on the server, with only temporary small datasets existing on the phone. For all of these reasons, the type of survey should be taken into account when choosing between a cell phone and PDAbased implementation of TRAC-IT. 


\section{Development of Travel Advisory Feedback System}

An expert system can be generally described as software that stores knowledge from a human expert in a particular area and applies that knowledge to solve problems in that domain similar to how the human expert would do it. Expert systems are widely accepted and have been used extensively since the mid 1970's in many diverse areas such as banking, medicine, manufacturing, military, business, etc. Among the reasons given for their wide use are their capability for capturing unique and elusive human expert knowledge and the relative ease with which this knowledge can be updated as more is learned about a problem domain.

\subsection{Overview}

The expert system in TRAC-IT includes rules to provide personalized feedback to individuals participating in the travel surveys. These rules are applied to the specific needs and travel patterns of individuals and their households and are aimed to increase use of transit and other alternatives to driving alone. As the travel behavior data are collected and transmitted to the centralized database (see Section 3, "TRAC-IT Data Collection System"), the expert system rules are triggered to reach the appropriate conclusions for each individual participating in the survey. These conclusions are then consolidated into personalized messages transmitted directly to each individual through the survey tool. Figure 11 shows this overall system.

\subsection{Expert Rules}

The rules included in TRAC-IT were based on a set of rules originally used to manually produce individualized feedback in a project using paperbased surveys (1). These rules had been applied by Transportation Demand Management (TDM) professionals to the data collected after the survey documents had been returned. The suggestions were then given to the individuals and their feedback recorded. Control groups also were used that had not been given suggestions, and their travel behavior trends were compared to the experimental groups. Generally, households and individuals had a positive response to the feedback that showed some improvement in travel behavior. 


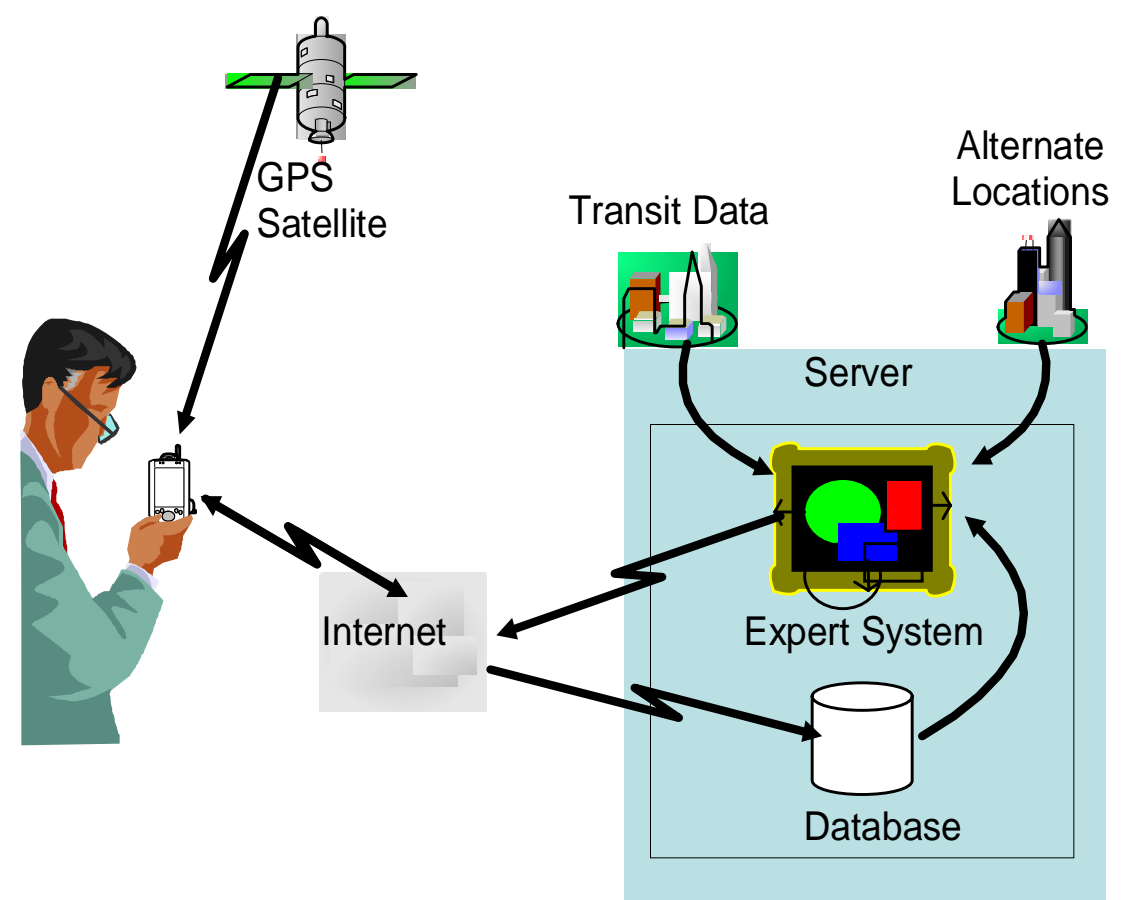

Figure 11: The Travel Advisory Feedback System Framework

The TRAC-IT Expert System aims to automate the suggestion generation process by examining the collected data and then producing individualized feedback using the rules that are supplied below.

- Bicycle suggestions.

All trips that were more than 1 mile and less than 3 miles in length, taken by one of the following modes and not taken for the purpose of picking up or dropping off someone, were identified:

- drive a vehicle with no passengers,

- passenger in a vehicle,

- motorcycle,

- taxi,

The days with trips meeting these criteria were analyzed individually to see if the bicycle suggestion was logical.

- Walk suggestions:

All trips that were equal to or less than one mile in length, taken by one of the following modes and not taken for the purpose of picking up or dropping off someone, were identified: 
- drive a vehicle,

- passenger in a vehicle,

- motorcycle,

- taxi,

The days with trips meeting these criteria were analyzed individually to see if the walk suggestion was logical.

- Eliminate trips through technology suggestions:

Survey respondents who had internet access were identified. Their shopping trips, taken by one of the following modes were identified:

- drive a car,

- motorcycle,

- taxi,

The days with these types of shopping trips and the destination locations were analyzed. If the shopping was done at a location, where the items for sale could be purchased over the internet, then internet shopping was suggested.

- Transit suggestions:

The household locations and the individuals' primary work or school locations were plotted on a map. These locations were compared with direct bus routes and park ' $\mathrm{n}$ ride locations. Individuals with bus service less than 2 miles from home and primary work or school locations were identified. A query was implemented to identify all days when these individuals went directly from home to work, then directly back home again, using one of these modes:

- drive a car,

- passenger in a car,

- motorcycle, and

- taxi.

If at least once during the week they showed the above travel pattern and met the above criteria, the transit suggestion was given.

- Trip chaining suggestions:

A query was implemented to compare individuals' home Zip codes and work locations. If two individuals had the same Zip code, and the same work location and their homes were less than 1.5 miles apart, their daily travel patterns were analyzed together, paying particular attention to their work hours, usual mode taken, and usual stops on the way to or from work to determine whether they could reasonably carpool to work. 
- Combine trips outside the household suggestions:

Days were identified for individuals who went to a location more than once in a day. These days were analyzed, paying particular attention to the modes taken, to identify whether the individual could have combined some of these trips into one long outing rather than multiple short outings.

- Combine trips within the household suggestions:

Households with members traveling to the same non-home, non-work location more than once on a single day, using one of the following modes were identified:

- drive a car,

- motorcycle,

- taxi ,

All trips on that particular day, taken by each household member were analyzed to see if it was logical to suggest that they could have traveled to that location together, rather than traveling separately.

- Combine trips across days suggestion:

Individuals traveling to duplicate non-home, non-work locations on separate days for the purpose of shopping or personal business were identified. All of the individuals' trips on those days were analyzed to identify whether it was logical to suggest that they could have gone to that location only once.

\subsection{How the TRAC-IT Expert System Works}

The Expert System and the database are both deployed on a common server and are closely integrated. The database is described in detail in subsection 4.2, "Data Storage and Transfer." The Expert System was implemented using Stored Procedures in the T-SQL language and are integrated into the SQL Server 2000 database. Figure 12 shows, when the data collected by the PDA unit arrives at the database, it is first stored in the appropriate database tables. After the data are stored, triggers in the database sets off the expert rules to be applied only to this newly-arriving data. The conclusions reached by the Expert System are then consolidated into appropriately-worded suggestions. These suggestions are stored in the database and sent to the individual as feedback. The user is then given the chance to evaluate the feedback and rate it accordingly. This mechanism provides a method for feedback analysis and a basis for future improvements to the Expert System based on what the individuals did or did not find helpful or sensible. 
It must be emphasized that the system is much more complex than what this figure shows and includes many more tables to store individuals' data, procedures that implement the expert rules, user interfaces, and software to receive the data sent to the database from the different PDAs.

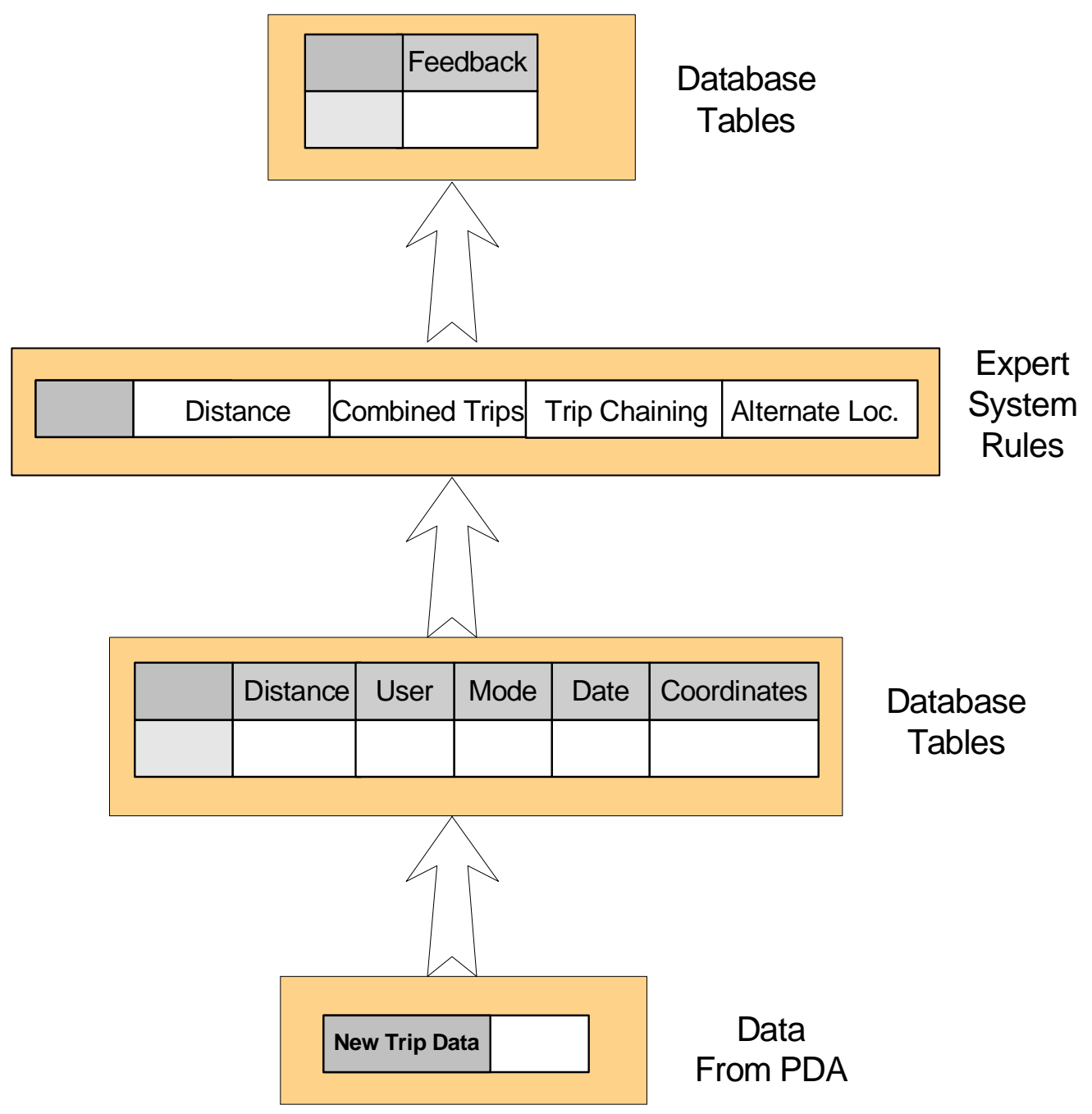

Figure 12: Travel Advisory Feedback System Scheme

In addition to the outlined sequence of steps below, Figure 13 describes how the expert system functions in more detail. 


\section{Flowchart Diagram for Main Feedback Procedure}
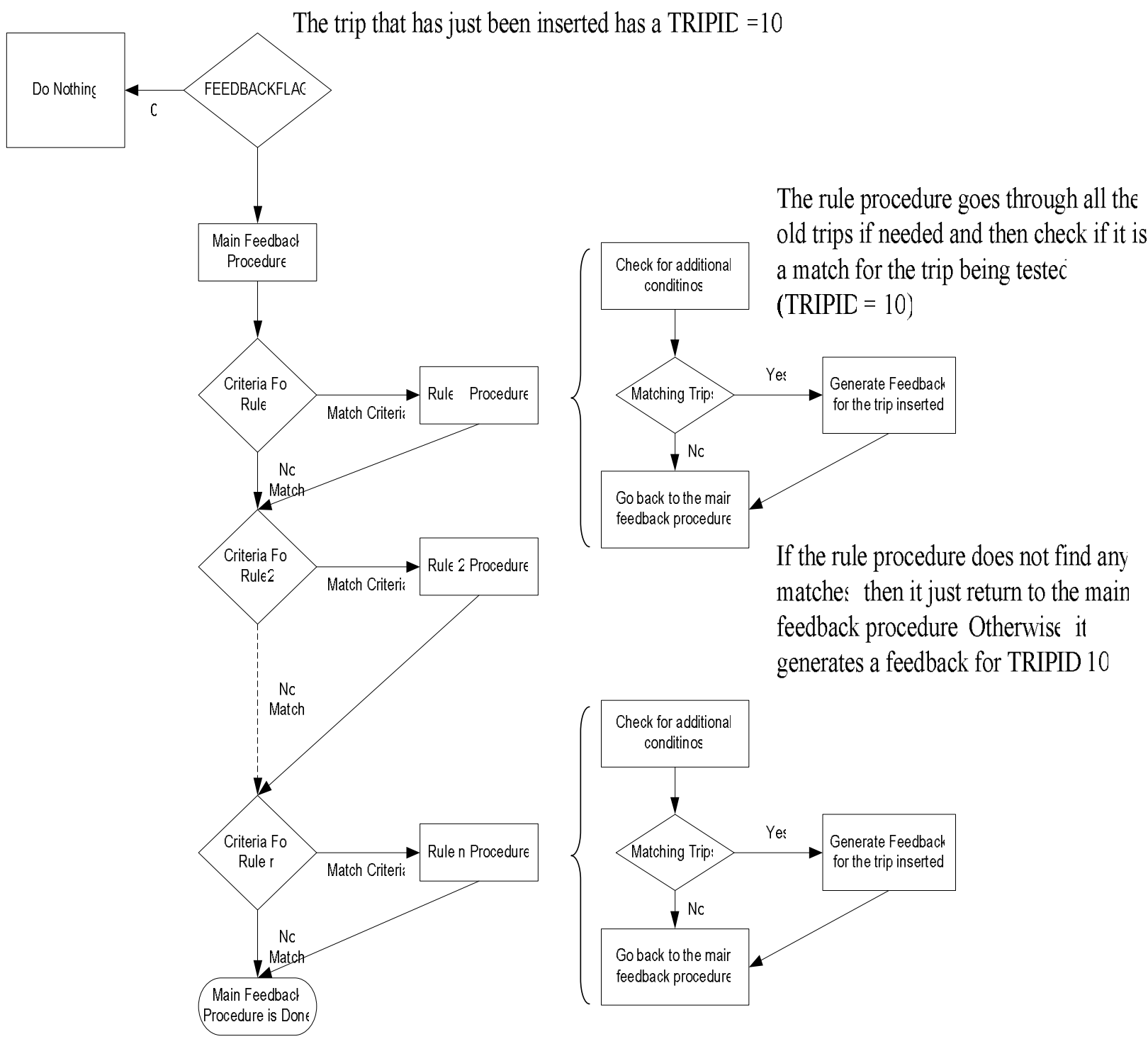

Figure 13: TRAC-IT Advisory Feedback System Main Feedback Procedure

\section{Sequence of functions}

1. When data for a new trip arrive at the database, the "feedback" field is set to "1," indicating that feedback needs to be created for this new trip.

2. After the data for the new trip has been inserted into the "trips" table with a new trip identification number, the expert system is started. 
3. The expert system examines all trips that still have their "feedback" field set to "1" by applying each expert rule in the system to these trips. If the data for a trip under consideration "match" the conditions (or antecedents) of a rule, then the rule generates a feedback message that is stored in the "feedback" table with the same trip identification number. The next rule in the sequence is applied in a similar fashion until all the rules are applied to that trip. It should be noted that rules that refer to members of a household would be applied not only to the new trip just inserted but also to previously stored trips for members of the same household.

4. After all the expert rules have been applied to a particular trip its "feedback" flag is set to "0."

5. This data-driven approach ensures that expert rules are applied in a just-in-time fashion and that feedback to the individuals is available immediately. Another advantage of this approach is that the data are separate from the rules, thus creating an environment conducive to rapidly-improving rules and feedback as more is learned using the system. 


\section{Prototype Field Test Application and Assessment}

For this phase of the research study, limited field testing was conducted to validate that the TRAC-IT technology works. Phase II of this research study will expand testing based on three waves (approximately 1 to 2 months in duration) of 10 to 20 households split into control and test groups. For the purposes of Phase 1, the participants were identified as representation of different market segments since the goal of the field test was to make sure the prototype works under various scenarios representing different modes of travel and varied household dynamics. These scenarios included:

- A two-income household, two adults, two-car ownership, and one child under driving age

- A single-income household, one female adult, zero-car ownership

- A single-income household, two adults, one car and one bicycle, and 3 children under driving age

- A single-income household, two adults, two-car ownership and one child under driving age (trips collected from one household member only)

Four out of the six participants were CUTR employees. This section presents the field test protocol, application, and assessment.

\subsection{The TRAC-IT Field Test}

The protocol for the field test is summarized as follows:

- A solicitation letter was sent to introduce the project, its benefits, the role of participants in the project, and contact information for the principal investigator, (see Appendix B)

- Four households were solicited as participant volunteers from CUTR. The households were selected based on mode of transportation used; transit, automobile or bicycle. Also, the dynamics of households varied from single to double income and from single persons with no children to married with one or more children.

- Participants and their spouses were invited to a 60-minute orientation session. (See Appendix B for the power point presentation handout given to participants at the session.) Participants were given the TRAC-IT units during the session and a demonstration of the application was presented. Reminders emphasized at the session 
were to charge the units and to email/phone techncial support for any difficulties.

- After signing and dating the informed adult consent form, (see attached in Appendix B), the PDA/GPS/Wireless card units were issued to the first wave of users. Data collection was conducted for one week intervals for two households at a time.

- An assessment to solicit participants' feedback on the orientation session and TRAC-IT unit usage will be conducted, (see Appendix B for evaluation form).

\subsection{Prototype Field Test Data Collection}

Before participants were given their TRAC-IT units, each participating household was identified with a unique number, and each adult in the household was issued a user identification number. In addition, to reduce data input burden, a user profile was created in the PDA with the person's home and work addresses pre-entered.

The first column in Table 5 presents all trip characteristics captured by the TRAC-IT unit. These include commonly collected travel diary data such as the purpose of the trip, the means or mode of transportation used, the duration and length of the trip, the time of day and day of the week when the trip took place and the number of people in the vehicle during the trip. Other trip information that was more GPS-specific, such as speed and route also are captured. Table 5 presents a sample of daily travel by one participant, and Table 6 presents a sample of GPS coordinates for one trip or trip link, the speed of travel, date, and time stamps of that trip. 
Table 5: Sample of Trip Characteristics Collected By One User for One Day

\begin{tabular}{|c|c|c|c|c|c|c|c|}
\hline \multirow{2}{*}{$\begin{array}{l}\quad \begin{array}{l}\text { Trip } \\
\text { Characteristics }\end{array} \\
\text { Trip ID }\end{array}$} & \multicolumn{7}{|c|}{ Example of Data Collected for One Day } \\
\hline & 916 & 917 & 918 & 919 & 920 & 921 & 922 \\
\hline User ID & 22 & 22 & 22 & 22 & 22 & 22 & 22 \\
\hline Household ID & 13 & 13 & 13 & 13 & 13 & 13 & 13 \\
\hline Mode ID & 62 & 60 & 62 & 62 & 60 & 62 & 62 \\
\hline Mode Type & Car & Walking & Car & Car & Walking & Car & Car \\
\hline Mode Description & Honda Civic & NULL & Honda Civic & Honda Civic & NULL & Honda Civic & Honda Civic \\
\hline Purpose ID & 6 & 1 & 1 & 6 & 1 & 6 & 8 \\
\hline Trip Purpose & $\begin{array}{r}\text { Transport } \\
\text { someone or } \\
\text { myself }\end{array}$ & $\begin{array}{r}\text { Work or work- } \\
\text { related }\end{array}$ & $\begin{array}{r}\text { Work or work- } \\
\text { related }\end{array}$ & $\begin{array}{r}\text { Transport } \\
\text { someone or } \\
\text { myself }\end{array}$ & $\begin{array}{r}\text { Work or work- } \\
\text { related }\end{array}$ & $\begin{array}{r}\text { Transport } \\
\text { someone or } \\
\text { myself }\end{array}$ & Return home \\
\hline Specific Purpose ID & 16 & NULL & NULL & 16 & NULL & 13 & \\
\hline Specific Purpose & $\begin{array}{r}\text { Change Mode } \\
\text { of } \\
\text { Transportation }\end{array}$ & & & $\begin{array}{r}\text { Change Mode } \\
\text { of } \\
\text { Transportation }\end{array}$ & & $\begin{array}{l}\text { Pickup } \\
\text { Someone }\end{array}$ & \\
\hline Start Date & $\begin{array}{r}\text { Tuesday, April } \\
05,2005\end{array}$ & $\begin{array}{r}\text { Tuesday, April } \\
05,2005\end{array}$ & $\begin{array}{r}\text { Tuesday, April } \\
05,2005\end{array}$ & $\begin{array}{r}\text { Tuesday, April } \\
05,2005\end{array}$ & $\begin{array}{r}\text { Tuesday, April } \\
05,2005\end{array}$ & $\begin{array}{r}\text { Tuesday, April } \\
05,2005\end{array}$ & $\begin{array}{r}\text { Tuesday, April } \\
05,2005\end{array}$ \\
\hline Start Time & 7:36:39 AM & $7: 57: 29$ AM & 9:22:23 AM & 11:13:06 AM & 11:22:08 AM & 5:06:54 PM & 5:34:32 PM \\
\hline End Date & $\begin{array}{r}\text { Tuesday, April } \\
05,2005\end{array}$ & $\begin{array}{r}\text { Tuesday, April } \\
05,2005\end{array}$ & $\begin{array}{r}\text { Tuesday, April } \\
05,2005\end{array}$ & $\begin{array}{r}\text { Tuesday, April } \\
05,2005\end{array}$ & $\begin{array}{r}\text { Tuesday, April } \\
05,2005\end{array}$ & $\begin{array}{r}\text { Tuesday, April } \\
05,2005\end{array}$ & $\begin{array}{r}\text { Tuesday, April } \\
05,2005\end{array}$ \\
\hline End Time & $7: 56: 55 \mathrm{AM}$ & 7:57:54 AM & 9:31:13 AM & $11: 21: 30$ AM & 11:23:58 AM & 5:27:50 PM & 5:39:24 PM \\
\hline Start Location ID & 212 & 228 & 228 & 237 & 228 & 228 & 231 \\
\hline Start Description & home & parking & parking & Holiday Inn & parking & parking & ymca \\
\hline End Location ID & 228 & 236 & 237 & 228 & 236 & 231 & 212 \\
\hline End Description & parking & office & h inn & parking & office & ymca & Home \\
\hline $\begin{array}{l}\text { Occupancy } \\
\text { Household }\end{array}$ & 1 & 1 & 1 & 1 & 1 & 1 & 2 \\
\hline $\begin{array}{l}\text { Occupancy Non } \\
\text { Household }\end{array}$ & NULL & NULL & NULL & NULL & NULL & NULL & NULL \\
\hline Driver & 1 & 1 & 1 & 1 & 1 & 1 & 1 \\
\hline
\end{tabular}




\begin{tabular}{|c|c|c|c|c|c|c|c|}
\hline \multirow{2}{*}{\begin{tabular}{l}
\multicolumn{1}{c}{ Trip } \\
Characteristics \\
Total Time (in \\
seconds
\end{tabular}} & \multicolumn{7}{|c|}{ Example of Data Collected for One Day } \\
\hline & 1216 & 25 & 530 & 504 & 110 & 1256 & 292 \\
\hline $\begin{array}{l}\text { Total Distance (in } \\
\text { miles) }\end{array}$ & 4.996524484 & $9.80 \mathrm{E}-02$ & 1.118691744 & 1.339468137 & 0.193047701 & 5.303604593 & 1.762747949 \\
\hline Chain ID & 102 & 102 & NULL & 103 & 103 & 104 & 104 \\
\hline Chain Begin & 1 & 0 & 0 & 1 & 0 & 1 & 0 \\
\hline Chain Link & 1 & 1 & 0 & 1 & 1 & 1 & 1 \\
\hline Chain End & 0 & 1 & 0 & 0 & 1 & 0 & 1 \\
\hline
\end{tabular}

Table 6: Sample of GPS Data collected for Each Trip

\begin{tabular}{|c|c|c|c|c|c|c|c|c|}
\hline Trip Data ID & 52654 & 52655 & 52656 & 52657 & 52658 & 52659 & 52660 & 52661 \\
\hline Trip ID & 916 & 916 & 916 & 916 & 916 & 916 & 916 & 916 \\
\hline $\begin{array}{l}\text { GPS Lat (Decimal } \\
\text { Degrees) }\end{array}$ & 28.09618 & 28.09619333 & 28.09635667 & 28.09653167 & 28.096575 & 28.09663167 & 28.096805 & 28.09698833 \\
\hline $\begin{array}{l}\text { GPS Long (Decimal } \\
\text { Degrees) }\end{array}$ & -82.39378667 & -82.39449333 & -82.39512833 & -82.39577333 & -82.39639167 & -82.39696167 & -82.39742 & -82.39769 \\
\hline Trip Start (T/F) & 0 & 0 & 0 & 0 & 0 & 0 & 0 & 0 \\
\hline Trip End (T/F) & 0 & 0 & 0 & 0 & 0 & 0 & 0 & 0 \\
\hline Speed $(\mathrm{m} / \mathrm{s})$ & 18.06278959 & 16.47343928 & 16.12619717 & 16.35734997 & 14.72662144 & 13.67227685 & 10.43843098 & 5.941903807 \\
\hline Date recorded & $\begin{array}{l}\text { Tuesday, April 05, } \\
2005\end{array}$ & $\begin{array}{l}\text { Tuesday, April 05, } \\
2005\end{array}$ & $\begin{array}{c}\text { Tuesday, April 05, } \\
2005\end{array}$ & $\begin{array}{c}\text { Tuesday, April 05, } \\
2005\end{array}$ & $\begin{array}{l}\text { Tuesday, April 05, } \\
2005\end{array}$ & $\begin{array}{l}\text { Tuesday, April 05, } \\
2005\end{array}$ & $\begin{array}{c}\text { Tuesday, April 05, } \\
2005\end{array}$ & $\begin{array}{l}\text { Tuesday, April 05, } \\
2005\end{array}$ \\
\hline Time recorded & 12:42:11 PM & 12:42:15 PM & 12:42:19 PM & 12:42:23 PM & 12:42:27 PM & 12:42:31 PM & 12:42:35 PM & 12:42:39 PM \\
\hline $\begin{array}{l}\text { Heading (0-360 } \\
\text { degrees) }\end{array}$ & 268.96 & 277.35 & 290.53 & 279.71 & 272.4 & 283.08 & 301.41 & 307.46 \\
\hline $\begin{array}{l}\text { Distance From Last } \\
\text { Point (miles) }\end{array}$ & 4.51E-02 & 4.31E-02 & 0.303338575 & 4.11E-02 & 3.78E-02 & 0.034937689 & 0.103091956 & 2.08E-02 \\
\hline Critical Point (T/F) & 0 & 0 & 1 & 1 & 0 & 0 & 1 & 0 \\
\hline
\end{tabular}


The field test can readily provide the daily travel pattern for any of the users. Table 7 gives a quick look into the amount of travel conducted by one user throughout the survey period. The field test was successful in minimizing data entry efforts by both participants and surveyors.

Table 7: Travel Summary for Entire Survey Period

\begin{tabular}{|c|c|c|c|}
\hline & Total Trips & $\begin{array}{l}\text { Time in } \\
\text { minutes }\end{array}$ & $\begin{array}{l}\text { Distance in } \\
\text { miles }\end{array}$ \\
\hline Day 1 & 8 & 59.800000 & 2.440 \\
\hline Day 2 & 11 & 537.71667 & 24.40 \\
\hline Day 3 & 11 & 30.416667 & 7.580 \\
\hline Day 4 & 3 & 20.700000 & 4.790 \\
\hline Day 5 & 10 & 34.500000 & 8.629 \\
\hline Day 6 & 9 & 0.3771667 & 2.882 \\
\hline Day 7 & 6 & 57.483333 & 6.650 \\
\hline Day 8 & 6 & 83.183333 & 8.480 \\
\hline Day 9 & 12 & 50.466667 & 7.490 \\
\hline Totals & $\mathbf{7 6}$ & $\mathbf{8 7 4 . 6 4 3 8 3}$ & $\mathbf{7 3 . 3 4 1}$ \\
\hline
\end{tabular}

\subsection{TRAC-IT Test Assessment}

\section{Technical Assessment}

\section{PDA Local Data Storage}

Local data storage proved to be more than adequate for a week worth of data. Based on the file size reported by the File Explorer application on the PDA, the average size of the database for a week's worth of collected data was 1.5MB. A total of 55MB of memory on the $\mathrm{H} 6315$ can be allocated between programs and storage. The configuration used during testing was to allocate $20 \mathrm{MB}$ to data storage and $35 \mathrm{MB}$ to running programs. Approximately $24 \mathrm{MB}$ of program memory is used with the TRAC-IT application running as well as other background application such as ActiveSync ${ }^{\circledR}$. Approximately $8 \mathrm{MB}$ of data storage is used to store TRAC-IT files, data, GPS driver, and software files. Of that $8 \mathrm{MB}$, approximately $1.5 \mathrm{MB}$ was used for the TRAC-IT database that stores user $\&$ trip data for about a week's worth of trips. Data stored in the main memory is kept intact only when the battery has a charge. The H6315 provides another $20 \mathrm{MB}$ of permanent storage that is not affected if the battery is very drained. The permanent storage memory along with the free data storage memory adds up to approximately $32 \mathrm{MB}$ of free storage space that could be used to hold user trip data. If a week's worth of travel is approximately $1.5 \mathrm{MB}$ of information, the PDA should be able to store 
approximately 21 weeks, or $5 \frac{1}{2}$ months, of trip data before it needs to be synchronized. For testing, this data collection included all GPS points gathered, including those points identified as "non-critical" (see section 3.2, "GPS Data Processing"). If non-critical point data are deleted from the device as trip data are collected, the PDA should be able to hold significantly more data. Additionally, the $\mathrm{H} 6315$ supports an additional Secure Digital (SD) memory card, which can store up to 512MB of data, which should be adequate for extended data collection periods (perhaps even up to 1 year).

\section{Synchronization Issues}

Using current methods, the amount of time taken to transfer the GPS coordinates for week's worth of trip data from the PDA to the server took approximately $1 \mathrm{hr}$ to $2 \mathrm{hrs}$. For system evaluation and testing purposes, all GPS points were transferred, including those identified as non-critical points (see Section 3.4, "GPS Data Processing"). Specifically, for a particular user making over 76 trips, 9,576 unique GPS points were recorded and the data transfer took 1 hour and 23 minutes. In a second scenario, 46 trips were recorded gathering 13,825 records, and the data transfer took 2 hours and 3 minutes. For this project, SQL Server software was not purchased. Therefore, the system was limited to using a SQL Server that was part of another department at USF. Because of limited access and lack of administrative privileges, less sophisticated data synchronization methods were implemented. The time needed for data synchronization should be significantly reduced in the future due to advanced synchronization options possible when administrative rights to a SQL Server are secured. A few miscellaneous software "bugs" were found, but none affected the integrity of the data and are being addressed as the updated version of the software is tested in Phases 2 and 3 of this research project.

\section{Battery Issues}

The battery life on the H5555 PDA and Navman 3450 was questionable. One user reported major battery problems, with battery life lasting under 12 hours and another user reporting that the battery life was adequate for a full day of travel. Battery life was expected to be an issue with the H5555 due to the technical specification of the device and power drain from both the PDA and GPS device on one battery. Other contributing factors may be due to participants forgetting to charge the PDA at night. The H6315 paired with the Navman 4410 had a significantly longer batter life, with one user reporting that the units were used for two days without charging and did not have any problems. Due to the device specifications, this was also expected. 


\section{Participants Assessment}

As previously mentioned, these participants are CUTR employees with varied degrees of knowledge in transportation. In addition to the evaluation form (Appendix B), the research team opted to conduct a debriefing session with participants at CUTR rather than mail/email the evaluation to get a first-hand account of the experiences with the TRAC-IT unit. Although spouses who participated in the field test did not attend this session, their views were conveyed to the research team.

\section{$\underline{\text { User }} \underline{\text { Interface }} \underline{\text { Issues }}$}

The QuickStop feature was used by many of the participants in the study. The QuickStop feature does not alter how the trip is recorded, only how the user enters the information that is recorded. The biggest difference between recording two separate trips and using the QuickStop feature is that the destination location for the first trip is assumed the starting location for the second trip, so the user has to enter that information only once. The only instructions given at the orientation session regarding the QuickStop was to use it when they felt like they were making a brief stop in the middle of a trip. It was anticipated that this feature would be used when purchasing gasoline or picking up a passenger. Instructions were intentionally somewhat vague to extract various user interpretations of the QuickStop concept, as well as what constitutes a "trip." The users extended the use of the QuickStop feature to many other activities as well, including grocery shopping, casual walks, changing modes of transportation, and more. While the feature seemed helpful in reducing user input, there seemed to be some anxiety on the part of the participants because they were not sure if they were using the feature correctly, or if the feature would alter the way that their trips are recorded.

For future tests, it would probably reduce user anxiety if they are given clear instructions were given and many examples on how to use the QuickStop feature in specific scenarios were provided, particularly those that may apply to their own personal travel behavior. Also, it should be made clear that the QuickStop feature is only a convenience tool to aid the user; it will not change how a specific trip is registered. In general, a specific definition of what constitutes as a "trip" should also be given for the sake of the current experiment, so users tend to use the device in a similar manner whether using the QuickStop feature or not. 


\section{User comments and suggestions}

- It works!

- Stylus - extra stylus should be readily available for replacement since stylus is easily dropped or lost.

- Portability - It was suggested that the unit be distributed in a waist "fanny" pack for easier portability.

- QuickStop - The definition of QuickStop was not clear. Also, it was suggested to give more examples in orientation session of what a QuickStop may be and also examples of different trip purposes.

- Forgetfulness - Remembering to take the TRAC-IT unit from home was a challenge throughout the survey period.

- Recall trips - It was suggested that a recall mechanism would help users fill in the trips that were not reported due to forgetfulness or due to being in a rush and not having the time to start the TRAC-IT unit before going to a destination. The concept of recalling trips is being considered, particularly utilizing the Microsoft outlook calendar already installed on the PDA unit.

\subsection{TRAC-IT Expert System Test Assessment}

For the purposes of this limited field test application, the TRAC-IT units were synchronized with the T-SQL server only once at the end of the field test period. The Expert System then generated feedback for each user based on his/her household travel behavior over the entire test period. It was concluded that the TRAC-IT Expert System works; however, more rules need to be added and others need to be refined. Phase 2 of this research project will refine the system and further test it to capture before and after changes in travel behavior based on the feedback provided.

A sample of feedback advice to one of the users for one trip occurrence was:

- Your Trip on 3/22/2005 from WALGREENS to CIRCUIT CITY was less than 1 mile. Please consider walking or biking to this location next time.

- Your Trip on 3/22/2005 from STAPLES to Home was less than 3 miles. Please consider biking to this location next time.

- Your Trip on 3/22/2005 from Home to STAPLES was less than 3 miles. Please consider biking to this location next time. 
- Your Trip on 3/22/2005 from STAPLES to Home was less than 3 miles. Please consider biking to this location next time.

Examples of other advice that proved the expert system technically works but logically needs to be more comprehensive and refined include:

- Your Trip on 3/25/2005 from Home to gas station was less than 1 mile. Please consider walking or biking to this location next time.

- You took 2 trips within one week of 03/23/2005 to child's school. Please consider combining these trips into a single trip.

- You took 2 trips within one week of 03/24/2005 to day care. Please consider combining these trips into a single trip.

The feedback system works based on the rules currently input in the system; however, these rules need to be more descriptive and less general. Phase 2 of this research project will refine the feedback advisory system. 


\section{Findings}

This final report presents Phase 1 of this research that developed a PDA/GPS/wireless card all-in-one portable prototype unit called "TRACIT." The unit collects comprehensive individual trip data including; start time, end time, origin, destination, travel speed, trip route, and trip distance with minimal input from participant. Limited field testing was conducted to validate that the technology works. The project also developed a preliminary personalized feedback system that provides suggestions and encourages participants to utilize other modes than the drive-alone option. After the trip data has been transferred from the PDA/GPS/wireless unit in the system.

In effect, TRAC-IT's first phase was a proof-of-concept project. The research team sought to develop a system to automatically collect travel behavior data at the person-level (rather than only track vehicles) and to be able to provide personalized feedback based on the data collected by the person and his or her household. As evidenced by the previous sections, the TRAC-IT system meets or exceeds these three primary requirements to demonstrate its feasibility:

1. Improve the quantity of data collected.

Through the GPS component, TRAC-IT was able to collect and record the location of the traveler, travel path, and speed. The PDA component was able to record GPS information as well as collect data on travel purpose and occupancy information. The PDA component also applied algorithms developed specifically for this project to reduce the amount of nonessential data were developed to simplify the analysis. Finally, the system demonstrated the ability to record travel for all major modes (auto, transit, bike and walk) to provide a richer and deeper view of travel behavior.

2. Improve the data quality.

The team found that TRAC-IT'S design minimized the need for user inputs through the adoption of GUI wizards (e.g., change of mode, frequently visited locations and QuickStops). The development of "Smart Diary" components reduced respondent fatigue (allowing for longer periods of data collection) and improved data quality by populating the fields based on previous patterns by performing complicated real-time data processing and analysis. For example, for most trips, there are only seven questions that the participant is expected to answer: 
- who is traveling,

- what is their current activity,

- what is the location at the end of trip,

- what is the purpose for being at that location,

- what travel mode did they use for this segment of the trip, whether they were a driver or passenger, and

- how many household and non-household vehicle occupants were there for this segment.

The automated aspects of TRAC-IT gathered completed data because of the development of wizards to capture quick stops, changes of mode, etc. The richness of the data collected via TRAC-IT includes the ability to collect and analyze multimodal travel behavior and patterns at the household level. TRAC-IT also eliminated the need for data entry and associated errors since data could be synched directly into the database.

\section{Analyze travel behavior at the individual and household levels}

TRAC-IT system was able to successfully upload the data to the server and provide suggestions for more efficient transportation options based on the household travel behavior. The basic expert system developed to test the ability of collecting and using the data will be refined in Phase II.

There remain additional considerations such as the costs for wide scale deployment or data collection, enhancements of the underlying technology to address specific transit needs, access to technology and privacy issues.

The costs of deploying TRAC-IT on a wide scale are changing rapidly with changes in the communication field (see the next section). The research team's preliminary testing of a cell phone application suggests that such a final system, potentially deployable as a client-side or server-side application on a cell phone rather than PDA, could drastically reduce the costs of deployment. In fact, TRAC-IT could be combined with other location-based services to become a desirable feature of cell phone users. Certainly, the e-911 compliance requirements on cell phone providers and expanding market for location-based services will increase the attractiveness of cell phones on which TRAC-IT can function.

The underlying technology to TRAC-IT could be adapted for other applications. For example, public transit is the only available means of transportation for some because they cannot drive, do not have a car, or have a physical or mental disability. Many of these individuals are intimidated by the complexities of public transit, including identifying proper routes and transfer points according to schedule, and therefore 
remain trapped in their homes. For those with special needs, it is especially daunting to get from one location to another without any assistance, especially on their first trip.

Some transit agencies and private providers now employ "travel trainers," whose sole job is to teach new riders with special needs how to successfully travel to and from a particular location using transit. Travel trainers ride with the individual until they feel that the rider can properly navigate the transit system on their own. Due to the extensive amount of time required in teaching and monitoring individuals with various needs, there is often an extensive waiting list for such assistance from the travel trainers.

TRAC-IT's cell phone application could be adapted to increase the productivity of the travel trainer by developing a system using existing mobile communication technologies to assist riders with special needs. Using TRAC-IT as a global positioning system (GPS) enabled cell phone could assist riders with special needs in using the system and enable a travel trainer and/or family members to monitor progress remotely via a simple web page. In addition, the system could be adapted to provide personalized reminders and notifications that are tailored to the specific route that the rider should take. This information could include key locations along the route and timing information that will enable the rider to successfully utilize the public transit system.

The enhancement of TRAC-IT to fill such a market need could allow travel trainers to manage numerous cases more efficiently and produce an increased sense of independence for the user while assuring the safety of the rider and allowing immediate communication with the rider if desired. 


\section{Future Research}

TRAC-IT is an example of a typical modern system made of an end system device hosting an application developed for a particular use with capabilities to exchange information with a central computer via a communication system. However, this system was not imaginable just a few years ago. This end system device is a hand held computer or PDA with GPS capabilities hosting a custom application that exchanges information over a wireless network with another computer (server) that not only stores the information provided but also that is intelligent enough to analyze it and provide meaningful insights back to the user in real-time. It is foreseen that more changes and advances in each of the system components will open up an entire new set of possibilities not imaginable today. The end device is an important consideration since it currently has several deficiencies that need to be addressed including:

- The PDA is still large, especially since people usually carry other devices, such as a laptop or cellular phone. In addition, extra capabilities usually require more devices attached to the main unit, increasing the size and making the PDA less manageable. This is the case of wireless communications and GPS devices, which are still not integrated into the PDAs, but could expect to see this happen in the near future. These extra devices not only make the PDA bulkier but also drain the battery faster.

- Batteries are drained fairly quickly and take a long time to recharge. Memory, both volatile and non-volatile, is still a limitation. Applications can not store much data because the memory gets full fairly fast. As a result, applications need to be carefully designed to avoid memory problems.

- CPU power is another aspect. Applications need to be designed so that most computations are done somewhere else, e.g. a server, otherwise not only the PDA will run very slowly but it will also drain the batteries faster. However, communication capabilities are such that applications can not be designed to transfer a lot of information somewhere else for real-time computations because the data transmission time will be excessive if users are waiting for instant replies.

- The issue of cost, PDAs cost about $\$ 400$, which make them very expensive to mainstream.

End systems are expected to improve considerably over the next few years. They will become more powerful in terms of CPU, more efficient in terms of energy use, with more capacity in terms of volatile and permanent 
memory, smaller, and with better and higher capacity batteries. In addition, extra items are expected to be integrated into these devices in the same way that wireless interfaces are already integrated into laptops today. In this regard, cellular telephones and PDAs may converge into one device, either a more powerful cellular phone with PDA capabilities or a PDA with better communication capabilities and smaller size. There are currently some devices in the market that point into that direction, offering PDAs with cellular phones and cellular phones with PDA functions.

Figures showing the past, present and future of CPU power and chip sizes, indicate that it is reasonable to expect better and smaller devices in the near future. According to Moore's law, the number of millions of instructions per second (MIPS) will double every 1.5 to 2 years (24). Similar trends account for the total number of transistors integrated in a chip. Table 8 shows the number of transistors integrated in the most important Intel processors over the years (25).

Table 8: Number of transistors on Intel processors

\begin{tabular}{|l|l|r|}
\hline Processor & Year & \multicolumn{1}{|c|}{ Transistors } \\
\hline 8080 & 1974 & 5,000 \\
\hline 8086 & 1978 & 29,000 \\
\hline 286 & 1982 & 120,000 \\
\hline 386 & 1985 & 275,000 \\
\hline 486 & 1989 & $1,180,000$ \\
\hline Pentium & 1993 & $3,100,000$ \\
\hline Pentium II & 1997 & $7,500,000$ \\
\hline Pentium III & 1999 & $24,000,000$ \\
\hline Pentium IV & 2000 & $42,000,000$ \\
\hline Itanium & 2002 & $220,000,000$ \\
\hline Itanium II & 2003 & $410,000,000$ \\
\hline
\end{tabular}

While these processors have seen their CPU power and logic capacity increased in such a steep manner, other advances have decreased the power consumption. For instance, the latest commercially available Intel processor operates at $3.4 \mathrm{Ghz}$ but needs only a 1.4 voltage supply.

It is believed that this unique end system device will be commercialized very soon and will be widely adopted, as it will become the wireless cellular phone of the near future. However, this new end system will be considerably better than the current PDAs used in TRAC-IT in several aspects. For example, current cellular systems are of the second generation or 2.5 generation, which means that data transmission, is limited to $128 \mathrm{Kbps}$. For now, this is a burdensome issue in particular 
when multimedia applications are included. The $128 \mathrm{Kbps}$ is just about 3 times faster than dial-up modems, which are being phased out in most cases because of the availability of broadband wired access networks like Asymmetric Digital Subscriber Line (ADSL) and cable modems, and wireless access networks like 802.11 wireless local area networks and Local Multipoint Distribution Service (LMDS). These new access technologies, which are usually asymmetric, allow users to send data at speeds of around $640 \mathrm{Kbps}$ and receive data at $2 \mathrm{Mbps}$ or more depending on the technology. In this regard, new standards and migration paths are being proposed towards the 4th generation wireless cellular network, known as the Universal Mobile Telecommunications System or UMTS. Standards proposed for 3rd generation systems will allow users to theoretically transmit $384 \mathrm{Kbps}$ (symmetrically) in high mobility situations and up to $2 \mathrm{Mbps}$ in stationary conditions. New technologies being investigated under the UMTS for 4th generation systems promise theoretical downlink speeds of up to $14.4 \mathrm{Mbps}$ and uplink transmissions in the order of $5.8 \mathrm{Mbps}$. These cellular networks will allow users to run applications in their cell phones that are unimaginable today.

The $4^{\text {th }}$ generation wireless networks will introduce a large amount of traffic over current wired networks, such as the Internet. Mobile users will be able to use these end systems to do what they do in their offices with their desktops at any time and place. Since wireless cellular networks do not work in isolation, it is important to look at developments in the Internet to make sure this new amount of traffic will not create problems. Cellular networks interface with the Internet for the transmission of data to and from the mobile users. Therefore, a larger amount of traffic will be carried through this interface and placed over the Internet backbone. Fortunately, developments in optical communications will be able to handle all these new traffic demands and much more.

New fiber optics systems under research and in early stages of market deployment will transfer terabits of data per second over a single fiber channel. Intelligent communication protocols and multiplexing techniques are being standardized to build the next generation Internet, in which users will be able to obtain end-to-end $10 \mathrm{Gbps}$ channels to transmit data on demand, in a very similar fashion as we do today with telephone calls (but not 64Kbps!) (26). This is Internet Protocol (IP) over Wavelength Division Multiplexing (WDM) next generation intelligent optical network that is being adopted by all major communication carriers because of the cost reductions and new service capabilities. The development of this new intelligent network was driven by foreseen physics applications that need steady transfer rates in the order of Gbps to allow collaborative scientific work among different researchers located in different parts of the globe. It is expected that these optical networks will be integrated with wireless 
cellular networks, wireless ad hoc, and sensor networks, etc., to provide seamless access and good performance to all users all the time at any place.

GPS devices are also a critical component in the TRAC-IT application. GPS chips are expected to be small and cheap enough to be integrated into PDAs and cell phones. The main problem with GPS systems, from the TRAC-IT application point of view, is that of the signal strength when users are inside buildings or blocked by physical objects. In this sense, wireless cellular telephones are better positioned to provide applications more accurate and reliable coordinates, as signals can be obtained directly from the satellites, if available, or from servers located in the carrier's network. More CPU power will allow the inclusion of appropriate algorithms in this unique end system to not only receive GPS signals directly from the satellite and/or query these GPS servers but also to obtain important information about the user automatically, such as the user speed, direction, mode of transportation, routes, etc., all of great interest for transportation professionals.

All these new capabilities will make possible the development of more complex and useful applications able to:

- include more elaborate CPU algorithms at the end-user device,

- store more information for processing,

- transmit more information faster, including real-time multimedia applications, and

- query servers for additional information regardless the locations.

In addition, new advances in battery devices and the integration of other devices in chips will allow individuals to carry only one small device in our pockets and fulfill all needs. As these devices are introduced, they will replace our current $2^{\text {nd }}$ or $3^{\text {rd }}$ generation cell phones, decreasing costs.

For all these reasons, it is believed that a natural extension to the TRACIT project is the development of the TRAC-IT application in a cellular telephone. Cellular telephones already address some of the issues mentioned above, such as size, integration of communication capabilities, availability of GPS coordinates, and battery issues. However, they introduce some new challenges, such as the design of the application user interface, more stringent memory capabilities, and CPU power. Nonetheless, given the experience obtained in TRAC-IT with PDAs and the expected trends, the development of TRAC-IT on a cellular telephone will position transportation professionals at the forefront of the new endsystem device technologies as they become commercially available. 
Finally, an important note on applications is discussed. Cellular telephones are already in the hands of millions of people. As expected, devices that are more powerful will make possible new applications, such as TRAC-IT, that will make daily lives easier, better, and more secure. These devices will not only be able to collect user travel data but also to send and receive customized traffic reports according to the position of the user, receive amber alerts, know location of children, report incidents on real-time including voice, video and images of the incident, query the network for directions and receive maps with precise routes, query the network for services, restaurants, phones, browse the Internet, send and receive e-mails, transfer files, and more. 


\section{References}

(1) Cleland, F., and P. Winters (1999) "Reducing vehicle trips and vehicle miles of travel through customized travel options, final report: results of survey and conclusions". Center for Urban Transportation Research, College of Engineering, University of South Florida. Department of Transportation State of Florida. http://www.cutr.usf.edu/tdm/pdf/reducing VMT.pdf, March 15, 2005.

(2) Schrank, David and Tim Lomax (2005) "Annual Urban Mobility Study". Texas Transportation Institute. http://mobility.tamu.edu/ums/report/congestion cost.pdf, July 8, 2005.

(3) Transportation Research Board, Circular Number E-C071 (2005) "Data for Understanding Our Nation's Travel National Household Travel Survey Conference November 1-2, 2004. http://trb.org/publications/circulars/ec071.pdf, April 15, 2005.

(4) Mehndiratta, S., et al. (2000) "Users of a regional telephone-based traveler information system - a study of TravInfo ${ }^{\mathrm{TM}}$ users in the San Francisco Bay Area". Transportation 27: 391-417.

(5) Asakura, Y., E. Hato and Y. Nishibe (1999) "Monitoring travel behavior using PHS based location positioning service system". Proceedings of the $6^{\text {th }}$ ITS World Congress, Toronto.

(6) Asakura., Y. J. Tanabe and Y.H. Lee (2001) "Characteristics of positioning data for monitoring travel behavior". Institute of Urban Transport Planning Co., Ltd.

(7) Asakura Y., and A. Okamoto (2001) "Monitoring Individual Travel Behavior using PEAMON: A Cellular Phone Based Location Positioning Instrument Combined with Acceleration Sensor". Institute of Urban Transport Planning Co. Ltd, Osaka, Japan.

(8) Draijer, G., N. Kalfs and J. Perdok (2000) "GPS as a Data Collection Method for Travel Research: The use of GPS for data collection for all modes of travel." Transportation Research Board 79th Annual Meeting, Washington, D.C.

(9) Wolf, J., R. Guensler and W. Bachman (2001) "Elimination of the Travel Diary: An Experiment to Derive Trip Purpose from GPS Travel Data," Transportation Research Record 1768, p. 125-134. http://www.fhwa.dot.gov/ohim/trb/wolf.pdf May 3, 2005.

(10) Guensler, R. and J. Wolf (1999) "Development of a Handheld Electronic Travel Diary for Monitoring Individual Trip-making Behavior," Transportation Research Board 78th Annual Conference, Washington, D.C. http://www.fhwa.dot.gov/ohim/trb/wolf3.pdf, May 3, 2005 
(11) Rose, G. and E. Ampt (March 2001) "Travel blending: an Australian travel awareness initiative," Transportation Research Part D volume 6, issue 2 pages 95-110.

(12) UK Department of the Environment, Transport and the Regions (2001) " $A$ review of the effectiveness of personalised journey planning techniques". http://www.dft.gov.uk/stellent/groups/dft susttravel/documents/pdf/dft susttrav el pdf 504131.pdf, March 15, 2005.

(13) Fujii, S. and Taniguchi, A. (2003) "Reducing family car use by providing travel advice or by requesting behavioral plans: an experimental analysis of travel feedback programs," 10th International Conference on Travel Behavior Research, Lucerne, August 2003. http://www.ivt.baum.ethz.ch/allgemein/pdf/fujii.pdf , March 15, 2005

(14) Chung E. and A. Shalaby. (2004) "Development of a Trip Reconstruction Tool to Identify Traveled Links and Used Modes for GPS-Based Personal Travel Surveys," Transportation Research Board 83rd Annual Meeting , Washington, D.C.

(15) Murakami, E., Wagner, D. P., Neumeister, D. M. (1997) "Using Global Positioning Systems and Personal Digital Assistants for Personal Travel Surveys in the United States," International Conference on Transport Survey Quality and Innovation, Grainau, Germany. http://gulliver.trb.org/publications/circulars/ec008/session b.pdf, July 2004.

(16) Murakami, E.and D. P.Wagner. (1999) Can using global positioning system (GPS) improve trip reporting? Transportation Research Part C, 7(2/3):149-165.

(17) Man, Michelle. "Mobile Phone Basics," (2001) Socket Communications,. http://www.socketcom.com/pdf/TechBriefMobilePhone.pdf July 2004

(18) Box, J. and D. Fox. (2003) "Building Solutions with the .NET Compact Framework," Addison Wesley Professional, Boston, Massachusetts.

(19) McGuckin, N. A., and E. R. Murkami. (1999) "Examining Trip-Chaining Behavior: Comparison of Travel by Men and Women," Paper presented at 78th Annual Meeting of the Transportation Research Board, Washington, D.C. http://npts.ornl.gov/npts/1995/Doc/Chain2.pdf. July 2004.

(20) Strathman, J.G and K.J. Deuker. (1995) "Understanding Trip Chaining" 1990 NPTS Special Reports on Trip and Vehicle Attributes. Report FHWA-PL-95033. FHWA, U.S. Department of Transportation.

(21) Bennett, P. The NMEA FAQ - Version 6.4. (2003). http://vancouverwebpages.com/peter/nmeafaq.txt. July, 2004

(22) Trimble®. Online GPS Tutorial, http://www.trimble.com/gps/, July, 2004.

(23) The UMTS Forum, http://www.umts-forum.org/ 
(24) G. E. Moore. (1999) "Cramming more Components onto Integrated Circuits." Electronics, 38(8):114-117.

(25) Hao, Li. (2004) "Low Power Technology Mapping and Performance Driven Placement for Field Programmable Gate-Arrays." Ph.D. Dissertation, University of South Florida.

(26) C. Siva Ram Murthy and M. Gurusamy. (2002) "WDM Optical Networks: Concepts, Design and Algorithms." Prentice Hall.

(27) P. Tomsu and C. Schmutzer. (2000) "Next Generation Optical Networks." Prentice Hall. 
Appendices 
Appendix A: PDA/GPS/Wireless Connection Matrix

PDA/GPS/Wireless Connection Comparison Tables

\begin{tabular}{|c|c|c|}
\hline Maker & Model & Pages \\
\hline \multirow[t]{8}{*}{ Palm } & Zire & $21-22$ \\
\hline & Zire 71 & \\
\hline & $\underline{\mathrm{m} 130}$ & \\
\hline & $\underline{\mathrm{m} 515}$ & \\
\hline & $\lcm{705}$ & \\
\hline & Tungsten $\mathrm{C}$ & \\
\hline & Tungsten T & \\
\hline & Tungsten W & \\
\hline \multirow[t]{6}{*}{$\underline{\mathrm{HP}}$} & IPAQ H1910 & $23-24$ \\
\hline & IPAQ H1940 & \\
\hline & iPAQ H2210/15 & \\
\hline & IPAQ H5150 & \\
\hline & iPAQ H5450 & \\
\hline & IPAQ H5555 & \\
\hline \multirow[t]{2}{*}{ Compaq } & IPAQ H3950 & $23-24$ \\
\hline & IPAQ H3970 & \\
\hline \multirow[t]{2}{*}{ Handspring } & Treo 300 & $25-26$ \\
\hline & Treo 270 & \\
\hline Audiovox & Thera & $25-26$ \\
\hline \multirow[t]{2}{*}{ Toshiba } & $\underline{\mathrm{e} 350}$ & \\
\hline & $\underline{\mathrm{e} 750}$ & \\
\hline Garmin & iQue 3600 & $25-26$ \\
\hline Dell & Axim $\times 5$ adv. & $25-26$ \\
\hline \multirow[t]{5}{*}{ Sony Clie } & PEG-SJ22 & $27-28$ \\
\hline & $\underline{\text { PEG-SJ33 }}$ & \\
\hline & $\underline{\text { PEG-NX60 }}$ & \\
\hline & PEG-NX70V & \\
\hline & PEG-TG50 & \\
\hline
\end{tabular}




\begin{tabular}{|c|c|c|c|c|c|c|c|c|}
\hline Maker & \multicolumn{8}{|c|}{ Palm } \\
\hline Model & \multirow{2}{*}{$\begin{array}{c}\text { Zire } \\
\text { Not All } \\
\text { Functions } \\
\end{array}$} & Zire 71 & $\underline{\mathrm{m} 130}$ & $\underline{\mathrm{m} 515}$ & $\underline{i 705}$ & $\frac{\text { Tungsten }}{\text { C }}$ & Tungsten T & \multirow{2}{*}{$\begin{array}{c}\frac{\text { Tungsten }}{\underline{\mathbf{W}}} \\
\text { All Functions, } \\
1 \text { device }\end{array}$} \\
\hline Functions & & \multicolumn{6}{|c|}{ All Functions, 2 devices } & \\
\hline OS & P v. 4.1 & P v. 5.2.1 & P v. 4.1 & P v. 4.1 & P v. 4.1 & P v. 5.2.1 & P v. 5.0 & P v. 4.1 \\
\hline RAM & 2 & 16 & 8 & 16 & 8 & 64 & 16 & 16 \\
\hline ROM & $\mathrm{N} / \mathrm{A}$ & $\mathrm{N} / \mathrm{A}$ & $\mathrm{N} / \mathrm{A}$ & 4 & $N / A$ & $N / A$ & 4 & 8 \\
\hline Processor & $\begin{array}{c}16 \mathrm{MHz} \text { DB } \\
(\mathrm{EZ})\end{array}$ & $144 \mathrm{MHZ}$ A & $\begin{array}{c}33 \mathrm{MHZ} \text { DB } \\
(\mathrm{EZ})\end{array}$ & $\begin{array}{l}33 \mathrm{MHZ} \text { DB } \\
\text { (EZ) }\end{array}$ & $\begin{array}{l}33 \mathrm{MHZ} \text { DB } \\
(\mathrm{EZ})\end{array}$ & $\begin{array}{c}400 \mathrm{MHz} \\
\text { Xscale }\end{array}$ & $144 \mathrm{MHZ}$ A & $\begin{array}{c}33 \mathrm{MHZ} \text { DB } \\
(\mathrm{EZ})\end{array}$ \\
\hline Screen & M & T 64k colors & T 60k Colors & R 64k colors & 16 grayscale & T 64k colors & R 64k colors & R 64k colors \\
\hline Expansion & $\mathrm{N} / \mathrm{A}$ & $\begin{array}{l}\text { SD, PUC, } \\
\text { MMC }\end{array}$ & $\begin{array}{l}\text { SD, PUC, } \\
\text { MMC }\end{array}$ & $\begin{array}{l}\text { SD, PUC, } \\
\text { MMC }\end{array}$ & $\begin{array}{l}\text { SD, PUC, } \\
\text { MMC }\end{array}$ & $\begin{array}{l}\text { SD, PUC, } \\
\text { MMC }\end{array}$ & $\begin{array}{l}\text { SD, PUC, } \\
\text { MMC }\end{array}$ & $\begin{array}{l}\text { SD, PUC, } \\
\text { MMC }\end{array}$ \\
\hline Connections & USB//rDA & USB/IrDA & USB/IrDA & USB/IrDA & USB/IrDA & USB/IrDA & USB/IrDA & USB/IrDA \\
\hline Dimensions/weight & $\begin{array}{c}4.4 \times 2.9 x \\
0.6 \mathrm{in} . / 3.8 \\
0 z\end{array}$ & $\begin{array}{c}4.5 \times 2.9 \times 0.6 \\
\text { in. } / 5.30 z\end{array}$ & $\begin{array}{c}4.8 \times 3.1 \times 0.9 \\
\text { in. } / 5.40 z\end{array}$ & $\begin{array}{c}4.5 \times 3.1 \times 0.5 \\
\text { in. } / 4.90 z\end{array}$ & $\begin{array}{c}4.7 \times 3.1 \times 0.6 \\
\text { in. } / 5.90 z\end{array}$ & $\begin{array}{c}4.8 \times 3.0 \times 0.6 \\
\text { in. } / 6.30 z\end{array}$ & $\begin{array}{c}4.7 \times 3.1 \times 0.6 \\
\text { in. } / 5.90 z\end{array}$ & $\begin{array}{c}4.8 \times 3.0 \times 0.6 \\
\text { in. } / 6.30 z\end{array}$ \\
\hline Battery type & $\mathrm{RLI}$ & RLP & $\mathrm{RLI}$ & RLI & RLP & RLP & RLP & $\mathrm{RLI}$ \\
\hline Battery life & $\mathrm{N} / \mathrm{A}$ & $7 \mathrm{hrs}$ & $5 \mathrm{hrs}$ & $5 \mathrm{hrs}$ & 10 days & $10 \mathrm{hrs} \mathrm{talk}$ & $10 \mathrm{hrs} \mathrm{talk}$ & $10 \mathrm{hrs}$ talk \\
\hline Price & 99.00 & 299.00 & 199.00 & 299.00 & 199.00 & 499.00 & 349.00 & 419.00 \\
\hline \multicolumn{9}{|l|}{ Notes } \\
\hline Bluetooth & $\mathrm{N} / \mathrm{A}$ & $\mathrm{N} / \mathrm{A}$ & SD Card & SD Card & SD Card & $\mathrm{N} / \mathrm{A}$ & Built in & $\underline{\text { SD Card }}$ \\
\hline WiFi & $\mathrm{N} / \mathrm{A}$ & $\mathrm{N} / \mathrm{A}$ & $\underline{\text { SD Card }}$ & $\underline{\text { SD Card }}$ & $\underline{\text { SD Card }}$ & Built in & $\underline{\text { SD Card }}$ & $\underline{\text { SD Card }}$ \\
\hline Modem & $\mathrm{N} / \mathrm{A}$ & $\begin{array}{c}\text { Sleeve: } \\
\text { PalmModem } \\
\end{array}$ & $\begin{array}{c}\text { Sleeve: } \\
\text { PalmModem } \\
\end{array}$ & $\begin{array}{c}\text { Sleeve: } \\
\text { PalmModem } \\
\end{array}$ & $\begin{array}{c}\text { Sleeve: } \\
\text { PalmModem }\end{array}$ & $\begin{array}{c}\text { Sleeve: } \\
\text { PalmModem }\end{array}$ & $\begin{array}{c}\text { Sleeve: } \\
\text { PalmModem } \\
\end{array}$ & $\begin{array}{c}\text { Sleeve: } \\
\text { PalmModem } \\
\end{array}$ \\
\hline Modem speed & $\mathrm{N} / \mathrm{A}$ & $56 k$ & $56 k$ & $56 k$ & $56 k$ & $56 \mathrm{k}$ & $56 \mathrm{k}$ & $56 \mathrm{k}$ \\
\hline $\begin{array}{l}\text { Add-on Price for } \\
\text { Modem }\end{array}$ & $\mathrm{N} / \mathrm{A}$ & 99.00 & 99.00 & 99.00 & 99.00 & 99.00 & 99.00 & 99.00 \\
\hline Wireless & $\mathrm{N} / \mathrm{A}$ & $\frac{\text { Sleeve and }}{\text { PC Card }}$ & $\frac{\text { Sleeve and }}{\text { PC Card }}$ & $\frac{\text { Sleeve and }}{\text { PC Card }}$ & Built-in & $\frac{\text { Sleeve and }}{\text { PC Card }}$ & $\frac{\text { Sleeve and }}{\text { PC Card }}$ & Built-in \\
\hline Network & $\mathrm{N} / \mathrm{A}$ & $\begin{array}{l}\text { GPRS or } \\
\text { CDMA }\end{array}$ & $\begin{array}{l}\text { GPRS or } \\
\text { CDMA }\end{array}$ & $\begin{array}{l}\text { GPRS or } \\
\text { CDMA }\end{array}$ & Palm. net & $\begin{array}{l}\text { GPRS or } \\
\text { CDMA }\end{array}$ & $\begin{array}{l}\text { GPRS or } \\
\text { CDMA }\end{array}$ & GPRS \\
\hline $\begin{array}{c}\text { Max Data } \\
\text { Throughput }\end{array}$ & $\mathrm{N} / \mathrm{A}$ & 115kbps & $115 \mathrm{kbps}$ & $115 \mathrm{kbps}$ & $115 \mathrm{kbps}$ & $115 \mathrm{kbps}$ & $115 \mathrm{kbps}$ & 115kbps \\
\hline Provider & $\mathrm{N} / \mathrm{A}$ & Varies & Varies & Varies & $\underline{\text { Palm. net }}$ & Varies & Varies & $\underline{A T \& T}$ \\
\hline Entry Plan Fee & $\mathrm{N} / \mathrm{A}$ & $\$ 19.95$ & $\$ 19.95$ & $\$ 19.95$ & $\$ 19.95$ & $\$ 19.95$ & $\$ 19.95$ & $\$ 19.95$ \\
\hline $\begin{array}{l}\text { Additional } \\
\text { Equipment }\end{array}$ & $\mathrm{N} / \mathrm{A}$ & $\underline{\text { RV Guyver }} \underline{\text { PC Card Sled }}$ & $\underline{\text { RV Guyver }} \underline{\underline{\text { PC Card Sled }}}$ & 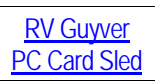 & N/A & 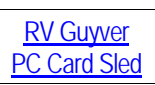 & 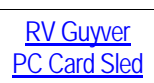 & $\mathrm{N} / \mathrm{A}$ \\
\hline Add. Equip. Price & $N / A$ & $\$ 170.00$ & $\$ 170.00$ & $\$ 170.00$ & $\mathrm{~N} / \mathrm{A}$ & $\$ 170.00$ & $\$ 170.00$ & $\mathrm{~N} / \mathrm{A}$ \\
\hline $\begin{array}{c}\text { Total Price for } \\
\text { wireless add-ons }\end{array}$ & $N / A$ & Varies & Varies & Varies & $\begin{array}{l}\text { N/A But } \\
\text { limited } \\
\text { wireless }\end{array}$ & Varies & Varies & $\mathrm{N} / \mathrm{A}$ \\
\hline GPS & $\mathrm{N} / \mathrm{A}$ & $\mathrm{N} / \mathrm{A}$ & Yes & Yes & Yes & Yes & Yes & Yes \\
\hline Maker & $\mathrm{N} / \mathrm{A}$ & $\mathrm{N} / \mathrm{A}$ & $\frac{\text { Navman at }}{\$ 199}$ & $\frac{\text { Navman at }}{\$ 199}$ & Mapopolis & Mapopolis & $\underline{\text { Mapopolis }}$ & Mapopolis \\
\hline GPS Type & $\mathrm{N} / \mathrm{A}$ & $\mathrm{N} / \mathrm{A}$ & Sleeve & Sleeve & Sled & Sled & Sled & Sled \\
\hline Another link & $\mathrm{N} / \mathrm{A}$ & $\mathrm{N} / \mathrm{A}$ & $\frac{\text { Navman at }}{\$ 199}$ & $\frac{\text { Navman at }}{\$ 199}$ & Mapopolis & Mapopolis & $\underline{\text { Mapopolis }}$ & Mapopolis \\
\hline $\begin{array}{l}\text { Additional } \\
\text { Equipment }\end{array}$ & $\mathrm{N} / \mathrm{A}$ & $\mathrm{N} / \mathrm{A}$ & $\overline{N / A}$ & $\overline{N / A}$ & $\mathrm{~N} / \mathrm{A}$ & $\mathrm{N} / \mathrm{A}$ & $\mathrm{N} / \mathrm{A}$ & $\mathrm{N} / \mathrm{A}$ \\
\hline
\end{tabular}




\begin{tabular}{|c|c|c|c|c|c|c|c|c|}
\hline \multirow{3}{*}{$\begin{array}{c}\text { Maker } \\
\text { Model } \\
\text { Functions } \\
\end{array}$} & \multicolumn{8}{|c|}{ Palm } \\
\hline & \multirow{2}{*}{$\begin{array}{c}\text { Zire } \\
\text { Not All } \\
\text { Functions }\end{array}$} & Zire 71 & $\underline{\mathrm{m} 130}$ & $\underline{\mathrm{m} 515}$ & $\underline{i 705}$ & $\frac{\text { Tungsten }}{\mathrm{C}}$ & $\underline{\text { Tungsten T }}$ & $\frac{\text { Tungsten }}{\underline{W}}$ \\
\hline & & \multicolumn{6}{|c|}{ All Functions, 2 devices } & $\begin{array}{c}\text { All Functions, } \\
1 \text { device }\end{array}$ \\
\hline Maker 2 & $\mathrm{~N} / \mathrm{A}$ & $\mathrm{N} / \mathrm{A}$ & $\frac{\text { Mapopolis at }}{\$ 229}$ & $\frac{\text { Magellan at }}{\$ 199}$ & $\mathrm{~N} / \mathrm{A}$ & $\mathrm{N} / \mathrm{A}$ & $\frac{\text { EMTAC at }}{\$ 349}$ & $\frac{\text { EMTAC at }}{\$ 349}$ \\
\hline GPS Type & $\mathrm{N} / \mathrm{A}$ & $\mathrm{N} / \mathrm{A}$ & Sled & Sled & $\mathrm{N} / \mathrm{A}$ & $\mathrm{N} / \mathrm{A}$ & $\begin{array}{l}\text { Separate, } \\
\text { wireless }\end{array}$ & $\begin{array}{l}\text { Separate, } \\
\text { wireless }\end{array}$ \\
\hline Another link & $N / A$ & $\mathrm{~N} / \mathrm{A}$ & $\frac{\text { Mapopolis at }}{\$ 229}$ & $\frac{\text { Magellan at }}{\$ 199}$ & $\mathrm{~N} / \mathrm{A}$ & $\mathrm{N} / \mathrm{A}$ & $\frac{\text { EMTAC at }}{\$ 349}$ & $\frac{\text { EMTAC at }}{\$ 349}$ \\
\hline $\begin{array}{l}\text { Additional } \\
\text { Equipment }\end{array}$ & $\mathrm{N} / \mathrm{A}$ & $\mathrm{N} / \mathrm{A}$ & $\mathrm{N} / \mathrm{A}$ & $\mathrm{N} / \mathrm{A}$ & $\mathrm{N} / \mathrm{A}$ & $\mathrm{N} / \mathrm{A}$ & $\mathrm{N} / \mathrm{A}$ & $\frac{\text { Bluetooth at }}{\$ 129}$ \\
\hline Maker 3 & $N / A$ & $\mathrm{~N} / \mathrm{A}$ & $\frac{\text { EMTAC at }}{\$ 349}$ & $\frac{\text { Mapopolis at }}{\$ 229}$ & $\mathrm{~N} / \mathrm{A}$ & $\mathrm{N} / \mathrm{A}$ & $\mathrm{N} / \mathrm{A}$ & $\mathrm{N} / \mathrm{A}$ \\
\hline GPS Type & $\mathrm{N} / \mathrm{A}$ & N/A & $\begin{array}{l}\text { Separate } \\
\text { Wireless }\end{array}$ & $\frac{\text { EMTAC at }}{\$ 349}$ & $\mathrm{~N} / \mathrm{A}$ & $\mathrm{N} / \mathrm{A}$ & $\mathrm{N} / \mathrm{A}$ & $\mathrm{N} / \mathrm{A}$ \\
\hline Another link & $\mathrm{N} / \mathrm{A}$ & $\mathrm{N} / \mathrm{A}$ & & $\frac{\text { Mapopolis at }}{\$ 229}$ & $\mathrm{~N} / \mathrm{A}$ & $\mathrm{N} / \mathrm{A}$ & N/A & N/A \\
\hline $\begin{array}{l}\text { Additional } \\
\text { Equipment }\end{array}$ & $\mathrm{N} / \mathrm{A}$ & $\mathrm{N} / \mathrm{A}$ & $\frac{\text { Bluetooth at }}{\$ 129}$ & $\mathrm{~N} / \mathrm{A}$ & $\mathrm{N} / \mathrm{A}$ & $\mathrm{N} / \mathrm{A}$ & $\mathrm{N} / \mathrm{A}$ & N/A \\
\hline Maker 4 & $\mathrm{~N} / \mathrm{A}$ & $\mathrm{N} / \mathrm{A}$ & $N / A$ & $\frac{\text { EMTAC at }}{\$ 349}$ & $\mathrm{~N} / \mathrm{A}$ & $\mathrm{N} / \mathrm{A}$ & $\mathrm{N} / \mathrm{A}$ & $\mathrm{N} / \mathrm{A}$ \\
\hline GPS Type & $\mathrm{N} / \mathrm{A}$ & N/A & N/A & $\begin{array}{l}\text { Separate, } \\
\text { Wireless }\end{array}$ & $\mathrm{N} / \mathrm{A}$ & $\mathrm{N} / \mathrm{A}$ & $\mathrm{N} / \mathrm{A}$ & $\mathrm{N} / \mathrm{A}$ \\
\hline Another link & $N / A$ & N/A & N/A & $\frac{\text { EMTAC at }}{\$ 349}$ & $\mathrm{~N} / \mathrm{A}$ & $\mathrm{N} / \mathrm{A}$ & N/A & $N / A$ \\
\hline $\begin{array}{l}\text { Additional } \\
\text { Equipment }\end{array}$ & $\mathrm{N} / \mathrm{A}$ & N/A & $\mathrm{N} / \mathrm{A}$ & $\frac{\text { Bluetooth at }}{\$ 129}$ & $\mathrm{~N} / \mathrm{A}$ & $\mathrm{N} / \mathrm{A}$ & $\mathrm{N} / \mathrm{A}$ & $\mathrm{N} / \mathrm{A}$ \\
\hline Price & 0 & 0 & $\$ 199$ & $\$ 199$ & $\$ 229.00$ & $\$ 229.00$ & $\$ 229.00$ & $\$ 229.00$ \\
\hline Notes & & & $\begin{array}{l}\text { Lowest price } \\
\text { is considered }\end{array}$ & $\begin{array}{l}\text { Lowest price } \\
\text { is considered }\end{array}$ & $\begin{array}{l}\text { Lowest price } \\
\text { is considered }\end{array}$ & $\begin{array}{l}\text { Lowest price } \\
\text { is considered }\end{array}$ & $\begin{array}{l}\text { Lowest price } \\
\text { is considered }\end{array}$ & $\begin{array}{l}\text { Lowest price } \\
\text { is considered }\end{array}$ \\
\hline Total Price & $\mathrm{N} / \mathrm{A}$ & Varies & Varies & Varies & 430 & Varies & Varies & $\$ 650$ \\
\hline Review 1 link & & Review 1 & Review 1 & Review 1 & Review 1 & Review 1 & Review 1 & Review 1 \\
\hline Review 2 link & & $\underline{\text { Review } 2}$ & & & Review 2 & Review 2 & Review 2 & Review 2 \\
\hline Comments & $\begin{array}{c}\text { No wireless } \\
\text { or GPS }\end{array}$ & The only & $\begin{array}{l}\text { y to have both } \\
\text { eection and two }\end{array}$ & $\begin{array}{l}\text { S and wireless } \\
\text { parate devices. }\end{array}$ & $\begin{array}{l}\text { cess is to have } \\
\text { herwise have to }\end{array}$ & $\begin{array}{l}\text { th connected to } \\
\text { witch between tl }\end{array}$ & $\begin{array}{l}\text { Bluetooth } \\
\text { am }\end{array}$ & $\begin{array}{c}\text { best choice } \\
\text { convenient: } \\
\text { two devices } \\
\text { compacted to } \\
1 \text { (because of } \\
\text { the sled) and } \\
\text { cheapest } \\
\text { price }\end{array}$ \\
\hline $\begin{array}{c}\text { Further Notes As } \\
\text { of } 8 / 25 / 2003\end{array}$ & $\begin{array}{l}\text { Palm OS } \\
\text { eliminated }\end{array}$ & $\begin{array}{l}\text { Palm OS } \\
\text { eliminated }\end{array}$ & $\begin{array}{l}\text { Palm OS } \\
\text { eliminated }\end{array}$ & $\begin{array}{l}\text { Palm OS } \\
\text { eliminated }\end{array}$ & $\begin{array}{l}\text { Palm OS } \\
\text { eliminated }\end{array}$ & $\begin{array}{l}\text { Palm OS } \\
\text { eliminated }\end{array}$ & $\begin{array}{l}\text { Palm OS } \\
\text { eliminated }\end{array}$ & $\begin{array}{l}\text { Palm OS } \\
\text { eliminated }\end{array}$ \\
\hline $\begin{array}{l}\text { Notes As of } \\
8 / 25 / 2003\end{array}$ & & $\mathrm{Pe}$ & $\begin{array}{l}\text { After Softwa } \\
\text { devices were }\end{array}$ & $\begin{array}{l}\text { evelopment } \\
\text { inated due t }\end{array}$ & $\begin{array}{l}\text { perating syste } \\
\text { ease of devel }\end{array}$ & $\begin{array}{l}\text { las considered } \\
\text { lent for the Pocl }\end{array}$ & $\mathrm{PCOS}$ & \\
\hline
\end{tabular}




\begin{tabular}{|c|c|c|c|c|c|c|c|c|}
\hline Maker & \multicolumn{6}{|c|}{$\underline{\mathrm{HP}}$} & \multicolumn{2}{|c|}{ Compaq } \\
\hline Model & $\underline{\mathrm{iPAQ} H 1910}$ & $\underline{\mathrm{iPAQ} H 1940}$ & $\frac{\mathrm{iPAQ}}{\mathrm{H} 2210 / 15}$ & $\underline{\mathrm{iPAQ} H 5150}$ & $\underline{\mathrm{iPAQ} H 5450}$ & $\underline{\mathrm{iPAQ} H 5555}$ & $\underline{\mathrm{iPAQ} H 3950}$ & $\underline{\mathrm{iPAQ} H 3970}$ \\
\hline Functions & \multicolumn{2}{|c|}{ Not All Functions } & $\begin{array}{c}\text { All } \\
\text { Functions, } \\
2 \text { devices } \\
\end{array}$ & \multicolumn{5}{|c|}{ All Functions, 1 device } \\
\hline OS & PPC 2K2 & PPC 2K3 & PPC 2K3 & PPC 2K3 & PPC 2K2 & PPC 2K3 & PPC 2K2 & PPC 2K2 \\
\hline RAM & 64 & 64 & 64 & 64 & 64 & 128 & 64 & 64 \\
\hline ROM & 16 & $N / A$ & 32 & 32 & 48 & 48 & 32 & 48 \\
\hline Processor & $200 \mathrm{MHz}$ Xscale & $\begin{array}{l}266 \mathrm{MHz} \\
\text { Samsung }\end{array}$ & $\begin{array}{l}400 \mathrm{MHz} \\
\text { Xscale }\end{array}$ & $\begin{array}{l}400 \mathrm{MHz} \\
\text { Xscale }\end{array}$ & $\begin{array}{c}400 \mathrm{MHz} \\
\text { Xscale }\end{array}$ & $\begin{array}{c}400 \mathrm{MHz} \\
\text { Xscale }\end{array}$ & $\begin{array}{c}400 \mathrm{MHz} \\
\text { Xscale }\end{array}$ & $\begin{array}{l}400 \mathrm{MHz} \\
\text { Xscale }\end{array}$ \\
\hline Screen & T 64k colors & T 64k colors & $\begin{array}{l}\text { T 64k } \\
\text { colors }\end{array}$ & T 64k colors & T 64k colors & T 64k colors & T64k colors & T 64k colors \\
\hline Expansion & $\mathrm{SD}, \mathrm{MMC}$ & $\mathrm{SD}, \mathrm{MMC}$ & $\begin{array}{c}\text { CF, SD, } \\
\text { MMC }\end{array}$ & $\begin{array}{c}\text { CF, SD, } \\
\text { MMC }\end{array}$ & $\mathrm{SD}, \mathrm{MMC}$ & $\begin{array}{c}\text { CF, SD, } \\
\text { MMC }\end{array}$ & $\mathrm{SD}, \mathrm{MMC}$ & $\mathrm{SD}, \mathrm{MMC}$ \\
\hline Connections & USB/IrDA & USB/IrDA & USB/IrDA & USB//rDA & USB//rDA & USB//rDA & USB//rDA & USB/IrDA \\
\hline Dimensions/weight & $\begin{array}{c}4.4 \times 2.7 \times .5 \mathrm{in} . / \\
4.2 \mathrm{oz}\end{array}$ & $\begin{array}{c}4.4 \times 2.7 \times .5 \\
\text { in. } / 4.30 z\end{array}$ & $\begin{array}{c}4.5 \times 3.0 x \\
.6 \text { in. } / 5.1 \\
0 z\end{array}$ & $\begin{array}{c}5.2 \times 3.3 \times .6 \\
\text { in. } / 60 z\end{array}$ & $\begin{array}{c}5.2 \times 3.3 x \\
.62 \text { in. } / 7.2 \\
0 z \\
\end{array}$ & $\begin{array}{c}5.4 \times 3.3 \times .6 \\
\text { in. } / 7.20 z\end{array}$ & $\begin{array}{c}5.3 \times 3.3 x \\
.62 \text { in. } / 6.5 \\
0 z \\
\end{array}$ & $\begin{array}{c}5.3 \times 3.3 \times .62 \\
\text { in. } / 6.50 z\end{array}$ \\
\hline Battery type & $R L P, R B$ & $\mathrm{RLP}, \mathrm{RB}$ & RLP, RB & $\mathrm{RLP}, \mathrm{RB}$ & $\mathrm{RLP}, \mathrm{RB}$ & $\mathrm{RLP}, \mathrm{RB}$ & RLP & RLP \\
\hline Battery life & N/A & $\mathrm{N} / \mathrm{A}$ & N/A & N/A & $8 \mathrm{hrs}$ & $\mathrm{N} / \mathrm{A}$ & N/A & $\mathrm{N} / \mathrm{A}$ \\
\hline Price & 299.99 & 373.99 & 399.95 & 549.95 & 629.95 & 649.95 & 389.99 & 449.95 \\
\hline Notes & $\begin{array}{l}\text { Does not support } \\
\text { Wireless nor } \\
\text { GPS/Discontinued }\end{array}$ & Discontinued & & Discontinued & Discontinued & & Discontinued & Discontinued \\
\hline Bluetooth & $\mathrm{N} / \mathrm{A}$ & Built in & Built in & Built in & Built in & Built in & $\frac{\text { Expansion }}{\text { pack }}$ & Built in \\
\hline WiFi & N/A & $\underline{\text { SD Card }}$ & $\underline{\text { CF Card }}$ & $\underline{\text { SD Card }}$ & Built in & Built in & $\underline{\text { SD Card }}$ & $\underline{\text { SD Card }}$ \\
\hline Modem & $N / A$ & $\mathrm{~N} / \mathrm{A}$ & $\underline{\text { CF card }}$ & $\underline{\text { CF card }}$ & $\underline{\text { CF card }}$ & $\underline{\text { CF card }}$ & $\underline{\text { CF card }}$ & $\underline{\text { CF card }}$ \\
\hline Modem speed & $\mathrm{N} / \mathrm{A}$ & $\mathrm{N} / \mathrm{A}$ & $56 k$ & $56 \mathrm{k}$ & $56 k$ & $56 k$ & $56 k$ & $56 k$ \\
\hline $\begin{array}{c}\text { Add-on Price for } \\
\text { Modem }\end{array}$ & N/A & $N / A$ & $\$ 97$ & $\$ 97$ & $\$ 97$ & $\$ 97$ & $\$ 97$ & $\$ 97$ \\
\hline Wireless & N/A & $\mathrm{N} / \mathrm{A}$ & $\underline{\text { CF card }}$ & $\underline{\text { CF card }}$ & $\underline{\text { CF card }}$ & $\underline{\text { CF card }}$ & $\underline{\text { CF card }}$ & $\underline{\text { CF card }}$ \\
\hline Network & $\mathrm{N} / \mathrm{A}$ & $\mathrm{N} / \mathrm{A}$ & CDMA & CDMA & CDMA & CDMA & CDMA & CDMA \\
\hline $\begin{array}{c}\text { Max Data } \\
\text { Throughput }\end{array}$ & N/A & $\mathrm{N} / \mathrm{A}$ & 115kbps & 115kbps & 115kbps & 115kbps & 115kbps & 115kbps \\
\hline Provider & N/A & $\mathrm{N} / \mathrm{A}$ & $\underline{\text { Sprint }}$ & Sprint & Sprint & Sprint & Sprint & Sprint \\
\hline Entry Plan Fee & N/A & $\mathrm{N} / \mathrm{A}$ & $\$ 50$ & $\$ 50$ & $\$ 50$ & $\$ 50$ & $\$ 50$ & $\$ 50$ \\
\hline $\begin{array}{l}\text { Additional } \\
\text { Equipment }\end{array}$ & & $N / A$ & $N / A$ & $\begin{array}{c}\text { Will use } \\
\text { Navman CF } \\
\text { slot }\end{array}$ & $\begin{array}{c}\text { Will use } \\
\text { Navman CF } \\
\text { slot }\end{array}$ & $\begin{array}{c}\text { Will use } \\
\text { Navman CF } \\
\text { slot }\end{array}$ & $\begin{array}{c}\text { Will use } \\
\text { Navman CF } \\
\text { slot }\end{array}$ & $\begin{array}{c}\text { Will use } \\
\text { Navman CF } \\
\text { slot }\end{array}$ \\
\hline Add. Equip. Price & & $\mathrm{N} / \mathrm{A}$ & N/A & N/A & $\mathrm{N} / \mathrm{A}$ & $\mathrm{N} / \mathrm{A}$ & $\mathrm{N} / \mathrm{A}$ & $\mathrm{N} / \mathrm{A}$ \\
\hline $\begin{array}{c}\text { Total Price for } \\
\text { wireless add-ons }\end{array}$ & N/A & $N / A$ & $\$ 179.99$ & $\$ 179.99$ & $\$ 179.99$ & $\$ 179.99$ & $\$ 179.90$ & $\$ 179.90$ \\
\hline GPS & N/A & Yes & Yes & Yes & Yes & Yes & Yes & Yes \\
\hline Maker & $\mathrm{N} / \mathrm{A}$ & $\frac{\text { EMTAC at }}{\$ 349}$ & $\frac{\text { Pharos at }}{\$ 249}$ & $\frac{\text { Navman }}{\underline{3450}}$ & $\frac{\text { Navman }}{\underline{3450}}$ & $\frac{\text { Navman }}{\underline{3450}}$ & $\frac{\text { Navman }}{\underline{3450}}$ & $\underline{\text { Navman } 3450}$ \\
\hline GPS Type & N/A & $\begin{array}{l}\text { Separate, } \\
\text { Wireless }\end{array}$ & CF Card & Sleeve & Sleeve & Sleeve & Sleeve & Sleeve \\
\hline Another link & N/A & $\frac{\text { EMTAC at }}{\$ 349}$ & $\mathrm{~N} / \mathrm{A}$ & N/A & $N / A$ & $\mathrm{~N} / \mathrm{A}$ & $\underline{\text { Navman }}$ & $\underline{\text { Navman }}$ \\
\hline
\end{tabular}




\begin{tabular}{|c|c|c|c|c|c|c|c|c|}
\hline Maker & \multicolumn{6}{|c|}{$\underline{\mathrm{HP}}$} & \multicolumn{2}{|c|}{ Compaq } \\
\hline Model & IPAQ H1910 & IPAQ H1940 & $\stackrel{\mathrm{iPAQ}}{\mathrm{H} 2210 / 15}$ & $\underline{\mathrm{PAQ} H} \mathrm{H} 150$ & $\underline{\mathrm{iPAO} H 5450}$ & $\underline{\mathrm{PAQ} H 5555}$ & $\underline{\mathrm{PAQ}} \mathrm{H} 3950$ & $\underline{\mathrm{PAO} H 3970}$ \\
\hline Functions & \multicolumn{2}{|c|}{ Not All Functions } & $\begin{array}{c}\text { All } \\
\text { Functions, } \\
2 \text { devices }\end{array}$ & \multicolumn{5}{|c|}{ All Functions, 1 device } \\
\hline $\begin{array}{l}\text { Additional } \\
\text { Equipment }\end{array}$ & $\mathrm{N} / \mathrm{A}$ & $\mathrm{N} / \mathrm{A}$ & $\mathrm{N} / \mathrm{A}$ & $\mathrm{N} / \mathrm{A}$ & $\mathrm{N} / \mathrm{A}$ & $\mathrm{N} / \mathrm{A}$ & N/A & $\mathrm{N} / \mathrm{A}$ \\
\hline Maker 2 & $\mathrm{~N} / \mathrm{A}$ & $\mathrm{N} / \mathrm{A}$ & $\frac{\text { EMTAC at }}{\$ 349}$ & $\frac{\text { EMTAC at }}{\$ 349}$ & $\frac{\text { EMTAC at }}{\$ 349}$ & $\frac{\text { EMTAC at }}{\$ 349}$ & $\frac{\text { EMTAC at }}{\$ 349}$ & $\frac{\text { EMTAC at }}{\$ 349}$ \\
\hline GPS Type & N/A & $\mathrm{N} / \mathrm{A}$ & $\begin{array}{l}\text { Separate, } \\
\text { Wireless }\end{array}$ & $\begin{array}{l}\text { Separate, } \\
\text { Wireless }\end{array}$ & $\begin{array}{l}\text { Separate, } \\
\text { Wireless }\end{array}$ & $\begin{array}{l}\text { Separate, } \\
\text { Wireless }\end{array}$ & $\begin{array}{l}\text { Separate, } \\
\text { Wireless }\end{array}$ & $\begin{array}{l}\text { Separate, } \\
\text { Wireless }\end{array}$ \\
\hline Another link & $N / A$ & $N / A$ & $\frac{\text { EMTAC at }}{\$ 349}$ & $\frac{\text { EMTAC at }}{\$ 349}$ & $\frac{\text { EMTAC at }}{\$ 349}$ & $\frac{\text { EMTAC at }}{\$ 349}$ & $\frac{\text { EMTAC at }}{\$ 349}$ & $\frac{\text { EMTAC at }}{\$ 349}$ \\
\hline $\begin{array}{l}\text { Additional } \\
\text { Equipment }\end{array}$ & $\mathrm{N} / \mathrm{A}$ & $\mathrm{N} / \mathrm{A}$ & $\mathrm{N} / \mathrm{A}$ & $\mathrm{N} / \mathrm{A}$ & $\mathrm{N} / \mathrm{A}$ & $\mathrm{N} / \mathrm{A}$ & $\frac{\text { Expansion }}{\text { pack }}$ & $N / A$ \\
\hline Maker 3 & $\mathrm{~N} / \mathrm{A}$ & N/A & N/A & N/A & N/A & N/A & $\mathrm{N} / \mathrm{A}$ & N/A \\
\hline GPS Type & $N / A$ & $N / A$ & $N / A$ & $N / A$ & $N / A$ & $N / A$ & N/A & $N / A$ \\
\hline Another link & $N / A$ & $\mathrm{~N} / \mathrm{A}$ & N/A & $N / A$ & N/A & N/A & N/A & N/A \\
\hline $\begin{array}{l}\text { Additional } \\
\text { Equipment }\end{array}$ & $\mathrm{N} / \mathrm{A}$ & $\mathrm{N} / \mathrm{A}$ & $\mathrm{N} / \mathrm{A}$ & $\mathrm{N} / \mathrm{A}$ & $\mathrm{N} / \mathrm{A}$ & $\mathrm{N} / \mathrm{A}$ & $\mathrm{N} / \mathrm{A}$ & $\mathrm{N} / \mathrm{A}$ \\
\hline Maker 4 & $N / A$ & N/A & N/A & N/A & N/A & N/A & $\mathrm{N} / \mathrm{A}$ & $N / A$ \\
\hline GPS Type & $\mathrm{N} / \mathrm{A}$ & N/A & N/A & N/A & N/A & N/A & $\mathrm{N} / \mathrm{A}$ & N/A \\
\hline Another link & $N / A$ & N/A & N/A & $N / A$ & N/A & N/A & N/A & N/A \\
\hline $\begin{array}{l}\text { Additional } \\
\text { Equipment }\end{array}$ & $\mathrm{N} / \mathrm{A}$ & $\mathrm{N} / \mathrm{A}$ & $\mathrm{N} / \mathrm{A}$ & $\mathrm{N} / \mathrm{A}$ & $\mathrm{N} / \mathrm{A}$ & $\mathrm{N} / \mathrm{A}$ & $\mathrm{N} / \mathrm{A}$ & $\mathrm{N} / \mathrm{A}$ \\
\hline Price & & 330 & $\$ 249$ & $\$ 249$ & $\$ 299$ & $\$ 249$ & $\$ 299$ & $\$ 299$ \\
\hline Notes & & & $\begin{array}{l}\text { Lowest } \\
\text { price is } \\
\text { considered }\end{array}$ & $\begin{array}{l}\text { Lowest price } \\
\text { is considered }\end{array}$ & $\begin{array}{l}\text { Lowest price } \\
\text { is considered }\end{array}$ & $\begin{array}{l}\text { Lowest price } \\
\text { is } \\
\text { considered }\end{array}$ & $\begin{array}{l}\text { Lowest price } \\
\text { is considered }\end{array}$ & $\begin{array}{l}\text { Lowest price is } \\
\text { considered }\end{array}$ \\
\hline Total Price & $\mathrm{N} / \mathrm{A}$ & $\mathrm{N} / \mathrm{A}$ & 880 & 1050 & 1110 & 1150 & 870 & 930 \\
\hline Review 1 link & Review 1 & & Review 1 & & Review 1 & Review 1 & Review 1 & Review 1 \\
\hline \multicolumn{9}{|l|}{ Review 2 link } \\
\hline Comments & No GPS & & & & & & & $\begin{array}{c}\text { You have to } \\
\text { keep switching } \\
\text { between them. } \\
\text { Dual CF packs } \\
\text { will not work }\end{array}$ \\
\hline $\begin{array}{l}\text { Further Notes As of } \\
\text { 8/25/2003 }\end{array}$ & & & & Discontinued & Discontinued & $\begin{array}{c}\text { Final Choice } \\
\text { due to OS, } \\
\text { Capability } \\
\text { with GPS } \\
\text { and Wireless }\end{array}$ & Discontinued & Discontinued \\
\hline $\begin{array}{l}\text { Notes As of } \\
8 / 25 / 2003\end{array}$ & \multicolumn{8}{|c|}{$\begin{array}{l}\text { After Software Development for operating system was considered all Palm OS devices were eliminated due to the ease of development for the } \\
\text { Pocket PC OS }\end{array}$} \\
\hline
\end{tabular}




\begin{tabular}{|c|c|c|c|c|c|c|c|}
\hline \multirow{2}{*}{$\begin{array}{l}\text { Maker } \\
\text { Model }\end{array}$} & \multicolumn{2}{|c|}{ Handspring } & \multirow{2}{*}{$\frac{\text { Audiovox }}{\text { Thera }}$} & \multicolumn{2}{|c|}{ Toshiba } & \multirow{2}{*}{$\frac{\text { Garmin }}{\underline{\text { iQue } 3600}}$} & \multirow{2}{*}{$\begin{array}{c}\frac{\text { Dell }}{} \\
\text { Axim } \times 5 \mathrm{adv} .\end{array}$} \\
\hline & Treo 300 & Treo 270 & & $\underline{\mathrm{e} 350}$ & $\underline{\mathrm{e} 750}$ & & \\
\hline Functions & $\begin{array}{l}\text { Not All } \\
\text { Functions }\end{array}$ & $\begin{array}{l}\text { All Functions, } 2 \\
\text { devices }\end{array}$ & $\begin{array}{l}\text { All Functions, } 2 \\
\text { devices }\end{array}$ & $\begin{array}{l}\text { Not All } \\
\text { Functions }\end{array}$ & $\begin{array}{c}\text { All } \\
\text { Functions, } 2 \\
\text { devices }\end{array}$ & Not All Functions & $\begin{array}{l}\text { All Functions, } 2 \\
\text { devices }\end{array}$ \\
\hline OS & P v. 3.5 .2 & P v. 3.5.2 & PPC $2 \mathrm{~K} 2$ & $\mathrm{PPC} 2 \mathrm{~K} 3$ & $\mathrm{PPC} 2 \mathrm{~K} 3$ & P v. 5.0 & PPC $2 \mathrm{~K} 3$ \\
\hline RAM & 16 & 16 & $32+32 S D$ & 64 & 64 & 32 & 64 \\
\hline ROM & $\mathrm{N} / \mathrm{A}$ & N/A & 32 & 32 & 32 & N/A & 48 \\
\hline Processor & $\begin{array}{l}33 \mathrm{MHZ} \\
\mathrm{DB}(\mathrm{VZ})\end{array}$ & $\begin{array}{c}33 \mathrm{MHZ} \text { DB } \\
(\mathrm{VZ})\end{array}$ & $\begin{array}{c}206 \mathrm{MHz} \\
\mathrm{SA}\end{array}$ & $\begin{array}{l}300 \mathrm{MHz} \\
\text { Xscale }\end{array}$ & $\begin{array}{l}400 \mathrm{MHz} \\
\text { Xscale }\end{array}$ & $\begin{array}{c}200 \mathrm{MHz} D B \\
(\mathrm{MXL})\end{array}$ & $\begin{array}{c}400 \mathrm{MHz} \\
\text { Xscale }\end{array}$ \\
\hline Screen & PS 4k & PS 4k & $\begin{array}{c}\mathrm{R} \\
64 \mathrm{~K} \text { Colors }\end{array}$ & $\begin{array}{l}\text { R 64k } \\
\text { colors }\end{array}$ & $\begin{array}{l}\text { T 64k } \\
\text { colors }\end{array}$ & T $64 \mathrm{k}$ colors & $\mathrm{T} 64 \mathrm{k}$ colors \\
\hline Expansion & N/A & $\mathrm{N} / \mathrm{A}$ & $S D, M M C$ & $S D, M M C$ & $\begin{array}{l}\text { CF, SD, } \\
M M C\end{array}$ & $S D, M M C$ & $\begin{array}{c}\text { CF, SD } \\
M M C\end{array}$ \\
\hline Connections & $\begin{array}{l}\text { USB or } \\
\text { Serial/ } \\
\text { IrDA }\end{array}$ & $\begin{array}{l}\text { USB or } \\
\text { Serial/ } \\
\text { IrDA }\end{array}$ & USB/IrDA & USB/IrDA & USB/IrDA & USB//rDA & USB/IrDA \\
\hline Dimensions/weight & $\begin{array}{c}4.8 \times 3.0 \times \\
.6 \mathrm{in.} / 6.3 \\
0 \mathrm{z}\end{array}$ & $\begin{array}{c}4.2 \times 2.8 \times \\
.82 \mathrm{in.} \\
5.4 \mathrm{oz}\end{array}$ & $\begin{array}{c}5.0 \times 3.0 \times \\
.7 \mathrm{in.} / 7.0 \\
0 \mathrm{z}\end{array}$ & $\begin{array}{c}4.9 \times 3.1 \\
\times .4 \mathrm{in.l} \\
5.9 \mathrm{oz} \\
\end{array}$ & $\begin{array}{c}4.9 \times 3.1 \\
\times .6 \mathrm{in.l} \\
6.7 \mathrm{oz} \\
\end{array}$ & $\begin{array}{c}5.0 \times 2.8 \times .8 \\
\text { in. } / 5.20 z\end{array}$ & $\begin{array}{c}5.0 \times 3.2 \times .7 \\
\text { in. } / 6.90 z\end{array}$ \\
\hline Battery type & $\mathrm{RLI}$ & RLI & RLI & RLI & $R L P, R B$ & RLI & $R L I, R B$ \\
\hline Battery life & $\begin{array}{l}2.5 \mathrm{hrs} \\
\text { talk }\end{array}$ & $3 \mathrm{hrs} \mathrm{talk}$ & 90 min talk & $5 \mathrm{hrs}$ & N/A & $N / A$ & $\mathrm{~N} / \mathrm{A}$ \\
\hline Price & 499.00 & 699.00 & 899.00 & 299.00 & 599.00 & 589.99 & 299.99 \\
\hline Notes & $\begin{array}{l}\text { This price } \\
\text { does not } \\
\text { include } \\
\text { Rebates } \\
\text { with } \\
\text { service } \\
\text { activation. }\end{array}$ & $\begin{array}{l}\text { This price } \\
\text { does not } \\
\text { include } \\
\text { Rebates } \\
\text { with } \\
\text { service } \\
\text { activation. }\end{array}$ & $\begin{array}{l}\text { This price } \\
\text { does not } \\
\text { include } \\
\text { Rebates } \\
\text { with } \\
\text { service } \\
\text { activation. }\end{array}$ & & & $\begin{array}{c}\text { To be } \\
\text { released in } \\
\text { mid July } 2003\end{array}$ & \\
\hline Bluetooth & N/A & N/A & $\underline{\text { SD Card }}$ & $\underline{\text { SD Card }}$ & $\underline{\text { SD Card }}$ & $\mathrm{N} / \mathrm{A}$ & $\underline{\text { CF Card }}$ \\
\hline WiFi & N/A & N/A & $\underline{\text { SD Card }}$ & $\underline{\text { SD Card }}$ & Built in & $\underline{\text { SD Card }}$ & $\underline{\text { CF Card }}$ \\
\hline Modem & N/A & N/A & $\mathrm{N} / \mathrm{A}$ & $\mathrm{N} / \mathrm{A}$ & $\underline{\text { CF card }}$ & N/A & Cable \\
\hline Modem speed & N/A & $\mathrm{N} / \mathrm{A}$ & $\mathrm{N} / \mathrm{A}$ & $\mathrm{N} / \mathrm{A}$ & $56 k$ & $\mathrm{~N} / \mathrm{A}$ & $56 k$ \\
\hline $\begin{array}{c}\text { Add-on Price for } \\
\text { Modem }\end{array}$ & $\mathrm{N} / \mathrm{A}$ & N/A & $\mathrm{N} / \mathrm{A}$ & N/A & $\$ 97$ & $\mathrm{~N} / \mathrm{A}$ & $\$ 40$ \\
\hline Wireless & Built-in & Built-in & Built-in & $\mathrm{N} / \mathrm{A}$ & $\underline{C F \text { card }}$ & N/A & CF card \\
\hline Network & CDMA & GPRS & CDMA & $\mathrm{N} / \mathrm{A}$ & CDMA & N/A & CDMA \\
\hline $\begin{array}{l}\text { Max Data } \\
\text { Throughput }\end{array}$ & $115 \mathrm{kbps}$ & $115 \mathrm{kbps}$ & $115 \mathrm{kbps}$ & $\mathrm{N} / \mathrm{A}$ & $115 \mathrm{kbps}$ & N/A & $115 \mathrm{kbps}$ \\
\hline Provider & $\underline{\text { Sprint }}$ & $\frac{\text { AT\&T/T- }}{\underline{\text { mobile }}}$ & Verizon & $\mathrm{N} / \mathrm{A}$ & $\underline{\text { Sprint }}$ & $\mathrm{N} / \mathrm{A}$ & Sprint \\
\hline Entry Plan Fee & $\$ 50.00$ & $\$ 19.95$ & $\$ 35$ & $\mathrm{~N} / \mathrm{A}$ & $\$ 50$ & N/A & $\$ 50$ \\
\hline $\begin{array}{l}\text { Additional } \\
\text { Equipment }\end{array}$ & N/A & $\mathrm{N} / \mathrm{A}$ & $\mathrm{N} / \mathrm{A}$ & & & $\mathrm{N} / \mathrm{A}$ & $\mathrm{N} / \mathrm{A}$ \\
\hline Add. Equip. Price & $\mathrm{N} / \mathrm{A}$ & $\mathrm{N} / \mathrm{A}$ & N/A & & & $\mathrm{N} / \mathrm{A}$ & $\mathrm{N} / \mathrm{A}$ \\
\hline $\begin{array}{c}\text { Total Price for } \\
\text { wireless add-ons }\end{array}$ & $\mathrm{N} / \mathrm{A}$ & N/A & N/A & $\mathrm{N} / \mathrm{A}$ & $\$ 179.90$ & N/A & $\$ 179.90$ \\
\hline GPS & $\mathrm{N} / \mathrm{A}$ & Yes & Yes & Yes & Yes & Yes & Yes \\
\hline
\end{tabular}




\begin{tabular}{|c|c|c|c|c|c|c|c|}
\hline Maker & \multicolumn{2}{|c|}{ Handspring } & Audiovox & \multicolumn{2}{|c|}{ Toshiba } & \multirow{2}{*}{$\begin{array}{c}\frac{\text { Garmin }}{\text { iQue } 3600} \\
\end{array}$} & \multirow{2}{*}{$\frac{\underline{\text { Dell }}}{\underline{\text { Axim } \times 5 \mathrm{adv} .}}$} \\
\hline Model & Treo 300 & Treo 270 & Thera & e350 & e 750 & & \\
\hline Functions & $\begin{array}{l}\text { Not All } \\
\text { Functions }\end{array}$ & $\begin{array}{c}\text { All Functions, } 2 \\
\text { devices }\end{array}$ & $\begin{array}{c}\text { All Functions, } 2 \\
\text { devices }\end{array}$ & $\begin{array}{l}\text { Not All } \\
\text { Functions }\end{array}$ & $\begin{array}{c}\text { All } \\
\text { Functions, } 2 \\
\text { devices }\end{array}$ & Not All Functions & $\begin{array}{l}\text { All Functions, } 2 \\
\text { devices }\end{array}$ \\
\hline Maker & $N / A$ & Mapopolis & $\frac{\text { Pharos at }}{\$ 239}$ & Pharos & $\frac{\text { Pharos }}{\text { at } \$ 319}$ & N/A & Pharos \\
\hline GPS Type & $N / A$ & $\begin{array}{c}\text { Separate, } \\
\text { serial }\end{array}$ & Car Mount & $\begin{array}{c}\text { Car } \\
\text { Mount }\end{array}$ & CF Card & Built-in & CF Card \\
\hline Another link & $\mathrm{N} / \mathrm{A}$ & $N / A$ & $\frac{\text { Pharos at }}{\$ 239}$ & $\mathrm{~N} / \mathrm{A}$ & $N / A$ & $\mathrm{~N} / \mathrm{A}$ & $\mathrm{N} / \mathrm{A}$ \\
\hline $\begin{array}{l}\text { Additional } \\
\text { Equipment }\end{array}$ & $\mathrm{N} / \mathrm{A}$ & $\mathrm{N} / \mathrm{A}$ & $N / A$ & $N / A$ & $\mathrm{~N} / \mathrm{A}$ & $\mathrm{N} / \mathrm{A}$ & $N / A$ \\
\hline Maker 2 & $\mathrm{~N} / \mathrm{A}$ & $\mathrm{N} / \mathrm{A}$ & $\frac{\text { Teletype at }}{\$ 249}$ & $\mathrm{~N} / \mathrm{A}$ & $\begin{array}{l}\text { Teletype } \\
\text { at } \$ 499\end{array}$ & $\mathrm{~N} / \mathrm{A}$ & $\mathrm{N} / \mathrm{A}$ \\
\hline GPS Type & $\mathrm{N} / \mathrm{A}$ & $\mathrm{N} / \mathrm{A}$ & Car mount & $\mathrm{N} / \mathrm{A}$ & CF Card & $\mathrm{N} / \mathrm{A}$ & $\mathrm{N} / \mathrm{A}$ \\
\hline Another link & $\mathrm{N} / \mathrm{A}$ & $\mathrm{N} / \mathrm{A}$ & $\frac{\text { Teletype at }}{\$ 249}$ & $\mathrm{~N} / \mathrm{A}$ & $\mathrm{N} / \mathrm{A}$ & $\mathrm{N} / \mathrm{A}$ & $\mathrm{N} / \mathrm{A}$ \\
\hline $\begin{array}{l}\text { Additional } \\
\text { Equipment }\end{array}$ & $\mathrm{N} / \mathrm{A}$ & $\mathrm{N} / \mathrm{A}$ & $\mathrm{N} / \mathrm{A}$ & $\mathrm{N} / \mathrm{A}$ & $\mathrm{N} / \mathrm{A}$ & $\mathrm{N} / \mathrm{A}$ & $\mathrm{N} / \mathrm{A}$ \\
\hline Maker 3 & $\mathrm{~N} / \mathrm{A}$ & $\mathrm{N} / \mathrm{A}$ & $N / A$ & $N / A$ & $\mathrm{~N} / \mathrm{A}$ & $N / A$ & $N / A$ \\
\hline GPS Type & $\mathrm{N} / \mathrm{A}$ & $\mathrm{N} / \mathrm{A}$ & $\mathrm{N} / \mathrm{A}$ & $\mathrm{N} / \mathrm{A}$ & $\mathrm{N} / \mathrm{A}$ & $\mathrm{N} / \mathrm{A}$ & $\mathrm{N} / \mathrm{A}$ \\
\hline Another link & $N / A$ & N/A & $\mathrm{N} / \mathrm{A}$ & $N / A$ & $\mathrm{~N} / \mathrm{A}$ & $\mathrm{N} / \mathrm{A}$ & N/A \\
\hline $\begin{array}{l}\text { Additional } \\
\text { Equipment }\end{array}$ & $\mathrm{N} / \mathrm{A}$ & $\mathrm{N} / \mathrm{A}$ & $\mathrm{N} / \mathrm{A}$ & $\mathrm{N} / \mathrm{A}$ & $\mathrm{N} / \mathrm{A}$ & $\mathrm{N} / \mathrm{A}$ & $\mathrm{N} / \mathrm{A}$ \\
\hline Maker 4 & $\mathrm{~N} / \mathrm{A}$ & $\mathrm{N} / \mathrm{A}$ & $\mathrm{N} / \mathrm{A}$ & $\mathrm{N} / \mathrm{A}$ & $\mathrm{N} / \mathrm{A}$ & $\mathrm{N} / \mathrm{A}$ & $\mathrm{N} / \mathrm{A}$ \\
\hline GPS Type & $\mathrm{N} / \mathrm{A}$ & $N / A$ & $N / A$ & $\mathrm{~N} / \mathrm{A}$ & $\mathrm{N} / \mathrm{A}$ & $\mathrm{N} / \mathrm{A}$ & $\mathrm{N} / \mathrm{A}$ \\
\hline Another link & $N / A$ & $\mathrm{~N} / \mathrm{A}$ & $N / A$ & $\mathrm{~N} / \mathrm{A}$ & $\mathrm{N} / \mathrm{A}$ & $\mathrm{N} / \mathrm{A}$ & $N / A$ \\
\hline $\begin{array}{l}\text { Additional } \\
\text { Equipment }\end{array}$ & $\mathrm{N} / \mathrm{A}$ & $\mathrm{N} / \mathrm{A}$ & $\mathrm{N} / \mathrm{A}$ & $\mathrm{N} / \mathrm{A}$ & $\mathrm{N} / \mathrm{A}$ & $\mathrm{N} / \mathrm{A}$ & $\mathrm{N} / \mathrm{A}$ \\
\hline Price & 0 & $\$ 199$ & $\$ 239$ & $\$ 215$ & $\$ 319$ & 0 & $\$ 319$ \\
\hline \multicolumn{8}{|l|}{ Notes } \\
\hline Total Price & $\mathrm{N} / \mathrm{A}$ & 900 & 1139 & $\mathrm{~N} / \mathrm{A}$ & 1100 & $\mathrm{~N} / \mathrm{A}$ & 800 \\
\hline Review 1 link & Review 1 & Review 1 & Review 1 & Review 1 & Review 1 & & \\
\hline Review 2 link & Review 2 & Review 2 & Review 2 & & & & \\
\hline Comments & $\begin{array}{c}\text { Not all } \\
\text { functions } \\
\text { available }\end{array}$ & $\begin{array}{c}\text { Not } \\
\text { considering } \\
\text { rebates }\end{array}$ & $\begin{array}{c}\text { Not } \\
\text { considering } \\
\text { rebates }\end{array}$ & $\begin{array}{l}\text { Not all } \\
\text { functions } \\
\text { available }\end{array}$ & & & \\
\hline $\begin{array}{c}\text { Further Notes As of } \\
8 / 25 / 2003\end{array}$ & $\begin{array}{l}\text { No GPS } \\
\text { available }\end{array}$ & $\begin{array}{c}\text { not } \\
\text { convenient, } \\
\text { Two } \\
\text { devices at } \\
\text { the same } \\
\text { time, also } \\
\text { Expensive }\end{array}$ & $\begin{array}{c}\text { not } \\
\text { convenient, } \\
\text { Two } \\
\text { devices at } \\
\text { the same } \\
\text { time, also } \\
\text { Expensive }\end{array}$ & & $\begin{array}{l}\text { You have } \\
\text { to keep } \\
\text { switching } \\
\text { between } \\
\text { GPS and } \\
\text { wireless } \\
\text { because } \\
1 \text { CF slot }\end{array}$ & $\begin{array}{c}\text { Wireless is } \\
\text { not available }\end{array}$ & $\begin{array}{c}\text { You have to } \\
\text { keep } \\
\text { switching } \\
\text { between } \\
\text { GPS and } \\
\text { wireless } \\
\text { because } 1 \\
\text { CF slot }\end{array}$ \\
\hline $\begin{array}{l}\text { Notes As of } \\
8 / 25 / 2003\end{array}$ & $\begin{array}{l}\text { Palm OS } \\
\text { eliminated }\end{array}$ & $\begin{array}{l}\text { Palm OS } \\
\text { eliminated }\end{array}$ & $\begin{array}{l}\text { Palm OS } \\
\text { eliminated }\end{array}$ & & & $\begin{array}{l}\text { Palm OS } \\
\text { eliminated }\end{array}$ & \\
\hline
\end{tabular}


Appendix B
a) Letter of Solicitation
b) Informed Consent Form
c) Orientation Session Power Point Presentation
d) Participants Evaluation Form 


\section{Letter of Solicitation}

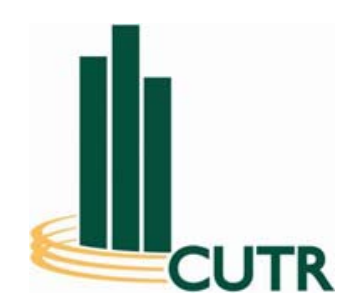

March 10, 2005

John and Jane Smith

1234 Tracit Lane

Tampa FL 33620

Dear Smith Family:

What do we need most to make the transportation system serve you better in the future? Can traffic congestion be reduced? Will new technology improve traffic conditions? Can you save on gas and other auto costs? The Center for Urban Transportation Research (CUTR) at the University of South Florida is conducting a survey to answer these and other important questions and we need your help! Only by knowing and understanding your travel needs can planners and decision makers effectively work on improving the mobility, safety, and security of our transportation system. We are asking you to help by telling us about your travel needs, the kinds of trips that you make, and the ways that you make these trips.

You have our promise that we will protect your privacy and that none of the information about your individual household will be used for any other purpose or provided to any other agency or business.

You will be provided with a personal digital assistant (PDA) equipped with global positioning system (GPS) capabilities to chronicle your travel activities with some input from you. Details of the process will be further discussed at the orientation session we prepared for you (please see attached consent form).

If you have any other questions or concerns about this survey, please feel free to contact me.

Sincerely,

Philip L. Winters

TDM Program Director

Center for Urban Transportation Research

University of South Florida

4202 E. Fowler Ave., CUT100

Tampa, FL 33620-5375

(813) 974-9811

winters@cutr.usf.edu 


\section{Informed Consent}

Social and Behavioral Sciences

University of South Florida

\section{Information for People Who Take Part in Research Studies}

The following information is being presented to help you decide whether or not you want to take part in a minimal risk research study. Please read this carefully. If you do not understand anything, ask the person in charge of the study.

Title of Study: Traveling Smart: Increasing Transit Ridership by Automatic Collection of Individual Travel Behavior Data and Personalized Feedback

Principal Investigator: Philip L. Winters, Center for Urban

Transportation Research, USF

Study Location(s): USF campus and Tampa Bay Area

You are being asked to participate because personal transportation is part of your daily activities (e.g. transportation to work, shopping, entertainment, medical, etc.) and we want to better understand travel choice decisions and travel patterns people make.

\section{General Information about the Research Study}

The purpose of this research study is to

1. Determine the capabilities of existing computer and communication technologies in tracking person movements across modes (car, bike, bus, etc.) and over extended time periods (e.g., week versus daily)

2. Design, develop and test a prototype application to automate the collection of travel behavior data and provide personalized advice to increase use of transit and other alternatives to driving alone.

\section{Plan of Study}

You will be required to carry a personal digital assistant/Pocket PC (PDA) with a global positioning system (GPS) attachment during the study period. The duration of your participation, including data collection periods and interviews with the research team, will be no more than six months.

The GPS system will record your trip ends, route, travel time, date/time of day and travel distance for each trip. Trips may be made by personal vehicle, bus, bike, walk or other mode. The PDA also will prompt you to provide additional information not collected by the GPS unit about the trip such as trip purpose (e.g., work or shopping), the mode of travel (e.g., drive or walk) and the number of occupants in the vehicle with you. We anticipate that it will take you a total of 15 minutes per day to complete the data record for trips made that day. We also anticipate that you will carry the PDA/GPS unit for at least two one-week periods. 
Upon your consent, we will spend about one hour to instruct you on the use of the PDA/GPS unit. We will contact you by email or phone to make sure no problems have been encountered and answer any questions you may have.

After data collected are analyzed, we will meet for the second visit (approximately 1 hour) to review your travel habits and gauge the effectiveness of our advice on ways you can reduce vehicle trips.

Following any necessary revisions to the software on the PDA/GPS unit, you will carry the PDA/GPS unit and record travel behavior for another one week period. A third visit (approximately 60 - 90 minutes) will be held with you so we may assess the following:

- The experience associated with participating in the project,

- The accuracy of the information provided by the PDA/GPS unit,

- The quality of the feedback based on the data collected from those units, and

- The changes made, if any, to reduce their vehicle trips based on advice received from researchers.

This project is funded by the Florida Department of Transportation and U.S. Department of Transportation under grants to the National Center for Transit Research at the University of South Florida.

\section{Payment for Participation}

You will not be paid for your participation in this study

\section{Benefits of Being a Part of this Research Study}

You will not directly benefit from participating in this study. However, by taking part in this research study, you may increase our overall knowledge on the travel behavior and patterns. Our overall knowledge enables us to assist communities and transportation agencies in planning improvements such as bike paths, sidewalks, transit routes and road improvements. Your participation will also allow us to test better ways to provide traveler information, meaningful advice and feedback on alternative methods of travel that realistically meet the mobility needs of Floridians.

\section{Risks of Being a Part of this Research Study}

There are no foreseeable risks in participating in this study.

\section{Confidentiality of Your Records}

Completed informed consent forms and travel information forms will remain with researchers at all times during data collection. They will be kept on file in secure offices at CUTR during analysis and storage. Data will be stored on password-protected computers. Documents will be stored in lockable research office. Data will be retained for the life of the project and comply with contractual requirements.

The results of this study may be published. The published results will not include your name. However, the inclusion of travel patterns in the 
published results in a tabular and/or map format and the accuracy of the GPS units could permit others to identify a particular household or even individual and link them with dates, times, and locations visited.

Your privacy and research records will be kept confidential to the extent of the law. Authorized research personnel, employees of the Department of Health and Human Services, and the USF Institutional Review Board and its staff, and any other individuals acting on behalf of USF, may inspect the records from this research project.

\section{Volunteering to Be Part of this Research Study}

Your decision to participate in this research study is completely voluntary. You are free to participate in this research study or to withdraw at any time. There will be no penalty if you stop taking part in the study.

\section{Questions and Contacts}

- If you have any questions about this research study, contact Phil Winters at 813974-9811.

- If you have questions about your rights as a person who is taking part in a research study, you may contact the Division of Research Compliance of the University of South Florida at (813) 974-5638.

\section{Consent to Take Part in This Research Study}

By signing this form I agree that:

1. I have fully read or have had read and explained to me this informed consent form describing this research project.

2. I have had the opportunity to question one of the persons in charge of this research and have received satisfactory answers.

3. I understand that I am being asked to participate in research. I understand the risks and benefits, and I freely give my consent to participate in the research project outlined in this form, under the conditions indicated in it.

4. I have been given a signed copy of this informed consent form, which is mine to keep.

\section{Signature of Participant Printed Name of Participant Date}

\section{Investigator Statement:}

I certify that participants have been provided with an informed consent form that has been approved by the University of South Florida's Institutional Review Board and that explains the nature, demands, risks, and benefits involved in participating in this study. I further certify that a phone number has been provided in the event of additional questions.

\footnotetext{
Signature of Investigator Printed Name of Investigator Date
} 


\section{Orientation Session Handout}
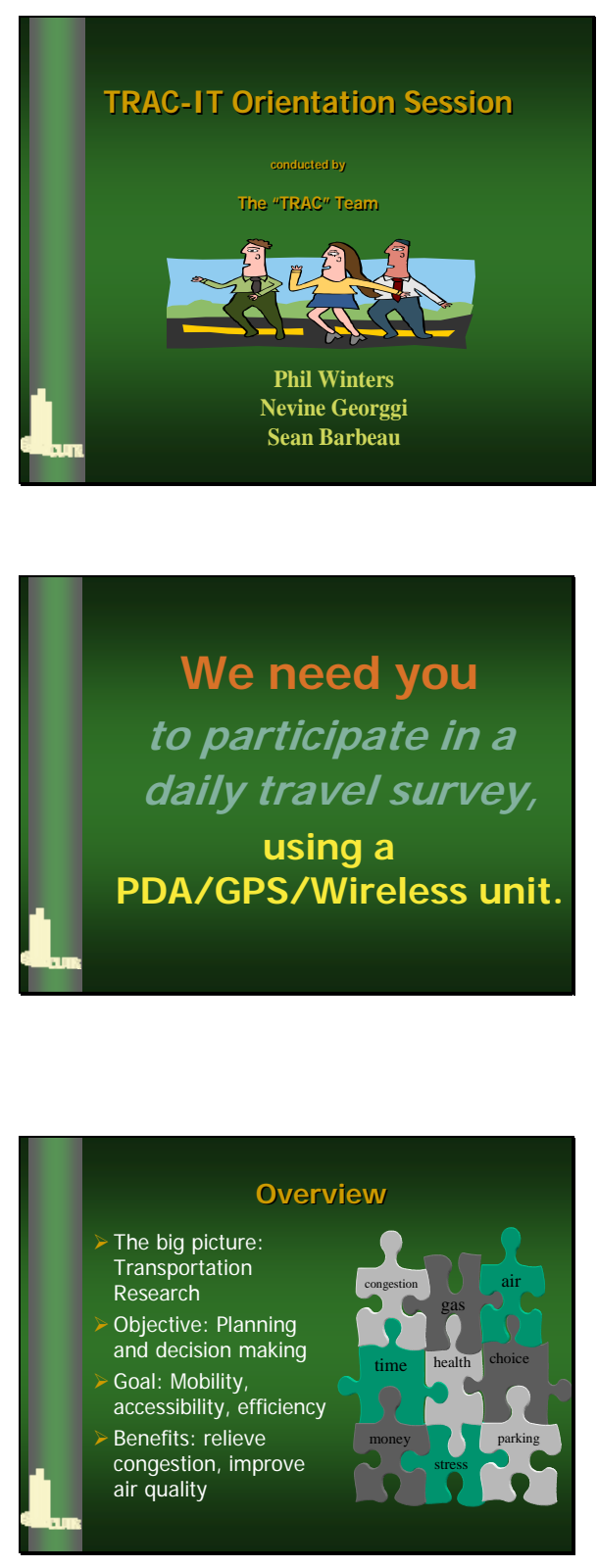


\section{Agenda}

Why collect this data?

What is a travel survey?

-What is it used for?

Who is conducting the survey?

Who is participating?

Where is the data collected?

When is the data collected?

How is it collected?

- How is my privacy protected?
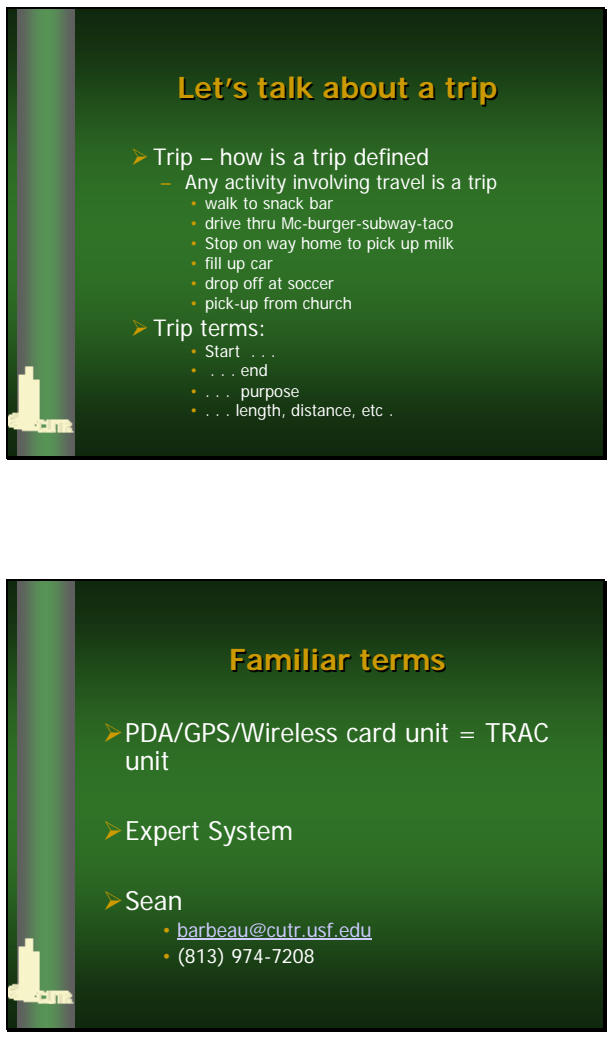

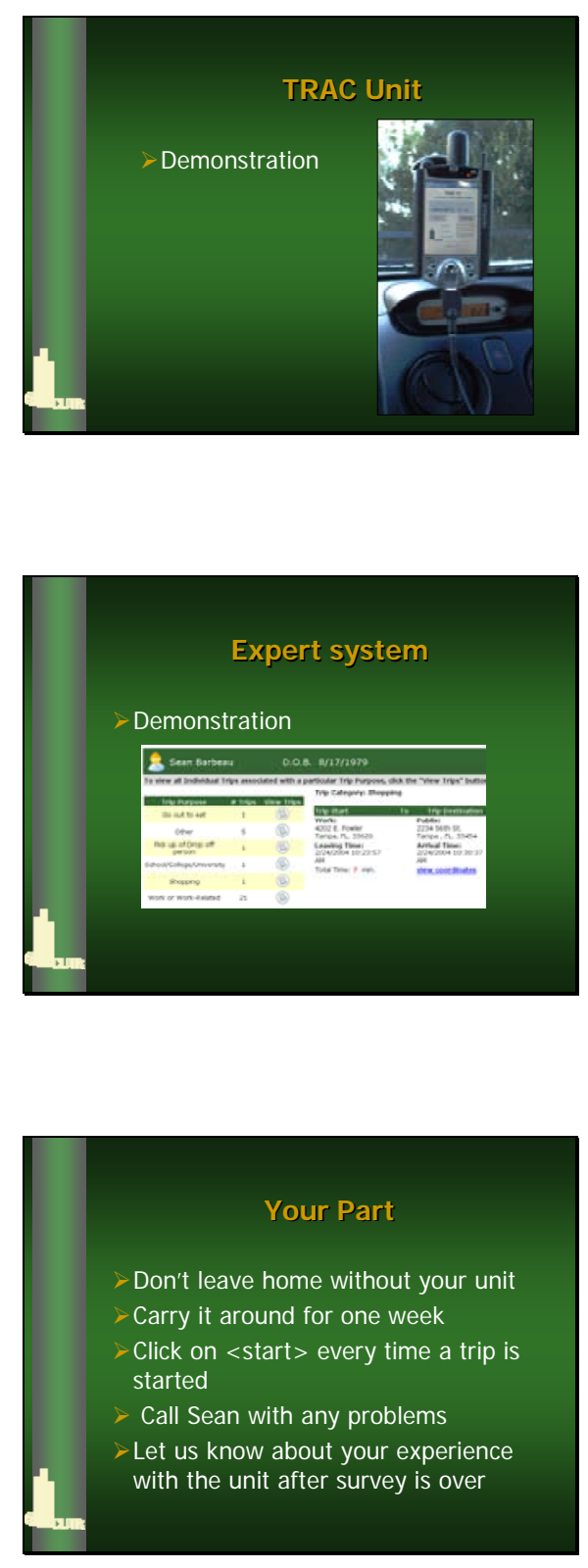


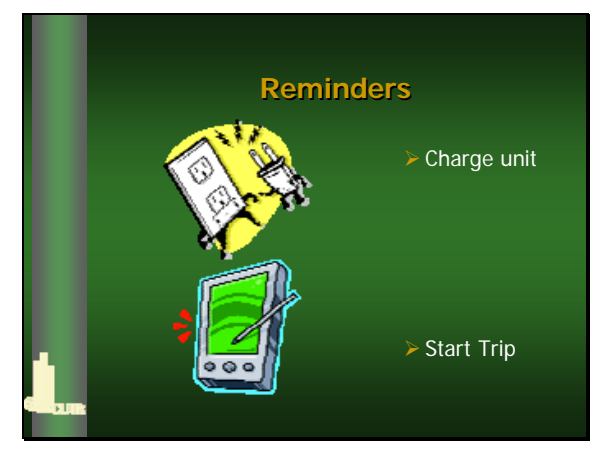

\section{Any questions at any time ...}

$>$ Contact email

barbeau@cutr.usf.edu

$>$ Contact Sean

(813) 974-7208

r.

5.2. Thank You \&es

Afercin isi

\section{GGrocias}




\section{Participants Evaluation Form}

\begin{tabular}{|c|c|c|c|c|c|}
\hline & $\begin{array}{l}\text { Strongly } \\
\text { Agree }\end{array}$ & Agree & Neutral & Disagree & $\begin{array}{l}\text { Strongly } \\
\text { Disagree }\end{array}$ \\
\hline \multicolumn{6}{|l|}{ Orientation was informative and helpful } \\
\hline \multicolumn{6}{|l|}{ Orientation was long } \\
\hline \multicolumn{6}{|l|}{ Objectives of survey were clearly stated } \\
\hline \multicolumn{6}{|l|}{ Demonstration of PDA was very helpful } \\
\hline \multicolumn{6}{|l|}{ The TRAC team was very professional } \\
\hline \multicolumn{6}{|l|}{ The PDA was easy to use } \\
\hline \multicolumn{6}{|l|}{ The PDA screen was easy to read } \\
\hline \multicolumn{6}{|l|}{ It was no trouble carrying the unit around } \\
\hline \multicolumn{6}{|l|}{$\begin{array}{l}\text { The battery was adequate for one day of } \\
\text { travel }\end{array}$} \\
\hline \multicolumn{6}{|l|}{$\begin{array}{l}\text { The process of sync data was } \\
\text { manageable }\end{array}$} \\
\hline \multicolumn{6}{|l|}{ Email reminders were very helpful } \\
\hline \multicolumn{6}{|l|}{$\begin{array}{l}\text { Response to my questions via email was } \\
\text { helpful }\end{array}$} \\
\hline \multicolumn{6}{|l|}{$\begin{array}{l}\text { Response to my questions via email was } \\
\text { timely }\end{array}$} \\
\hline \multicolumn{6}{|l|}{$\begin{array}{l}\text { Response to my questions via phone was } \\
\text { efficient }\end{array}$} \\
\hline $\begin{array}{l}\text { Response to my questions via phone was } \\
\text { timely }\end{array}$ & & & & & \\
\hline
\end{tabular}

